\title{
Contribuições para interação pelo olhar com teclados virtuais
}

\author{
Antonio Diaz Tula
}

TESE APRESENTADA

$\mathrm{AO}$

Instituto De MatemáticA e Estatística

DA

UNIVERSIDADE DE SÃo PAUlO

PARA

OBTENÇÃO DO TÍTULO

$\mathrm{DE}$

DOUTOR EM CIÊNCIAS

\author{
Programa: Ciência da Computação \\ Orientador: Prof. Dr. Carlos Hitoshi Morimoto
}

Durante o desenvolvimento deste trabalho o autor recebeu auxílio financeiro da FAPESP, processos no 2010/14075-4 e 2012/04426-0

São Paulo, setembro de 2015 


\section{Contribuições para interação pelo olhar com teclados virtuais}

Esta versão da tese contém as correções e alterações sugeridas pela Comissão Julgadora durante a defesa da versão original do trabalho, realizada em 03/09/2015. Uma cópia da versão original está disponível no Instituto de Matemática e Estatística da Universidade de São Paulo.

Comissão Julgadora:

- Prof. Dr. Carlos Hitoshi Morimoto (orientador) - IME-USP

- Prof. Dr. Flávio Soares Corrêa da Silva - IME-USP

- Prof ${ }^{a}$. Dra ${ }^{a}$ Fátima de Lourdes dos Santos Nunes Marques - EACH-USP

- Prof ${ }^{\mathrm{a}}$. Dra ${ }^{\mathrm{a}}$. Junia Coutinho Anacleto - UFScar

- Prof ${ }^{\mathrm{a}}$. Dr ${ }^{\mathrm{a}}$. Roseli de Deus Lopes - EP-USP 


\section{Agradecimentos}

Antes de nada, gostaria de agradecer a Deus por abençoar minha vida de tantas maneiras. Um especial agradecimento a meu orientador, o Prof. Carlos Hitoshi Morimoto, por ter me dado a possibilidade de ser orientado por ele e por todos os ensinamentos que oportunamente me deu, durante esses anos de doutorado. Agradeço infinitamente a minha filha Angélica María e a minha esposa Yuslay Fernández, por tanto amor incondicional e por sempre estar do meu lado nos momentos mais difíceis. Agradeço também a meus pais, irmãs e a toda a família em geral, pelo apoio que sempre me deram. Agradeço também aos membros do LaTIn e aos professores e colegas do grupo de eScience. Agradeço também à Fundação de Amparo à Pesquisa do Estado de São Paulo (FAPESP), pelas bolsas de estudo concedidas, processos $\mathrm{n}^{\circ}$ 2010/14075-4 e 2012/04426-0. Igualmente agradeço à Fundação de Desenvolvimento Tecnológico da Engenharia pelo apoio financeiro, processo $n^{\circ} 1449$. 


\section{Resumo}

Diaz Tula, A. Contribuições para interação pelo olhar com teclados virtuais. Tese (Doutorado) - Instituto de Matemática e Estatística, Universidade de São Paulo, São Paulo, 2015.

A presente tese de doutorado insere-se na área de interação pelo olhar. A interação pelo olhar é uma forma de comunicação com o computador utilizando os movimentos oculares do usuário. Pessoas com deficiência física, que não conseguem usar dispositivos convencionais como um teclado e um mouse de computador, podem se beneficiar da interação pelo olhar para se comunicarem e se inserirem na sociedade. Para isso a entrada de texto ou digitação pelo olhar é um recurso importante e assunto principal dessa tese.

O instrumento mais comum para entrada de texto pelo olhar consiste de um teclado virtual onde os caracteres são selecionados por tempo de latência. Essa forma de interação, embora simples, sofre de seleções involuntárias (problema conhecido como toque de Midas) se o tempo de latência for curto (menos de 500 ms). Já para tempos de latência mais longos, a interação se torna lenta. Alternativas para entrada de texto pelo olhar são os gestos discretos ou contínuos do olhar. O uso de gestos discretos permite reduzir o toque de Midas, porém o desempenho é inferior ao tempo de latência. Já nos métodos baseados em gestos contínuos, o olhar está sempre preso ao controle da interface. Uma técnica de interação proposta recentemente, chamada de "alternância entre contextos", permite reduzir o efeito do toque de Midas, utilizando apenas uma sacada para cada seleção. Além disso, essa técnica permite aos usuários manterem o ritmo de interação sem ajustar nenhum parâmetro na interface.

A presente tese de doutorado visa melhorar a usabilidade e experiência dos usuários na interação pelo olhar com teclados virtuais. Os objetivos específicos são: investigar a relação entre a manipulação do contraste dos estímulos visuais e o tempo de reação sacádico para facilitar os movimentos oculares e tornar a interação mais rápida e agradável; propor e investigar novas extensões e aplicações da alternância entre contextos, visando reduzir o toque de Midas e ao mesmo tempo generalizar o método para outras tarefas de navegação e seleção de objetos pelo olhar; e desenvolver novos métodos de entrada de texto pelo olhar para melhorar a velocidade de digitação dos usuários, sem incrementar a carga de trabalho e mantendo a interação simples e fácil de aprender. A avaliação dos novos métodos e modelos propostos foi feita por meio de vários estudos com usuários. Os dados coletados nos estudos, tanto quantitativos quanto qualitativos, foram analisados com métodos estatísticos utilizados na área de interação homem-computador.

As contribuições originais apresentadas na presente tese são: a proposta e a avaliação do efeito gap gradiente como feedback visual para facilitar a execução de movimentos sacádicos durante a interação pelo olhar; a proposta e investigação de contextos dinâmicos como extensão da alternância entre contextos, para permitir um melhor aproveitamento da área útil do monitor com uma baixa 
taxa de erros de seleção, assim como de meta-keys para navegação e execução de comandos de forma geral; e a proposta e a avaliação de AugFix, um novo modelo de feedback visual que melhora a velocidade e a experiência dos usuários na entrada de texto pelo olhar, com aplicação em teclados virtuais baseados nos paradigmas do tempo de latência e a alternância entre contextos.

Palavras-chave: interação pelo olhar, rastreamento do olhar, acessibilidade, interfaces para pessoas com deficiência física, efeito gap, digitação pelo olhar. 


\section{Abstract}

Diaz Tula, A. Contributions for gaze interaction with virtual keyboards. Tese (Doutorado) - Instituto de Matemática e Estatística, Universidade de São Paulo, São Paulo, 2015.

This $\mathrm{PhD}$ thesis lays in the context of gaze-based interaction. Gaze-based interfaces allows the user to control a computer using his/her eye movements. Gaze interaction is specially useful for people with physical disabilities who cannot use conventional devices (such as a keyboard and/or mouse) to communicate. Entering text by gaze (also known as eye typing) is a very important activity and the main focus of this dissertation.

The most common eye typing technique uses a virtual keyboard, where the letters are selected by dwell time. Though simple, this interaction technique suffers from involuntary activations (known as the Midas' touch problem) for short dwell times (shorter than $500 \mathrm{~ms}$ ). On the other hand, with longer dwell times the interaction becomes slow. Alternatives to dwell time are discrete and continuous gaze gestures. The use of discrete gaze gestures reduces the Midas' touch problem, but its performance is slower compared to dwell time. When using continuous gaze gestures, the user gaze is always controlling the interface. A recently proposed technique called "context switching" avoids the Midas touch problem by mapping selection to a single saccade. Furthermore, with this technique the users can keep their rhythm of interaction without adjusting any parameter of the interface.

This $\mathrm{PhD}$ thesis aims at improving the usability and user experience in gaze interaction with virtual keyboards. The objectives are: to investigate the relationship between contrast manipulation of visual stimuli and saccadic reaction time, to facilitate eye movements and make the interaction faster and more comfortable; to propose and investigate new extensions and applications of the context switching paradigm, in order to reduce the Midas touch problem and generalize the extensions to other tasks such as browsing and selection; and to develop new methods of eye typing that can improve typing performance without increasing the user workload, while keeping the interaction simple and easy to learn. Several user studies were designed and conducted to evaluate the methods and models proposed in this thesis. The data (both quantitative and qualitative) collected in the experiments is rigorously analysed using statistical methods.

The original contributions of this thesis are: the proposal and investigation of the gradient gap effect as a visual feedback to facilitate the execution of saccadic movements during gaze interaction; the proposal and investigation of two extensions to the context switching paradigm: dynamic contexts that improve the utilization of the screen space while keeping a low selection error rate, and meta-keys for browsing and executing general-purpose commands; and the proposal and evaluation of AugFix, a new method that improves eye typing speed and user experience without increasing the cognitive load, that can be used with virtual keyboards controlled by both dwell time and context 
switching.

Keywords: gaze-based interaction, gaze tracking, accessibility, interfaces for people with disabilities, gap effect, eye typing. 


\section{Sumário}

Lista de Abreviaturas $\quad$ xi

Lista de Figuras $\quad$ xiii

Lista de Tabelas $\quad$ xvii

1 Introdução $\quad 1$

1.1 Motivação . . . . . . . . . . . . . . . . . . . . . . . . . . . 2

1.1.1 Alternância entre contextos . . . . . . . . . . . . . . . . . 3

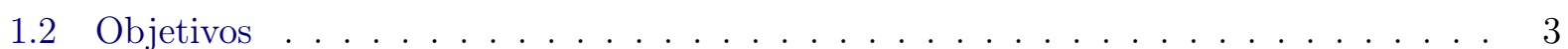

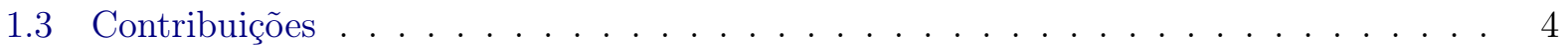

1.4 Aprovação dos protocolos experimentais pela Comissão de Ética em Pesquisa Envolvendo Seres Humanos ． . . . . . . . . . . . . . . . . . . . . . 4

1.5 Apresentação dos resultados dos testes estatísticos . . . . . . . . . . . . . . . . 4

1.6 Estruturação da tese . . . . . . . . . . . . . . . . . . . . . . 4

$\begin{array}{lll}2 & \text { Revisão bibliográfica } & \mathbf{7}\end{array}$

2.1 Breve introdução aos movimentos oculares . . . . . . . . . . . . . . . . . 7

2.2 Resumo das principais técnicas de interação pelo olhar . . . . . . . . . . . . . . 8

2.2 .1 Tempo de latência . . . . . . . . . . . . . . . . . . . . 8

2.2 .2 Alternância entre contextos . . . . . . . . . . . . . . . . . . . . . . 9

2.2.3 Menus circulares hierárquicos . . . . . . . . . . . . . . . . . . . . . . 10

2.2 .4 Gestos discretos do olhar . . . . . . . . . . . . . . . . . . . . . . . 11

2.2 .5 Gestos contínuos do olhar . . . . . . . . . . . . . . . . . . . . 12

2.2.6 Técnicas baseadas no padrão de movimento do olhar no teclado . . . . . . . . 13

2.2 .7 Técnicas baseadas em piscadas . . . . . . . . . . . . . . . . . 15

3 Investigação tempo reação sacádico $\quad 17$

3.1 Efeito gap: redução no tempo de reação sacádico . . . . . . . . . . . . . . . . 17

3.2 Proposta do efeito gap gradiente . . . . . . . . . . . . . . . . . . . . 19

3.3 Modelo de feedback baseado no efeito gap gradiente para interação pelo olhar . . . . 19

3.4 Investigação do efeito gap gradiente . . . . . . . . . . . . . . . . . . 21

3.4.1 Comparação entre o efeito gap e o gradiente . . . . . . . . . . . . . . . . 21

3.4.2 Comparação entre o gradiente descendente e ascendente . . . . . . . . . . . 23

3.5 Experimento usando um teclado virtual controlado pelo olhar . . . . . . . . . . . . . 24 
4 Modelo matemático tempo de reação sacádico

4.1 Modulação do engajamento da atenção no efeito gap . . . . . . . . . . . . . . . . . 29

4.1.1 Resumo de alguns trabalhos sobre o efeito gap . . . . . . . . . . . . . . 29

4.1.2 Hipótese sobre a modulação do engajamento da atenção no efeito gap . . . . 30

4.2 Modelo matemático do tempo de reação sacádico . . . . . . . . . . . . . . . . . . 31

4.3 Validação modelo tempo de reação sacádico . . . . . . . . . . . . . . . . . . . 31

4.3.1 Design experimental e método . . . . . . . . . . . . . . . . 32

4.3 .2 Resultados . . . . . . . . . . . . . . . . . . 33

4.3.3 Análise do modelo matemático do tempo de reação sacádico . . . . . . . . . . 35

4.3.4 Comparação dos resultados experimentais com estudos na literatura . . . . . 35

4.3.5 Discussão sobre o modelo e implicações para o efeito gap . . . . . . . . . . 36

$5 \quad$ Estudo e extensão da alternância entre contextos $\quad 41$

5.1 Mudança dinâmica no tamanho dos contextos . . . . . . . . . . . . . . . . 41

5.1 .1 Uma segunda extensão: meta-keys . . . . . . . . . . . . . . . . . . 43

5.2 Comparação entre contextos com tamanho fixo e dinâmicos . . . . . . . . . . . . 44

5.2 .1 Método . . . . . . . . . . . . . . . . . . . . . . . 44

5.2 .2 Resultados do experimento $1 \ldots \ldots \ldots \ldots \ldots$

5.2 .3 Discussão do experimento $1 \ldots \ldots \ldots$. . . . . . . . . . . . . . 48

5.3 Comparando contextos dinâmicos com tempo de latência . . . . . . . . . . . . . . 51

5.3 .1 Método . . . . . . . . . . . . . . . . . . . . . . 51

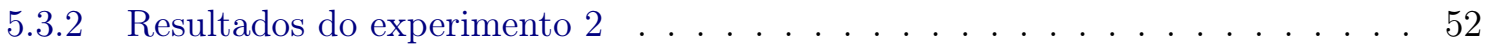

5.3.3 Discussão sobre a comparação entre o tempo de latência e a alternância entre contextos dinâmicos . . . . . . . . . . . . . . . . . . 54 54

5.3.4 Comentários finais sobre alternância entre contextos dinâmicos e meta-keys 55

6 AugFix: melhorando a velocidade na digitação pelo olhar

6.0.5 Teclados virtuais com aceleração para entrada de texto pelo olhar baseados em AugFix . . . . . . . . . . . . . . . . . . . . 5 58

6.1 Experimento de entrada de texto pelo olhar usando AugFix . . . . . . . . . . . . 58

6.1 .1 Método . . . . . . . . . . . . . . . . . . . . . . 59

6.1 .2 Apresentação e discussão dos resultados . . . . . . . . . . . . . . . . 65

6.1.3 Resultados do estudo longitudinal: tempo de latência e alternância entre contextos com aceleração . . . . . . . . . . . . . . . . . . . 65

6.1 .4 Discussão do estudo longitudinal . . . . . . . . . . . . . . . . 67

6.1.5 Resultados da comparação entre os teclados com e sem aceleração . . . . . . . 71

6.1.6 Discussão dos resultados dos métodos sem aceleração . . . . . . . . . . . . 75

6.1 .7 Aceleração $\times$ sem aceleração . . . . . . . . . . . . . . 76

6.2 Considerações finais sobre AugFix f . . . . . . . . . . . . . . . . . . . . . 79

7 Conclusões $\quad 81$

7.1 Sugestões para Pesquisas Futuras . . . . . . . . . . . . . . . . . . . . 82

$\begin{array}{lr}\text { A Publicações } & 83\end{array}$ 
B Questionários aplicados no de digitação pelo olhar usando AugFix 


\title{
Lista de Abreviaturas
}

\author{
SRT Tempo de reação sacádico (Saccadic Reaction Rime) \\ IB Brilho inicial (Initial Brightness) \\ FB Brilho final (Final Brightness) \\ BG Ganho de brilho (Brightness Gain) \\ PPM Palavras por minuto \\ TE Taxa de erros \\ STPC Seleções de teclas por caractere \\ TA Taxa de aceleração \\ APT Tempo médio de navegação (Average Paging Time) \\ AST Tempo médio de seleção (Average Selection Time) \\ ATT Tempo médio de tarefa (Average Task Time) \\ TP Verdadeiros positivos (True Positives) \\ TN Verdadeiros negativos (True Negatives) \\ FN Falsos negativos (False Negatives) \\ STPD Tempo de seleção por dígito (Selection Time per Digit) \\ VP Páginas visitadas (Visited Pages)
}




\section{Lista de Figuras}

2.1 Teclado virtual com predição de palavras. Imagem extraída de MacKenzie e Zhang (2008). . . . . . . . . . . . . . . . . . . . . . . . . . . 9 9

2.2 Interfaces Gazetalk e KKeyboard para interação pelo olhar . . . . . . . . . . . . . . . 10

2.3 Menu circular hierárquico e interface EyeWrite. . . . . . . . . . . . . . . . . . . . . . 11

2.4 Interfaces Dasher e StarGazer . . . . . . . . . . . . . . . . . . . . . . . . . . . . . 13

2.5 Interfaces Pursuits e SMOOVS. . . . . . . . . . . . . . . . . . . . . . . . . . . 14

2.6 Interface Filteryedping, imagem reproduzida de Pedrosa et al. (2015). . . . . . . . . 14

2.7 Interface BlinkWrite, imagem reproduzida de Scott MacKenzie e Ashtiani (2011). . . 15

3.1 Condições de gap e de controle . . . . . . . . . . . . . . . . . . . . . . . . . . . . . . 19

3.2 Efeito gap gradiente descendente, no qual o brilho do estímulo é reduzido de forma gradual. . . . . . . . . . . . . . . . . . . . . . . . . . . 20

3.3 Modelos de feedback baseados no efeito gap gradiente . . . . . . . . . . . . . . . . . . 20

3.4 Configuração utilizada durante o experimento. . . . . . . . . . . . . . . . . . . . . . . 22

3.5 Média e 1 desvio padrão do SRT para 8 participantes, para o efeito gap e o efeito gap gradiente. Para gap $=0$ existe apenas uma condição. . . . . . . . . . . . . . . 23

3.6 Média e 1 desvio padrão do SRT para 8 participantes, para o efeito gap gradiente descendente e ascendente. . . . . . . . . . . . . . . . . . . . . . . 25

3.7 Teclado virtual usado no experimento de entrada de texto pelo olhar. . . . . . . . . . 26

3.8 Modelos de feedback usados no experimento de digitação pelo olhar. . . . . . . . . . . 27

3.9 Resultados de 5 sessões do experimento de digitação pelo olhar comparando o modelo de feedback baseado no efeito gap gradiente com o modelo de animação. Os valores mínimo e máximo correspondem aos extremos da linha tracejada, os quartis inferior e superior aos extremos da caixa sombreada, a mediana à linha dentro da caixa e a média ao círculo também dentro da caixa. . . . . . . . . . . . . . . . . . . . . . . . 28

4.1 Condições de controle, apagamento, menor brilho e maior brilho usadas no experimento 38

4.2 Resultados experimentais para os dois valores de gap (0 e $200 \mathrm{~ms}$ ). Para cada condição é mostrado o SRT mínimo e máximo como sendo os extremos da linha tracejada, os quartis inferior e superior como os extremos da caixa sombreada, a mediana como uma linha dentro da caixa e a média como um círculo também dentro da caixa. Os valores da média e um desvio padrão são mostrados acima de cada caixa, e os outliers são mostrados com uma estrela. . . . . . . . . . . . . . . . . . . . . . . . 39

4.3 Resultados da regressão para calcular os parâmetros da equação 4.2 para os valores de gap de 0 e 200 ms. Note que o eixo $x$ possui uma escala logarítmica. . . . . . . . . 40 
5.1 Três interfaces baseadas na alternância entre contextos de tamanho fixo e dinâmicos.

Em todas as configurações a ponte (área azul) separa os dois contextos.

5.2 Representação gráfica de um meta-key. O gesto de dois passos feito com o olhar começa em um meta-contexto, depois vá até o marcador (quadrado azul) e finalmente volta para um meta-contexto vizinho, cruzando a ponte duas vezes.

5.3 Menu ativado meta-keys localizados à direita ou esquerda dos contextos para iniciar e finalizar cada teste, e também para desfazer a última seleção.

5.4 Média e um desvio padrão de 6 participantes para precisão, para as configurações $2 \mathrm{C}, 3 \mathrm{C}$ e $4 \mathrm{C}$.

5.5 Média e um desvio padrão de 6 participantes para revocação, para as configurações $2 \mathrm{C}, 3 \mathrm{C}$ e $4 \mathrm{C}$.

5.6 Média e um desvio padrão de 6 participantes para tempo médio de navegação, para as configurações $2 \mathrm{C}, 3 \mathrm{C}$ e $4 \mathrm{C}$.

5.7 Média e um desvio padrão de 6 participantes para tempo médio de seleção, para as configurações $2 \mathrm{C}, 3 \mathrm{C}$ e $4 \mathrm{C}$.

5.8 Média e um desvio padrão de 6 participantes para tempo médio de tarefa, para as configurações $2 \mathrm{C}, 3 \mathrm{C}$ e $4 \mathrm{C}$. . . . . . . . . . . . . . . . . . . . . . . . . . . . . . . . . . 49

5.9 Interface baseada no tempo de latência usada no experimento 2. . . . . . . . . . . 52

5.10 Média e um desvio padrão para precisão, para o tempo de latência e a alternância entre contextos dinâmicos.

5.11 Média e um desvio padrão para revocação, para o tempo de latência e a alternância entre contextos dinâmicos.

5.12 Média e um desvio padrão para tempo médio de navegação, para o tempo de latência e a alternância entre contextos dinâmicos.

5.13 Média e um desvio padrão para tempo médio de seleção, para o tempo de latência e a alternância entre contextos dinâmicos.

5.14 Média e um desvio padrão para tempo médio de tarefa, para o tempo de latência e a alternância entre contextos dinâmicos.

6.1 Teclado virtual baseado no tempo de latência com o prefixo, sufixos e lista de palavras. 59

6.2 Teclado virtual baseado na alternância entre contextos com o prefixo, sufixos e lista de palavras. . . . . . . . . . . . . . . . . . . . . . . . . . . 6 60

6.3 Estados do teclado virtual baseado em tempo de latência durante o experimento. 63

6.4 Média e um desvio padrão de 7 participantes para ppm, para os dois teclados com aceleração durante 9 sessões.

6.5 Média e um desvio padrão de 7 participantes para TE, para os dois teclados com aceleração durante 9 sessões.

6.6 Média e um desvio padrão de 7 participantes para $S T P C$, para os dois teclados com aceleração durante 9 sessões.

6.7 Média e um desvio padrão de 7 participantes para $T A$, para os dois teclados com aceleração durante 9 sessões. A linha horizontal tracejada representa a aceleração máxima possível para o texto de treinamento e as frases usadas no estudo. . . . . . .

6.8 Resultados do questionário 1 sobre os métodos com aceleração, em relação ao desempenho, taxa de erros e conforto. 
6.9 Média e um desvio padrão de 7 participantes para o índice de carga de trabalho, para os dois teclados com aceleração. . . . . . . . . . . . . . . . . . . . 70

6.10 Ajuste de curva para a média de ppm ao longo das 9 sessões para os dois métodos com aceleração ( $\mathrm{TL}=$ tempo de latência, $\mathrm{AC}=$ alternância entre contextos). A função tem a forma $y=\alpha_{m} x^{\gamma_{m}}$, onde $x$ é u número da sessão, $y$ é o ppm e $m \in\{\mathrm{TL}, \mathrm{AC}\} . \quad 71$

6.11 Média de um dos participantes para ppm, para os dois teclados com aceleração durante 9 sessões. . . . . . . . . . . . . . . . . . . . . . . 72

6.12 Média e um desvio padrão de 7 participantes para ppm, para os dois teclados com e sem aceleração durante 3 sessões. . . . . . . . . . . . . . . . . . . . . . . 73

6.13 Média e um desvio padrão de 7 participantes para $T E$, para os dois teclados com e sem aceleração durante 3 sessões. . . . . . . . . . . . . . . . . . . . . . . . . . . 74

6.14 Média e um desvio padrão de 7 participantes para $S T P C$, para os dois teclados com e sem aceleração durante 3 sessões. . . . . . . . . . . . . . . . . . . 75

6.15 Resultados do questionário 2 sobre os métodos sem aceleração, em relação ao desempenho, taxa de erros e conforto. . . . . . . . . . . . . . . . 76

6.16 Resultados do questionário 3 sobre os métodos com e sem aceleração, em relação ao desempenho, taxa de erros, conforto e método escolhido. . . . . . . . . . . 76

6.17 Média e um desvio padrão para 7 participantes sobre o questionário 3, avaliando o impacto da aceleração no desempenho, taxa de erros e conforto. . . . . . . . . . . 77

6.18 Média e um desvio padrão de 7 participantes para o índice de carga de trabalho, para os dois teclados sem aceleração. . . . . . . . . . . . . . . . . . . 77

6.19 índice de carga de trabalho para os dois métodos (tempo de latência e alternância entre contextos) com e sem aceleração. . . . . . . . . . . . . . . . . . . . . 79 


\section{Lista de Tabelas}

4.1 Conversão dos níveis de brilho usados no experimento para valores de luminância. Os níveis de brilho são expressados como porcentagens do brilho máximo do monitor

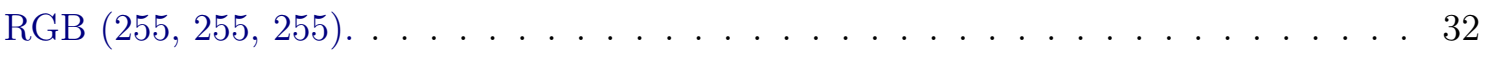

5.1 Impressões subjetivas dos participantes em relação a velocidade percebida e conforto 50 


\section{Capítulo 1}

\section{Introdução}

A presente tese de doutorado insere-se na área de interação humano-computador, especificamente no tema de interação pelo olhar. Na interação pelo olhar os movimentos dos olhos do usuário são utilizados para interagir com o computador. Pessoas com deficiência física, como Esclerose Lateral Amiotrófica (Amyotrophic Lateral Sclerosis) ou Síndrome do Encarceramento (Locked-in Syndrome), não tem controle dos músculos do corpo e, portanto, não conseguem utilizar dispositivos convencionais (teclado, mouse e telas sensíveis ao toque) para interagir com o computador. Muitas dessas pessoas sofrem de paralisia total, conseguindo apenas movimentar os olhos, não sendo viável para elas utilizar formas alternativas de interação com computadores, como sistemas de reconhecimento de voz, movimentos de cabeça ou por meio da contração de um ou vários músculos do corpo.

Para as pessoas que apenas conseguem movimentar os olhos, o uso do olhar representa a única alternativa para se comunicarem com o mundo exterior. A possibilidade de comunicação melhora significativamente a qualidade de vida dessas pessoas, pois elas podem expressar sentimentos, necessidades e se reinserirem na sociedade.

A tarefa mais comum na interação pelo olhar é a entrada de texto ou digitação pelo olhar. As interfaces de entrada de texto pelo olhar tem como dispositivo de entrada um rastreador de olhar. Os rastreadores de olhar modernos utilizam uma câmera de vídeo apontada para os olhos do usuário (Morimoto e Mimica, 2005), para detectar e rastrear características como a pupila, iris, reflexos corneais produzidos por fontes de luz infravermelha, entre outros. Por meio de um processo de calibração, no qual o usuário tem que olhar para vários pontos no monitor (usualmente 9), é possível estimar o ponto observado.

A tecnologia de rastreamento de olhar possui várias limitações, como a necessidade de iluminação controlada, pouca robustez a oclusão (produzida pelas pálpebras e cílios, por exemplo), assim como a baixa acurácia na estimação do ponto observado, que é de aproximadamente 1 grau de ângulo visual (Hansen e Ji, 2010; Morimoto e Mimica, 2005). Essas características limitam sua utilização a ambientes fechados, sem incidência de luz solar. A baixa acurácia na estimação do ponto observado no monitor implica que as interfaces controladas por meio do olhar possuam teclas grandes, para evitar erros de seleção. 


\subsection{Motivação}

A usabilidade de aplicativos que utilizam o olhar depende muito da forma de interação utilizada. Ao associar o cursor à posição do olhar, o apontamento de objetos da interface pode ser feito de forma bastante natural, porém a seleção dos objetos ("clicar" com o olhar) continua um problema que ainda não foi resolvido satisfatoriamente. Dentre os métodos sugeridos podemos citar o piscar do olho (Scott MacKenzie e Ashtiani, 2011), gestos do olhar (Drewes e Schmidt, 2007) e tempo de latência (ou dwell time) (Hansen et al., 2004; Lankford, 2000; Majaranta e Räihä, 2007). Essa última alternativa, talvez devido a sua simplicidade, é a mais utilizada até o momento. A ideia é que o usuário precisa manter o olhar fixo sobre um objeto (por um período de latência), para selecioná-lo.

Apesar de simples, utilizando um tempo de latência muito curto temos o problema do toque de Midas (Jacob, 1991): todo objeto observado pelo usuário é ativado de forma involuntária. Caso o tempo seja longo, a interação se torna lenta. O desempenho atingido com o tempo de latência, medido em número de palavras por minuto (ppm), é em torno de 5-10 ppm (Bee e André, 2008; Majaranta e Räihä, 2002; Rough et al., 2014). Com um tempo de latência abaixo de $300 \mathrm{~ms}$ é possível atingir até 20 ppm, porém aumenta também o número de seleções involuntárias e o estresse dos usuários durante a interação (Majaranta, 2009; Räihä e Ovaska, 2012).

Para tentar incrementar a velocidade na digitação pelo olhar, vários autores tem proposto o uso de predição de palavras (Majaranta, 2009; Urbina e Huckauf, 2010; Wobbrock et al., 2008). Em uma interface com predição de palavras, o usuário pode selecionar palavras de uma lista, digitando vários caracteres com apenas um apertamento de tecla. Um problema com essa abordagem, porém, é que o usuário não sabe quais palavras estão na lista, precisando alternar o foco entre o teclado e a lista. Além disso, o usuário precisa olhar para a área de texto para detectar erros na digitação. Essa mudança de foco entre o teclado e a lista de palavras/área de texto reduz o desempenho do usuário, provocando estresse e incrementando a carga cognitiva durante a interação.

Como alternativas ao tempo de latência, surgiram técnicas de seleção baseadas em gestos do olhar. Gestos podem ser compostos por uma sequência de movimentos discretos do olho (Huckauf e Urbina, 2007; Wobbrock et al., 2008). Cada gesto é então mapeado para um caractere do alfabeto. $\mathrm{O}$ uso de gestos discretos evita alguns dos problemas do tempo de latência. Por exemplo, eles podem utilizar regiões menores da tela para realização dos gestos (Wobbrock et al., 2008), ou mesmo locais fora da tela como alvos (Isokoski, 2000). No entanto, no caso de gestos complexos o usuário tem que aprender o alfabeto de gestos inteiro, além de sofrer cansaço visual e apresentar um desempenho inferior ao tempo de latência (Porta, 2015; Wobbrock et al., 2008).

O uso de movimentos contínuos também tem sido explorado para entrada de texto pelo olhar (Hansen et al., 2008; Vidal et al., 2013; Ward e MacKay, 2002). Gestos contínuos podem ser mais apropriado para rastreadores menos robustos (Hansen et al., 2008) ou inclusive em ambientes sem calibração (Vidal et al., 2013). No entanto, o desempenho desses métodos também é inferior ao tempo de latência (Hansen et al., 2008; Lutz et al., 2015). O Dasher, de Ward e MacKay (2002), é um dos aplicativos mais eficientes para a entrada de texto pelo olhar, baseado em movimentos contínuos do olhar. O sucesso do Dasher é devido ao uso de predição de caracteres. No entanto, apesar de permitir o controle sobre a velocidade de digitação, o Dasher não possui uma posição adequada para descanso, pois o olhar está sempre preso ao controle da interface. 


\subsubsection{Alternância entre contextos}

Em um trabalho recente apresentado por Morimoto e Amir (2010), foi introduzido um novo paradigma de interação baseado na alternância entre contextos. Esse paradigma surge como alternativa ao método baseado em tempo de latência para seleção de objetos em interfaces controladas pelo olhar.

A ideia do novo paradigma é atribuir as tarefas de foco e seleção a movimentos diferentes do olho. O foco sobre um objeto (que corresponde à tarefa de apontamento por um mouse, por exemplo) é ativado por fixações do olhar e a seleção (que corresponde aos "cliques" do mouse) é ativada por sacadas (movimentos rápidos do olho). No paradigma de tempo de latência, apenas as fixações são utilizadas. Em interfaces baseadas em gestos discretos, nas quais a seleção é feita quando o olhar se desloca para uma "tecla especial de seleção" (Isokoski, 2000; Ohno, 1998) (uma região especial que pode ser fora da tela do computador), são necessárias duas sacadas para se fazer uma seleção. Ao invés de utilizar uma tecla especial, na nova técnica a interface é dividida em dois contextos, sendo que a seleção está associada à troca de contextos, utilizando apenas uma sacada.

A alternância entre contextos permite que o usuário olhe para qualquer tecla pelo tempo que desejar, sem que seu olhar esteja sempre preso ao controle da interface como no caso do Dasher, e sem se preocupar com a sua ativação devido ao toque de Midas, pois a seleção só acontece quando há troca de contexto por meio de uma sacada. Como a sacada é um movimento rápido do olho, o usuário pode ajustar a sua velocidade de digitação de maneira natural e transparente, que pode ser rápida para usuários avançados, ou lenta para novatos, sem a necessidade de ajustar nenhum parâmetro da interface.

\subsection{Objetivos}

O objetivo geral da presente tese de doutorado é melhorar a usabilidade e a experiência dos usuários de interfaces baseadas em teclados virtuais controladas pelo olhar. Neste contexto, usabilidade refere-se a velocidade de digitação e taxa de seleções involuntárias (erros), enquanto que a experiência do usuário está relacionada com os sentimentos dos usuários em relação à utilização das interfaces controladas pelo olhar (conforto, facilidade de usar, entre outros).

Os objetivos específicos da tese são:

(i) investigar a relação entre manipulação do contraste dos estímulos visuais e o tempo de reação sacádico para facilitar os movimentos oculares e tornar a interação mais rápida e agradável;

(ii) propor e investigar novas extensões e aplicações da alternância entre contextos, visando reduzir o toque de Midas e ao mesmo tempo generalizar o método para outras tarefas de navegação e seleção de objetos pelo olhar;

(iii) desenvolver novos métodos de entrada de texto pelo olhar para melhorar a velocidade de digitação dos usuários, sem incrementar a carga de trabalho e que sejam simples e fácil de aprender. 


\subsection{Contribuições}

As contribuições apresentadas nessa tese de doutorado são todas originais, com o potencial de impactar a qualidade de vida das pessoas com deficiência física que dependem do olhar para se comunicarem. As contribuições são enunciadas a seguir:

- Proposta e avaliação do efeito gap gradiente como um novo modelo de feedback visual que facilita a execução de movimentos sacádicos durante a interação pelo olhar, comparado com um modelo de feedback tradicional. O modelo tem aplicação em interfaces que utilizam sacadas durante a interação.

- Proposta e avaliação de contextos dinâmicos como extensão da alternância entre contextos, para um melhor aproveitamento da área útil do monitor com uma taxa de erros menor que o tempo de latência, assim como a proposta e avaliação de Meta-keys para navegação e execução de comandos de forma geral. As extensões tem potencial de aplicação em interfaces controladas pelo olhar para gerenciamento de documentos, fotos, conteúdo multimídia, entre outros.

- Proposta e avaliação de AugFix, um novo modelo de feedback visual que melhora a velocidade e a experiência dos usuários na digitação pelo olhar, aumentando a informação passada ao usuário durante a interação. O novo método pode ser usado em teclados virtuais com predição de palavras controlados por tempo de latência e também pela alternância entre contextos.

\subsection{Aprovação dos protocolos experimentais pela Comissão de Ética em Pesquisa Envolvendo Seres Humanos}

Os procedimentos experimentais apresentados na presente tese de doutorado foram aprovados pela Comissão de Ética em Pesquisa Envolvendo Seres Humanos do Instituto de Ciências Biomédicas da Universidade de São Paulo. O protocolo experimental sobre os estudos do tempo de reação sacádico encontra-se resumido no documento intitulado "Estudo do Efeito Gap para Aplicação em Interfaces Baseadas no Olhar", com Certificado de Apresentação para Apreciação Ética (CAAE) $\mathrm{n}^{\circ}$ 20455713.5.0000.5467. Já os estudos sobre interação pelo olhar foram resumidos no documento intitulado "Avaliação de Interfaces Controladas pelo Olhar", com CAAE no 39524514.1.0000.5467.

\subsection{Apresentação dos resultados dos testes estatísticos}

Para apresentar os resultados dos testes estatísticos, adotamos o padrão sugerido na $6^{a}$ Edição do Manual da Associação Americana de Psicologia (APA, do inglês American Psychological Association), disponível em www. apastyle.com. Todos os valores estatísticos são arredondados para duas casas decimais, com exceção dos valores do nível de significância (p) menores que 0.001, em cujo caso será usada a notação "p < 0.001".

\subsection{Estruturação da tese}

A tese se encontra estruturada da forma seguinte: 
O capítulo 2 começa descrevendo brevemente os principais movimentos oculares que são utilizados na interação pelo olhar. A seguir, é apresentada uma revisão das principais técnicas de interação pelo olhar existentes na literatura, com foco nas interfaces para entrada de texto, evidenciando os principais problemas existentes.

O capítulo 3 apresenta a investigação da relação entre a manipulação do contraste dos estímulos visuais e o tempo de reação sacádico, por meio de experimentos psicofísicos com voluntários. Introduzimos também o efeito gap gradiente, que é um novo modelo de feedback visual para facilitar a entrada de texto pelo olhar. O modelo proposto é avaliado em um estudo de digitação pelo olhar, comparando-o com um modelo de feedback tradicional.

Dando continuidade a esse estudo, no capítulo 4 propomos um modelo matemático do tempo de reação sacádico em função do ganho de brilho. O modelo foi derivado de forma analítica tendo como base a lei psicofísica de Weber-Fechner (Fechner, 1860). Apresentamos também a validação do modelo proposto na predição do tempo de reação sacádico por meio de um experimento psicofísico com usuários. Os parâmetros do modelo foram calculados utilizando a técnica de regressão linear com os dados experimentais.

As extensões propostas para a alternância entre contextos, sua avaliação em estudos de usabilidade com usuários, assim como a sua comparação com o tempo de latência são apresentados no capítulo 5. Mostramos que as extensões propostas apresentam uma taxa de erros menor que o tempo de latência, generalizando o método da alternância entre contextos para outras tarefas além da digitação pelo olhar, como navegação, seleção e gerenciamento de documentos e conteúdo multimídia em geral.

O capítulo 6 apresenta uma nova técnica chamada de AugFix, que explora a visão foveal/parafoveal para aumentar a informação passada ao usuário durante a interação pelo olhar. Mostramos, por meio de um experimento com voluntários, que AugFix permite melhorar a velocidade e a experiência dos usuários na digitação pelo olhar, com uma baixa carga de trabalho. O método foi aplicado a teclados controlados por tempo de latência e a alternância entre contextos, mas pode ser generalizado a outras formas de interação pelo olhar.

No capítulo 7 apresentamos as conclusões da presente tese, assim como as sugestões de pesquisa no futuro.

A lista completa de artigos publicados e submetidos como resultado dessa pesquisa são mostrados no apêndice A. 


\section{Capítulo 2}

\section{Revisão bibliográfica}

Nesse capítulo fazemos uma breve descrição das características dos movimentos oculares mais utilizados na interação pelo olhar. Depois apresentamos uma revisão bibliográfica das principais técnicas de interação pelo olhar existentes, com o objetivo de mostrar os últimos avanços alcançados na área e destacar os desafios que ainda existem.

\subsection{Breve introdução aos movimentos oculares}

Os olhos são os órgãos da visão: eles permitem perceber o mundo em imagens que são transmitidas ao cérebro. Os raios de luz atravessam a córnea, que é a estrutura mais externa do olho, passando por várias outras estruturas até chegar na retina, onde estão localizados os fotorreceptores. Esses neurônios transformam o estímulo luminoso em impulsos nervosos, que são transmitidos ao cérebro (Liversedge et al., 2011). Dentro da retina existe uma área de maior concentração de fotorreceptores, que é chamada de fóvea. A fóvea cobre aproximadamente 2 graus no centro do campo visual e permite perceber a informação em alta resolução.

Devido a fato de que nosso entorno é muito dinâmico, os olhos estão em constante movimento para garantir que a fóvea esteja focada nos objetos de interesse. De acordo com Duchowski (2000), os movimentos oculares básicos são fixações, sacadas, perseguições lentas, vergência, reflexos vestíbulooculares e nistagmo fisiológico. Dentre eles, fixações, sacadas e perseguições lentas tem sido utilizados para controlar interfaces pelo olhar (Møllenbach et al., 2013).

As fixações são movimentos que estabilizam a fóvea no objeto que está sendo observado, tendo uma duração entre 150-600 ms (Duchowski, 2000). Durante uma fixação o olho não fica completamente estacionário, pois movimentos muito pequenos, como tremores e microsacadas, também são observados (Møllenbach et al., 2013).

O movimento de perseguição lenta é utilizado para rastrear um objeto em movimento, com uma velocidade máxima de 100-200 graus/seg (Møllenbach et al., 2013). Para fazer um movimento de perseguição lenta é necessário ter um estímulo que possa guiar o olhar. Durante a perseguição de um objeto, sacadas corretivas podem ser feitas para garantir a precisão no acompanhamento.

As sacadas são movimentos rápidos do olho para mudar o objeto que está sendo captado pela fóvea (Kowler, 2011). Elas são uma forma rápida e eficiente de explorar nosso entorno visual. O movimento sacádico tem uma duração entre 10-100 ms e uma velocidade angular de até 600 graus/seg (Baloh et al., 1975). Para iniciar uma sacada, no entanto, há um tempo de preparação entre 150-250 ms (Saslow, 1967). Devido ao mecanismo de supressão sacádica, durante uma sacada 
não há percepção visual (Bridgeman et al., 1975). As sacadas são movimentos balísticos, pois uma vez iniciado o movimento sacádico a posição final não pode mudar. Além disso, sacadas também são estereotipadas, pois a trajetória seguida pelo olho é pre-programada (Duchowski, 2000).

\subsection{Resumo das principais técnicas de interação pelo olhar}

A seguir descrevemos as principais técnicas de interação pelo olhar existentes.

\subsubsection{Tempo de latência}

O paradigma de interação pelo olhar mais utilizado é conhecido como "tempo de latência". Nessa forma de interação, a seleção é feita fixando o olhar no caractere desejado por um determinado tempo, tipicamente entre 500-1000 ms (Majaranta e Räihä, 2002). Um exemplo de interface que usa essa técnica de seleção é Gazetalk, de Hansen et al. (2004), mostrada na figura 2.2a. GazeTalk possui uma interface dinâmica com 10 teclas de $8 \times 8 \mathrm{~cm}$. A cada instante, apenas os caracteres mais prováveis são mostrados na interface. O usuário pode selecionar um botão para mostrar as 8 palavras mais prováveis, com o intuito de acelerar a digitação. Hansen et al. (2004) avaliaram a interface GazeTalk em um experimento de entrada de texto pelo olhar. Os resultados desse estudo, no qual 12 participantes digitaram 12 frases em dinamarquês durante duas sessões, mostraram um desempenho de $5.82 \mathrm{ppm}$ na primeira sessão e $6.61 \mathrm{ppm}$ na segunda sessão. Além de entrada de texto, a interface também foi projetada para controlar outros aplicativos como internet e multimídia.

A maior vantagem da seleção por tempo de latência é a sua simplicidade e fácil aprendizado. O principal problema, porém, é a escolha do tempo de fixação mais apropriado: tempos curtos provocam seleções involuntárias se o olhar descansar em uma tecla por um tempo maior que o de latência, ou seja, temos o toque de Midas. Já tempos mais longos reduzem o número de seleções involuntárias, porém a interação se torna lenta, reduzindo a velocidade de digitação e produzindo cansaço visual.

Em uma tentativa de amenizar esse problema, Špakov e Miniotas (2004) desenvolveram um algoritmo para ajustar o tempo de latência de forma automática, usando informação sobre o tempo que os usuários demoravam em sair de uma tecla depois de selecioná-la. Embora os resultados tenham sido promissores, o sistema respondia lentamente a mudanças rápidas na velocidade de digitação dos usuários.

O ajuste manual também foi estudado por Majaranta et al. (2009), permitindo que os usuários configurem manualmente o tempo de latência durante a interação. Usuários pouco experientes geralmente requerem de um tempo de latência grande, enquanto que usuários mais avançados usam um tempo menor. Essa solução tem como desvantagem a necessidade de configurar a velocidade de interação de forma manual.

O desempenho médio atingido com teclados virtuais controlados por tempo de latência varia entre 5-10 ppm (Hansen et al., 2004; Majaranta e Räihä, 2002; Rough et al., 2014). Já com um tempo de latência ajustável, Majaranta et al. (2009) e Räihä e Ovaska (2012) obtiveram um desempenho em torno de $20 \mathrm{ppm}$. No entanto, esse desempenho foi possível devido a que os participantes configuraram um tempo de seleção muito baixo, o que na prática é desconfortável para ser usado durante longos períodos de tempo, além de ter um maior número de erros por causa do toque de Midas. 
Para tentar incrementar a velocidade na digitação pelo olhar, vários autores têm proposto o uso de predição de palavras (Majaranta, 2009; Urbina e Huckauf, 2010; Wobbrock et al., 2008). Em uma interface de digitação pelo olhar com predição de palavras, o sistema mostra a lista de palavras mais prováveis baseado no texto escrito até o momento e um modelo de linguagem, como descrito por Majaranta (2009). A figura 2.1 mostra um teclado virtual com a lista de palavras mais prováveis, desenvolvido por MacKenzie e Zhang (2008). Durante a digitação o usuário pode selecionar palavras da lista, reduzindo o número de toques necessários para produzir o texto desejado. A lista é atualizada dinamicamente conforme novos caracteres ou palavras forem digitados.

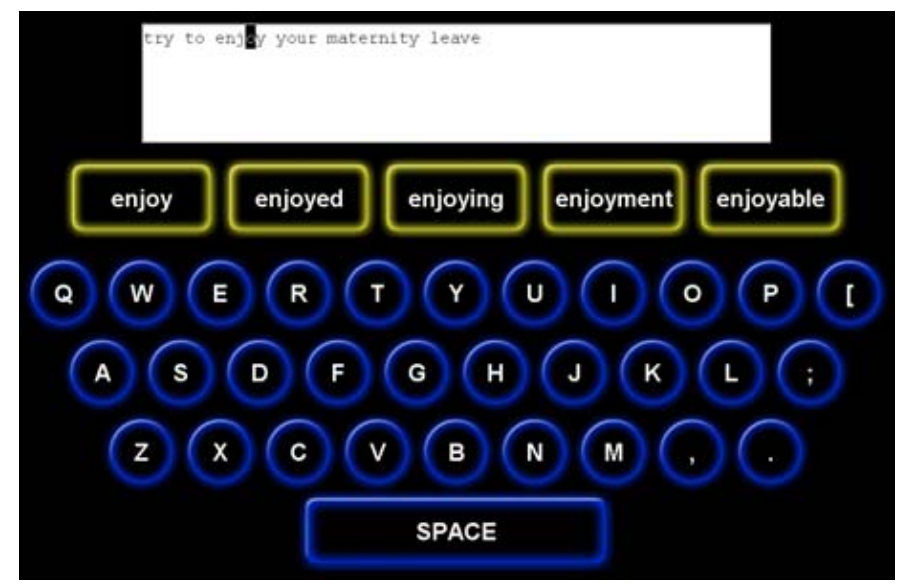

Figura 2.1: Teclado virtual com predição de palavras. Imagem extraída de MacKenzie e Zhang (2008).

Um dos problemas do mecanismo de predição de palavras, porém, é que os usuários precisam parar de digitar para buscar a palavra desejada na lista. Essa mudança de foco entre o teclado e a lista introduz uma carga cognitiva maior (Majaranta, 2009; Ward e MacKay, 2002), podendo inclusive piorar o desempenho usando predição de palavras (Koester e Levine, 1994; Pouplin et al. , 2014).

Um outro problema na digitação pelo olhar é manter o usuário atualizado sobre o contexto de digitação. Como o olhar está focado no controle da interface, não existe feedback direto sobre as últimas seleções feitas pelo usuário. Por exemplo, em um teclado físico, os usuários podem ler o texto escrito enquanto digitam ou fazem correções. A diferença, durante a digitação pelo olhar, os usuários não podem ler o texto escrito (para verificar os últimos caracteres digitados e corrigir eventuais erros) sem parar de digitar e olhar para a área de texto (Majaranta et al., 2006). Isto pode aumentar a carga cognitiva e piorar o desempenho.

Em uma tentativa de amenizar esse problema, Majaranta et al. (2006) propuseram um tipo de feedback auditivo no qual cada caractere digitado era falado pelo computador. Esse feedback, embora tenha recebido avaliações positivas dos participantes de um experimento de entrada de texto pelo olhar, ainda tem alguns problemas. Alguns participantes esperavam a letra selecionada ser falada antes de ir para a próxima tecla, o que pode piorar o desempenho. Além disso, esse feedback falado não permite aos usuários manterem o ritmo da interação.

\subsubsection{Alternância entre contextos}

Recentemente uma nova técnica de interação pelo olhar foi proposta por Morimoto e Amir (2010), chamada "alternância entre contextos" (Context Switching). A técnica consiste em dividir a 


\begin{tabular}{|c|c|c|c|}
\hline \multicolumn{2}{|l|}{ This is the text $\mathrm{f}_{-}$} & A to $\mathrm{Z}$ & Backspace \\
\hline $\begin{array}{c}{[8 \text { most }} \\
\text { likely } \\
\text { words }]\end{array}$ & A & I & O \\
\hline Space & R & L & U \\
\hline
\end{tabular}

a) Interface Gazetalk, imagem reproduzida de Hansen et al. (2004).

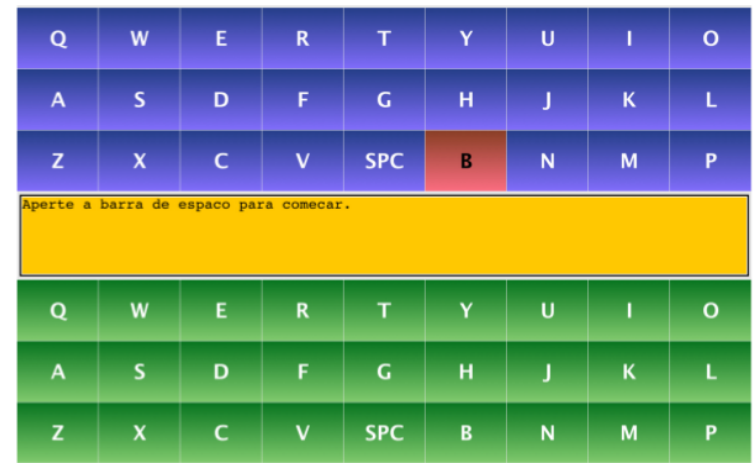

b) Teclado virtual baseado na alternância entre contextos, imagem reproduzida de Morimoto e Amir (2010).

Figura 2.2: Interfaces Gazetalk e KKeyboard para interação pelo olhar

área do monitor em duas regiões idênticas que são os contextos. O usuário pode explorar livremente os contextos sem risco de seleção acidental, reduzindo o toque de Midas. Para realizar uma seleção, é necessário fixar o olhar na tecla desejada por um tempo curto (entre 50-100 ms) e depois fazer uma sacada para o outro contexto. A figura $2.2 \mathrm{~b}$ mostra uma interface baseada na alternância entre contextos para entrada de texto, chamada KKboard (Morimoto e Amir, 2010).

Como as tarefas de apontamento e seleção são feitas usando movimentos diferentes do olhar, o usuário fica livre para explorar o conteúdo dos contextos sem o estresse do toque de Midas, podendo descansar em qualquer tecla. Além disso, a velocidade de interação é ajustada naturalmente sem necessidade de configurar nenhum parâmetro da interface, a diferença do tempo de latência ajustável. Como apenas uma sacada é necessária para fazer uma seleção, o usuário não sente muito cansaço visual quando o método for usado por muito tempo.

Os resultados de um teste piloto de entrada de texto pelo olhar com 7 participantes mostraram uma velocidade média de $12 \mathrm{ppm}$, resultado acima da média dos métodos tradicionais, com uma baixa taxa de erros. Os participantes acharam o método fácil de aprender e usar de forma natural. Além disso, não reportaram fadiga visual depois de cada sessão do experimento.

\subsubsection{Menus circulares hierárquicos}

Urbina e Huckauf (2010) apresentaram extensões de uma interface baseada em menus circulares hierárquicos (pie menus) com três níveis para entrada de texto pelo olhar, como pode ser observado na figura 2.3a. Cada menu consiste em um círculo dividido em vários setores circulares.

No primeiro menu da hierarquia cada setor contém um subconjunto das letras do alfabeto. Para selecionar um caractere, o usuário fixa o olhar por um certo tempo no setor contendo o caractere desejado ou, alternativamente, cruza com o olhar a borda exterior do setor circular (desde dentro do setor até a parte de fora). Nesse instante um novo menu circular é mostrado, contendo todos os caracteres que pertencem ao setor selecionado no primeiro menu. O usuário então seleciona o caractere desejado nesse menu. Um terceiro menu mostra os próximos caracteres mais prováveis levando em conta o caractere selecionado no segundo menu. Os autores incluíram três teclas controladas por tempo de latência contendo as três palavras mais prováveis considerando o texto escrito pelo 


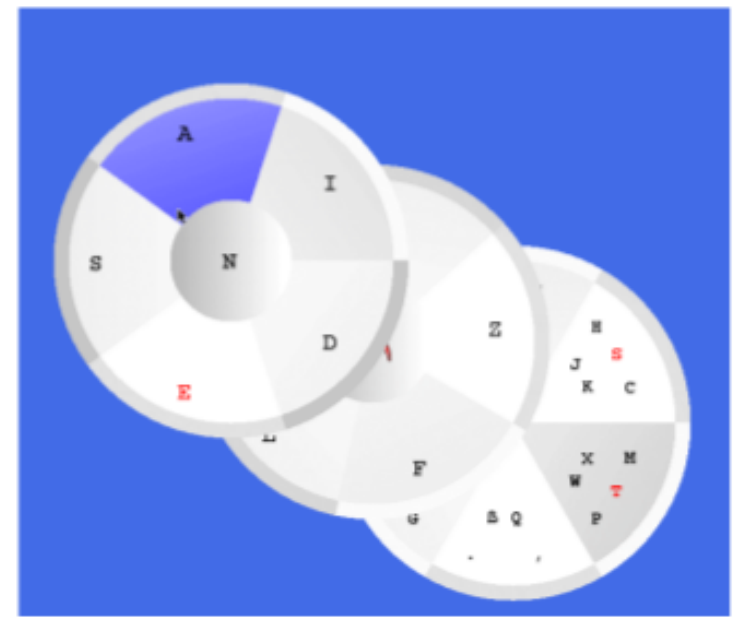

a) Menu circular hierárquico com três níveis, imagem reproduzida de Urbina e Huckauf (2010).

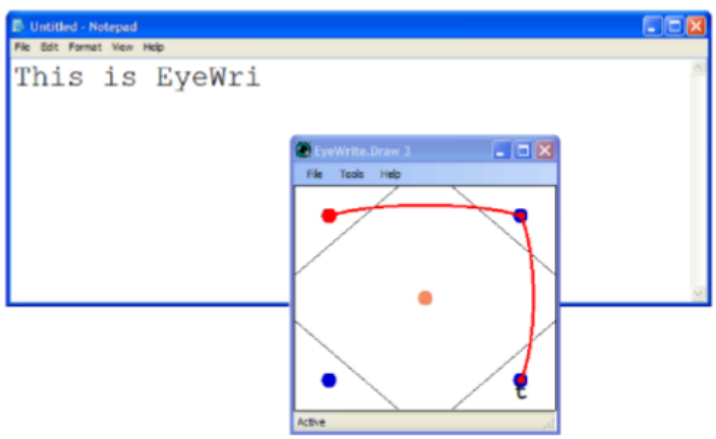

b) Interface EyeWrite, imagem reproduzida de Wobbrock et al. (2008).

Figura 2.3: Menu circular hierárquico e interface EyeWrite.

usuário, com o intuito de melhorar o desempenho.

Os resultados de um estudo de entrada de texto mostraram um desempenho máximo de $13 \mathrm{ppm}$ utilizando um mecanismo de predição de palavras, com uma taxa de erros inferior ao 5\%. Uma vantagem dessa forma de interação é que os usuários podem aprender o caminho para selecionar cada caractere, fazendo um gesto com o olhar. Como desvantagens, a interface ainda sofre do toque de Midas, além de utilizar um espaço considerável na tela.

\subsubsection{Gestos discretos do olhar}

As técnicas baseadas em gestos discretos do olhar mapeiam padrões de movimentos feitos com o olhar para caracteres. Um exemplo de aplicativo que utiliza gestos do olhar para entrada de texto desenvolvido por Wobbrock et al. (2008) é o EyeWrite, mostrado na figura 2.3b. No EyeWrite, uma janela de $400 \times 400$ pixels é utilizada para executar os gestos do olhar. A cada letra do alfabeto corresponde uma determinada sequência de movimentos do olhar feitos entre os quatro cantos dessa janela. Para evitar seleções falsas, cada gesto começa e termina no centro da janela. Em um estudo longitudinal do EyeWrite, 8 participantes atingiram um desempenho médio de $4.87 \mathrm{ppm}$. Uma outra interface baseada em gestos discretos do olhar é o EyeS, de Porta e Turina (2008), que a diferença do EyeWrite utiliza nove pontos para fazer os gestos.

Os métodos baseados em gestos discretos do olhar reduzem o toque de Midas, pois a chance de fazer uma sequência de gestos por acidente é baixa. Uma outra vantagem é que esses métodos utilizam uma área pequena do monitor para a interação (no caso do EyeWrite, uma janela de $400 \times 400$ pixels). Como desvantagem, o usuário tem que memorizar um grande número de padrões de movimentos (pelo menos 26 caracteres do alfabeto inglês). Além disso, devido aos padrões estarem formados por vários gestos (média de 4.52 sacadas no EyeWrite), o desempenho é menor que nos teclados virtuais (Porta, 2015).

Recentemente, Møllenbach et al. (2013) estudaram o uso de gestos curtos do olhar (formados apenas por uma sacada) para interação, concluindo que eles são mais apropriados para executar 
comandos como mudar de tarefa, de leiaute do teclado (numérico, por exemplo) e para navegação entre vistas da interface.

\subsubsection{Gestos contínuos do olhar}

Várias interfaces utilizam gestos contínuos do olhar para interação com o computador. Dentre elas, o Dasher, desenvolvido por Ward e MacKay (2002), é considerada a interface mais rápida para entrada de texto pelo olhar. Inicialmente, o Dasher mostra todos os caracteres do alfabeto ordenados em uma coluna à direita. Para fazer uma seleção, o usuário olha para a letra desejada enquanto ela começa a se deslocar para a esquerda. Conforme o usuário acompanha o caractere enquanto ele anda, a interface amplia a área observada, como mostrado na figura 2.4a. Usando um modelo de linguagem, os caracteres mais prováveis de serem digitados depois do caractere observado se deslocam com maior velocidade que os menos prováveis, permitindo selecioná-los de forma mais rápida. A seleção é completada quando o caractere acompanhado cruza a linha horizontal no centro da interface. Para corrigir erros é necessário olhar para esquerda, o que faz a coluna retornar para a direita.

No artigo de Ward e MacKay (2002), que apresentou o Dasher pela primeira vez, depois de uma hora de uso dois usuários experts (os autores) atingiram 22 e 25 ppm, respectivamente, enquanto que dois usuários inexperientes atingiram 12 e 14 ppm, respectivamente. No entanto, o estudo foi muito curto e contou com poucos participantes. No estudo de Tuisku et al. (2008), 12 participantes atingiram uma média de $17 \mathrm{ppm}$ após 10 sessões de 15 minutos cada um, escrevendo frases em finlandês. Como apontado pelos autores, o texto usado para treinar o Dasher pode ter influenciado no resultado, pois palavras pouco comuns recebiam alta probabilidade.

Em um estudo mais recente, Rough et al. (2014) avaliaram o Dasher utilizando modelos estatísticos de linguagem mais avançados e o compararam com um teclado virtual baseado em tempo de latência, utilizado como condição de controle. Em um primeiro experimento, 9 participantes conseguiram um desempenho de $12.4 \mathrm{ppm}$ com o Dasher e $6.0 \mathrm{ppm}$ com o teclado virtual (com um tempo de latência de 1000 ms) após 9 sessões de 10 minutos com cada método. Em um segundo experimento, os participantes podiam ajustar o tempo de latência para selecionar os caracteres, além de ajustar também a velocidade do Dasher. Após 9 sessões de 15 minutos com cada método, 12 participantes conseguiram uma média de 14.2 ppm com o Dasher e 7.0 ppm com o teclado virtual.

Um problema do Dasher, no entanto, é que se o próximo caractere tiver baixa probabilidade, o usuário precisa "manobrar" para evitar selecionar os caracteres mais prováveis no caminho até o caractere desejado.

Uma outra interface para entrada de texto utilizando gestos contínuos do olhar é StarGazer, desenvolvida por Hansen et al. (2008), mostrada na figura 2.4b. A interface faz a interação parecida com a navegação 3D em um mundo de objetos. A direção do olhar é utilizada para deslocar o objeto desejado até o centro da tela, enquanto a interface amplia a área ao redor do ponto observado. O objeto é selecionado quando ele chega ao centro da interface. A principal característica do StarGazer é a tolerância ao ruído do rastreador de olhar. No entanto, os experimentos realizados mostraram um desempenho de 5 ppm, inferior ao obtido com o tempo de latência.

Tanto o Dasher quanto o StarGazer têm como desvantagem que o usuário está sempre controlando a interface, ou seja, olhar para algum lugar da interface gera uma resposta do sistema, mesmo que a intenção fosse não fazer nada. Isso pode provocar estresse e cansaço visual pois o olhar não 


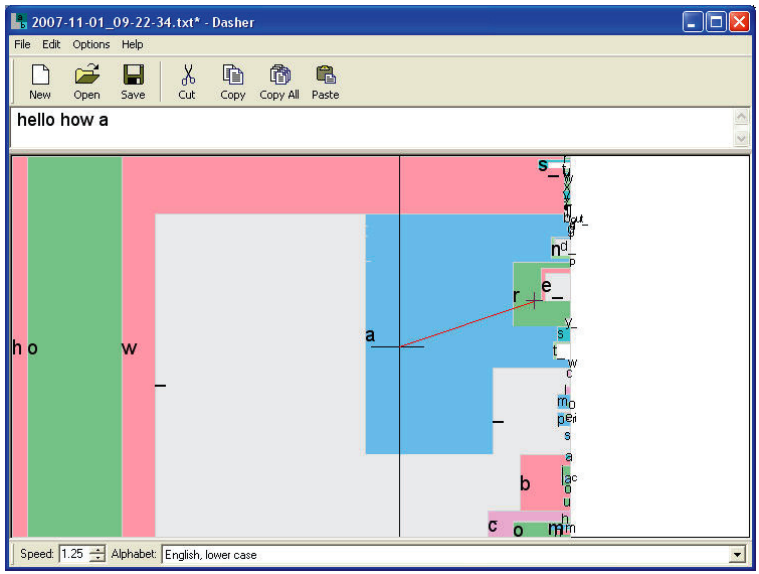

a) Escrevendo a palavra are no Dasher, imagem reproduzida de Tuisku et al. (2008).

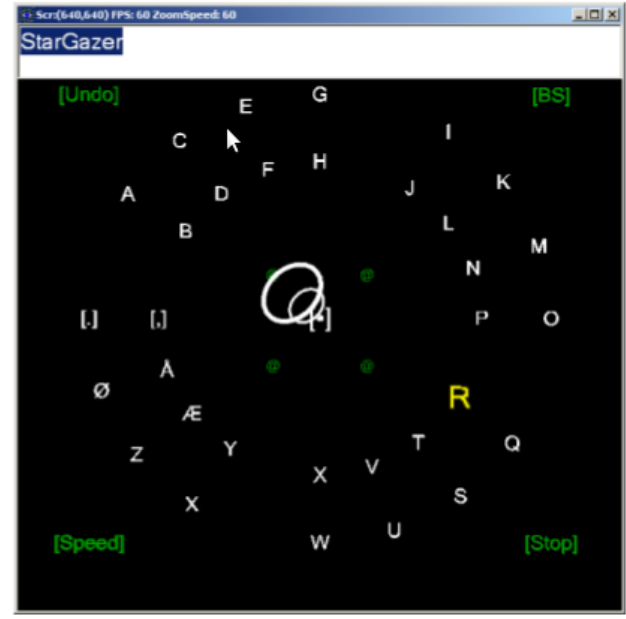

b) Interface StarGazer, imagem reproduzida de Hansen et al. (2008).

Figura 2.4: Interfaces Dasher e StarGazer

pode descansar.

Uma técnica mais recente utiliza movimentos de perseguições lentas para selecionar os objetos. Na interface chamada Pursuits, de Vidal et al. (2013), os objetos estão em constante movimento, seguindo trajetórias diferentes. Para selecionar um objeto, o usuário precisa acompanhá-lo com o olhar por um certo intervalo de tempo, como mostrado na figura 2.5a. A grande vantagem dessa técnica é que o rastreador de olhar não precisa estar calibrado, pois a seleção é feita pela correlação entre a trajetória do estímulo e os movimentos oculares. Dentre as desvantagens, o número de objetos que podem ser mostrados na interface é limitado a no máximo oito para garantir que a seleção seja eficiente, além de sofrer do toque de Midas se o usuário acompanhar um objeto por um certo tempo sem o intuito de selecioná-lo.

Recentemente, Lutz et al. (2015) desenvolveram a interface SMOOVS para digitação pelo olhar baseada em movimentos de perseguições lentas, mostrada na figura 2.5b. A interface consiste de 5 clusters de caracteres colocados em forma de hexágono, sendo que cada um contém 6 caracteres. A seleção é feita em vários passos: quando o usuário olha desde o centro da interface para algum dos clusters, eles começam a se afastar entre si, e o usuário acompanha o cluster com o caractere desejado. Depois que o sistema detecta o acompanhamento do cluster, todos os clusters ficam parados e os caracteres do cluster selecionado começam a se afastar entre si. O usuário completa a seleção acompanhando o caractere desejado com o olhar. Como vantagem, apenas um ponto de calibração é necessário para usar a interface. No entanto, devido ao processo de seleção em dois níveis, o desempenho dessa técnica é baixo, em torno de $3.34 \mathrm{ppm}$.

\subsubsection{Técnicas baseadas no padrão de movimento do olhar no teclado}

Kristensson e Vertanen (2012) estudaram o potencial de digitação pelo olhar sem tempos de latência, usando apenas o padrão de movimento do olhar em um teclado virtual, ou seja, o caminho seguido pelo olhar para escrever cada palavra. Embora Kristensson e Vertanen não tenham chegado a implementar tal sistema, resultados de simulações mostraram o potencial de digitar até $46 \mathrm{ppm}$.

Nessa mesma linha, Pedrosa et al. (2015) propuseram a interface Filteryedping, mostrada na 


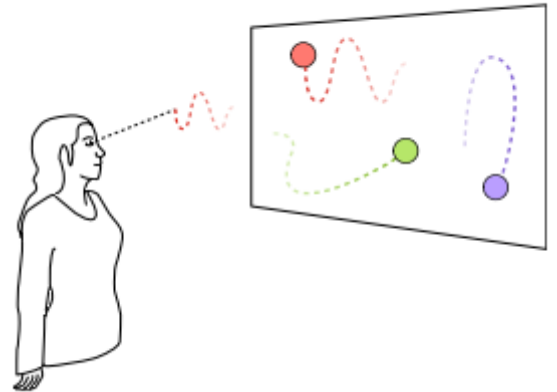

a) Interface Pursuits, imagem reproduzida de Vidal et al. (2013).

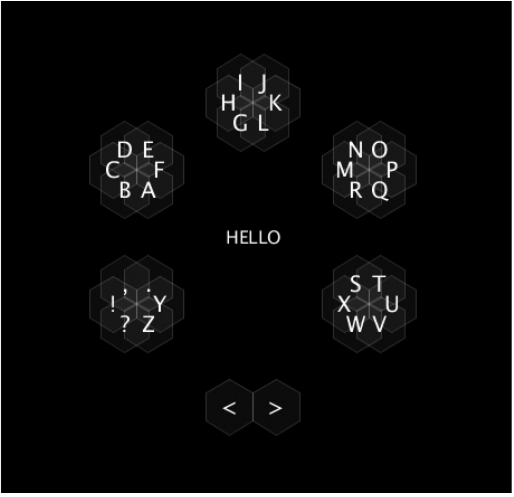

b) Interface $S M O O V S$, imagem reproduzida de Lutz et al. (2015).

Figura 2.5: Interfaces Pursuits e SMOOVS.

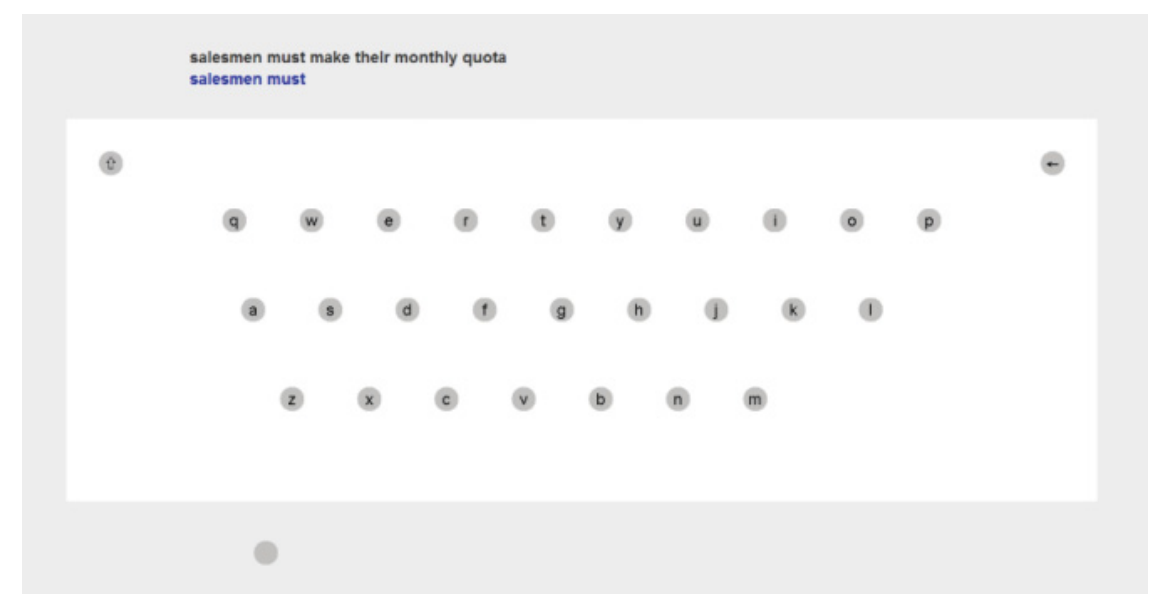

Figura 2.6: Interface Filteryedping, imagem reproduzida de Pedrosa et al. (2015).

figura 2.6. A ideia é que o usuário olha para as teclas que deseja digitar, mas sem fixar nelas. Com essa informação, a interface filtra as letras selecionadas de forma involuntária da sequência de letras que o usuário olhou no teclado e calcula então as palavras mais prováveis a partir dessas sequências. As palavras são mostradas em uma área separada e o usuário pode selecionar a palavra desejada olhando para a palavra e depois para a área de texto.

Pedrosa et al. fizeram um estudo com 6 participantes (todos fisicamente capazes) para comparar o Filteryedping com um teclado virtual baseado no tempo de latência ajustável. Os resultados mostraram um desempenho de aproximadamente $16 \mathrm{ppm}$ com o Filteryedping e 12 ppm com o tempo de latência ajustável, após 6 sessões de 20 minutos com cada método.

Essa técnica tem a vantagem de não utilizar tempos de latência, reduzindo o toque de Midas. No entanto, se a palavra desejada não se encontrar na lista, o usuário tem que navegar pela lista, ou olhar novamente para as teclas que formam a palavra desejada no teclado, o que poderia introduzir demoras na interação. Se a palavra não se encontrar no dicionário (por exemplo, um nome próprio), o usuário pode digitar caractere por caractere, usando um tempo de latência em cada tecla. 


\subsubsection{Técnicas baseadas em piscadas}

Em estados avançados de algumas doenças a pessoa perde os movimentos oculares, sendo impossível utilizar as técnicas baseadas em apontamento pelo olhar, como as descritas nesse capítulo. Uma alternativa para essas pessoas é a utilização de piscadas.

As técnicas de interação utilizando piscadas estão baseadas em interfaces de varredura (scanning interfaces). Devido a que o usuário apenas pode piscar os olhos, o sistema vai varrendo os objetos selecionáveis na tela, dando o foco a cada um deles por um certo tempo. Quando o objeto desejado ganhar o foco, o usuário pisca o(s) olho(s) para completar a seleção. Um exemplo de interface baseada em piscadas é BlinkWrite, de Scott MacKenzie e Ashtiani (2011), mostrada na figura 2.7, na qual o foco se encontra na palavra beginning.

O desempenho nessa forma de interação é lento, pois o foco tem que ficar um tempo razoável (entre 700-1000 ms) em cada objeto para permitir que o usuário possa piscar para selecioná-lo. Um estudo de entrada de texto com BlinkWrite mostrou um desempenho abaixo de 5 palavras por minuto. Os desafios nessa técnica de interação são diferentes das demais técnicas mostradas nesse capítulo, portanto, o uso de piscadas para interação pelo olhar não será abordado na presente tese de doutorado.

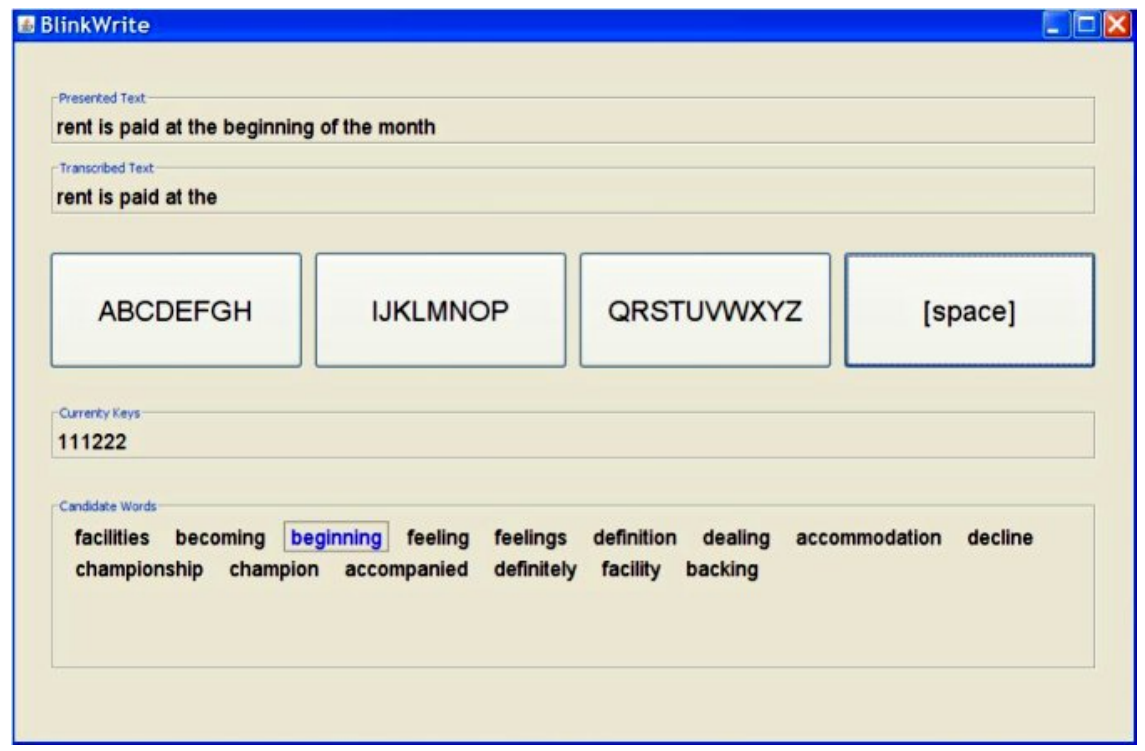

Figura 2.7: Interface BlinkWrite, imagem reproduzida de Scott MacKenzie e Ashtiani (2011). 


\section{Capítulo 3}

\section{Investigação sobre o tempo de reação sacádico e sua exploração na entrada de texto pelo olhar}

Durante a revisão bibliográfica das técnicas de interação pelo olhar foi constatado que, embora o comportamento e as características dos movimentos oculares e do sistema visual humano tenham sido amplamente estudados na área de psicofísica, a comunidade de interação humano-computador pouco explorou esses conhecimentos no design de interfaces controladas pelo olhar.

Um exemplo de estudo do comportamento do olhar é a Lei de Fitts (Fitts, 1954). Tal lei descreve o comportamento psicomotor humano em tarefas que requerem realizar movimentos motoros com velocidade e precisão. Segundo esse modelo, o tempo necessário para se deslocar até um alvo de tamanho $W$ colocado a uma distância $A$ é dado pela expressão: $M T=a+b \cdot \log _{2}\left(2 \frac{A}{W}+c\right)$, onde $M T$ é o tempo de movimento, $a$ e $b$ são constantes calculadas empiricamente e $c$ é uma constante cujo valor pode ser 0, 0.5 ou 1. Zhang et al. (2010) adaptaram o modelo de Fitts para tarefas de seleção usando tempo de latência, propondo um modelo que leva em consideração fixações e sacadas.

Nós acreditamos que o estudo, compreensão e modelagem de aspectos psicofísicos do olhar permitirá o design de interfaces controladas pelo olhar que possam melhorar o desempenho e a experiência dos usuários, facilitando seu uso no dia a dia. Nas seções seguintes descrevemos os estudos realizados sobre um fenômeno psicofísico do olhar conhecido como efeito gap e sua aplicação em interfaces controladas pelo olhar.

\subsection{Efeito gap: redução no tempo de reação sacádico}

Considere a tarefa de fixar o olhar em um estímulo visual e, assim que um estímulo excêntrico aparecer, olhar para ele o mais rápido possível. A latência para iniciar a sacada desde o ponto de fixação até o estímulo excêntrico, conhecida como "tempo de reação sacádico" (SRT, do inglês saccadic reaction time), tem sido o foco de vários estudos psicofísicos (Craig et al., 1999; Fischer e Breitmeyer, 1987; Jin e Reeves, 2009; Kingstone e Klein, 1993; Pratt et al., 2006, 2000; Reulen, 1984; Reuter-Lorenz et al., 1991; Saslow, 1967; Ueda et al., 2013). Tais estudos manipulam os estímulos visuais e descrevem como o $S R T$ varia de acordo com a manipulação. Os resultados tipicamente são comparados com o $S R T$ obtido na condição de controle, conhecida como "controle" 
(overlap), na qual o ponto de fixação não muda nem antes nem depois de apresentar o estímulo excêntrico.

O efeito gap, fenômeno descrito inicialmente por Saslow (1967), corresponde a uma redução no SRT quando o ponto de fixação é apagado um certo tempo antes de apresentar o estímulo excêntrico, ou seja, quando existe um gap temporal entre os eventos de apagamento e apresentação. Essa redução é máxima para valores de gap de aproximadamente 200 ms. Jin e Reeves (2009) apresentaram uma revisão das teorias que explicam o efeito gap. De acordo com Ueda et al. (2013), as duas teorias predominantes são o efeito do apagamento da fixação e o desengajamento da atenção.

A teoria do efeito do apagamento da fixação está baseada no estudo de Munoz e Wurtz (1992). Eles descobriram, em experimentos feitos com macacos, que durante a fixação em um estímulo visual, alguns neurônios no colículo superior ${ }^{1}$ ficam muito ativos, inibindo a execução de sacadas. Durante uma sacada, esses neurônios pausam a atividade para permitir o movimento sacádico. Vários estudos (Dorris e Munoz, 1995; Kingstone e Klein, 1993; Reuter-Lorenz et al., 1991) têm sugerido que o apagamento do ponto de fixação pausa a atividade dos neurônios de fixação durante o intervalo gap, produzindo uma liberação oculomotora que facilita a sacada e, portanto, reduz o $S R T$.

A teoria do desengajamento da atenção está baseada no modelo de atenção de Posner e Petersen (1990). De acordo com esse modelo, para alternar entre dois estímulos visuais, a atenção primeiro tem que ser desengajada de seu foco atual, depois mudar para a nova localização, e finalmente deve ser reengajada no estímulo visual final. Fischer e Breitmeyer (1987) propuseram que o apagamento do ponto de fixação inicia um processo de desengajamento da atenção que reduz o SRT. Essa teoria tem sido suportada por estudos posteriores (Mackeben e Nakayama, 1993; Pratt et al., 2006).

Estudos recentes (Jin e Reeves, 2009; Pratt et al., 2006; Ueda et al., 2013) sugerem que o efeito gap é resultado tanto de uma liberação oculomotora quanto do desengajamento da atenção. Portanto, a redução no $S R T$ parece ser resultado de uma combinação das duas teorias explicadas acima, o que implica que a atenção poderia modular a atividade dos neurônios de fixação no colículo superior.

Vários fatores influenciam no tempo de reação sacádico, como o valor do gap (Saslow, 1967), o tipo de sacada (reflexiva ou voluntária) (Reuter-Lorenz et al., 1995, 1991), o brilho do estímulo excêntrico (Bell et al., 2006; Reuter-Lorenz et al., 1991) e a área, forma ou brilho inicial do ponto de fixação (Pratt et al., 2006, 2000; Reulen, 1984).

A figura 3.1a mostra a condição gap em forma de um gráfico de tempo $\times$ brilho, sendo que a linha superior corresponde ao ponto de fixação, enquanto que a linha inferior corresponde ao estímulo excêntrico. Já a figura 3.1b mostra a condição de controle, na qual o estímulo fixado não sofre mudanças.

\footnotetext{
${ }^{1} \mathrm{O}$ colículo superior é uma estrutura localizada no cérebro médio que participa do controle dos movimentos oculares.
} 


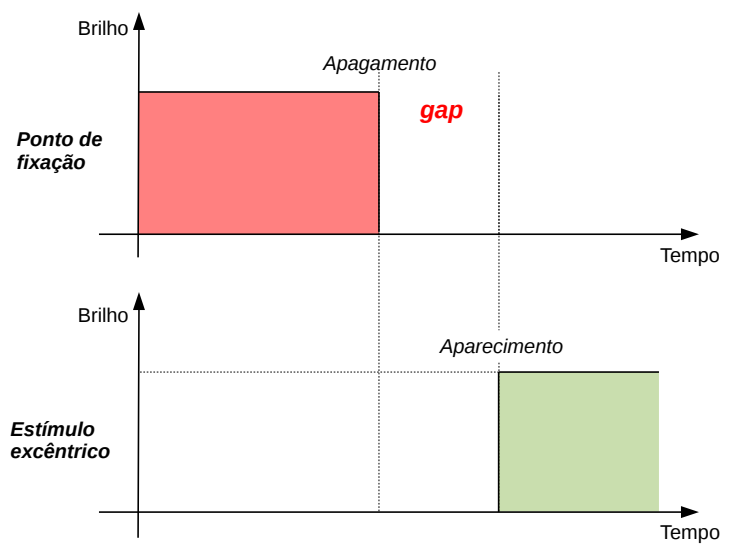

a) Condição de gap.

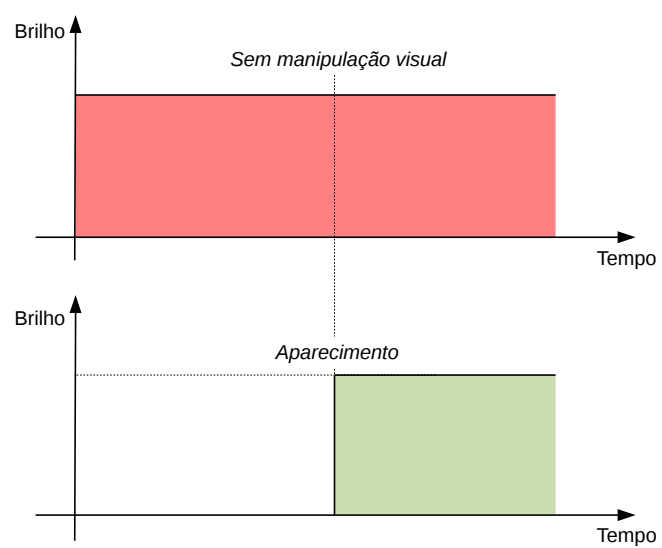

b) Condição de controle.

Figura 3.1: Condições de gap e de controle

\subsection{Proposta do efeito gap gradiente}

Como foi visto no capítulo 2, várias técnicas de interação pelo olhar estão baseadas em fixações e sacadas. Portanto, uma maneira de aplicar o efeito gap na interação pelo olhar seria apagar o objeto fixado pelo usuário, com o objetivo de facilitar o movimento sacádico até o próximo alvo, que no caso de um teclado virtual, seria o próximo caractere.

No entanto, se a tecla fixada for apagada antes de ser selecionada, o usuário não teria feedback visual sobre quanto tempo falta para completar a seleção em andamento e iniciar a sacada até o próximo caractere no teclado. Tal feedback é muito importante para fazer correções caso o foco estivesse na tecla errada, além de permitir manter o ritmo da interação (Majaranta et al., 2006). Assim, torna-se necessário um modelo de feedback que forneça a informação visual necessária para o usuário e, ao mesmo tempo, explore o efeito gap para facilitar a interação.

Nós introduzimos o efeito gap gradiente como uma variante do efeito gap. A diferença principal é que no gradiente a manipulação do brilho no ponto de fixação é feita de forma gradual. A figura 3.2 mostra um exemplo de gradiente descendente, pois o brilho é gradualmente reduzido durante o intervalo gap. O gradiente também pode ser ascendente e, nesse caso, o brilho seria incrementado ao invés de reduzido. Isto implica que, a diferença da manipulação visual originalmente proposta por Saslow, no efeito gap gradiente o estímulo fixado não necessariamente é apagado.

O efeito gap gradiente depende, além do valor do intervalo gap, do brilho inicial $(I B)$ e final $(F B)$ do ponto de fixação. Se $I B>F B$ então o brilho vai ser gradualmente reduzido durante o intervalo de gap. Já se $F B>I B$, então o brilho vai ser gradualmente aumentado durante o intervalo de gap.

\subsection{Modelo de feedback baseado no efeito gap gradiente para inte- ração pelo olhar}

Como a manipulação do brilho no ponto de fixação é gradual, o efeito gap gradiente pode ser usado em um modelo de feedback visual para interfaces controladas pelo olhar. A figura 3.3a mostra o modelo de feedback com gradiente descendente, enquanto que a figura 3.3b mostra o modelo com 


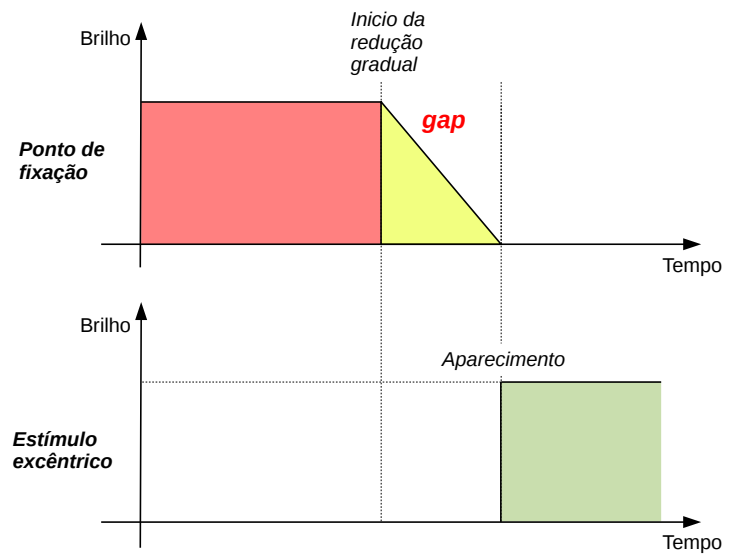

Figura 3.2: Efeito gap gradiente descendente, no qual o brilho do estímulo é reduzido de forma gradual.

gradiente ascendente.

O processo de seleção é dividido em vários intervalos ou fatias de tempo. Inicialmente o ponto de fixação tem um brilho padrão. O processo começa quando o usuário olha para o ponto de fixação, iniciando o intervalo pre. Tal intervalo garante que o usuário está fixando no estímulo. Logo após o período pre, para indicar que o estímulo ganhou o foco do usuário, seu brilho é mudado para o valor $I B$, que é mantido durante o intervalo de focus. Após acabar o intervalo de focus, começa o intervalo de warning, durante o qual o brilho do ponto de fixação é aumentado ou reduzido de forma gradual. Durante o warning o usuário tem feedback sobre o progresso da seleção, permitindo que ele olhe para fora do ponto de fixação, caso queira interromper o processo. Quando o intervalo warning acabar, o ponto de fixação terá seu brilho com valor $F B$ e a seleção é completada, dando início ao intervalo post. Durante esse intervalo, o ponto de fixação mantém seu brilho com valor $F B$, enquanto o usuário está olhando para a próxima tecla. Após o intervalo post, o ponto de fixação recupera seu brilho padrão.

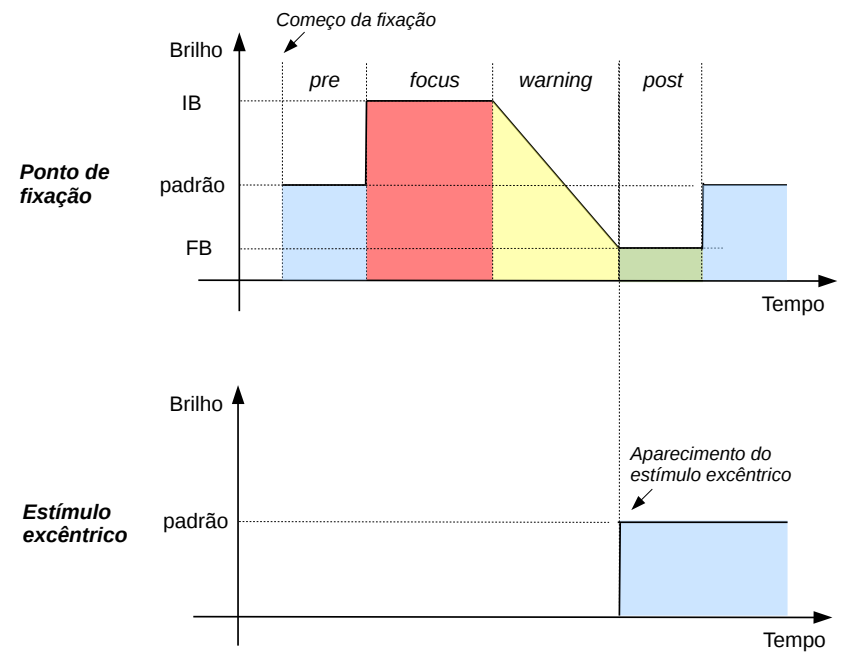

a) Gradiente descendente

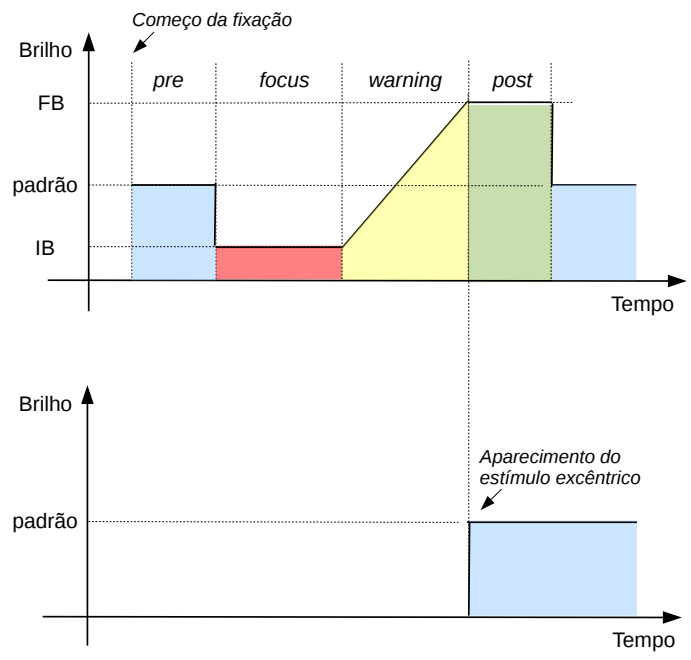

b) Gradiente ascendente

Figura 3.3: Modelos de feedback baseados no efeito gap gradiente 


\subsection{Investigação do efeito gap gradiente}

Com o objetivo de estudar o efeito gap gradiente e compará-lo com o efeito gap, além de avaliar o modelo de feedback proposto em uma interface controlada pelo olhar real, realizamos três estudos com voluntários. Os experimentos foram realizados usando um rastreador de olhar comercial da marca SMI RED500, adquirido em 2012 por nosso laboratório com auxílio da FAPESP. O RED500 possui uma frequência de amostragem de $500 \mathrm{~Hz}$ e uma precisão de aproximadamente 0.5 graus de ângulo visual. A seguir descrevemos cada um dos experimentos realizados e os resultados obtidos.

\subsubsection{Comparação entre o efeito gap e o gradiente}

O objetivo do primeiro experimento foi comparar o efeito gap com o efeito gap gradiente descendente, mostrado na figura 3.3a.

\section{Design experimental e método}

O valor do intervalo pre foi $200 \mathrm{~ms}$, enquanto que os valores para warning foram 0, 200 e 400 ms. Já o valor de post utilizado foi de $400 \mathrm{~ms}$, para minimizar o efeito de distração produzido pelo ponto de fixação após esse intervalo. O valor de focus foi definido de forma tal que focus + warning $=600 \mathrm{~ms}$ em todas as condições. Portanto, o tempo total de latência, desde o contato visual até selecionar o estímulo, foi constante e igual a $800 \mathrm{~ms}$.

O valor do brilho nos estímulos visuais foi definido em porcentagens do valor RGB máximo $(255,255,255)$. Os controles de contraste e brilho do monitor foram configurados nos seus valores máximos. Para comparar o efeito gap com o efeito gap gradiente descendente, os valores de $I B$ e FB foram $100 \%$ e 15\% respectivamente. Assim, o estímulo fixado não foi completamente apagado, mas teve seu brilho reduzido para um nível baixo, no caso, 15\%. O brilho padrão dos estímulos foi definido como sendo $50 \%$.

Cada teste começou mostrando o ponto de fixação no centro do monitor, para o qual o usuário foi instruído a olhar. Após uma breve fixação, correspondente ao intervalo de pre, o ponto de fixação mudou seu brilho do valor padrão para $I B$, que foi mantido durante o intervalo de focus. Na condição de gap, o estímulo fixado teve o brilho reduzido de $I B$ para $F B$ logo após o intervalo de focus, e manteve o brilho em $F B$ durante os intervalos de warning e post. Já na condição de gradiente, o brilho no ponto de fixação foi reduzido de $I B$ para $F B$ de forma gradual durante o intervalo de warning, e manteve o brilho em $F B$ durante o intervalo de post. Na condição de controle o ponto de fixação manteve o brilho padrão durante o teste inteiro.

Em todas as condições, o estímulo excêntrico foi mostrado no mesmo instante em que acabou o intervalo de warning, em uma posição aleatória em relação ao ponto de fixação (à direita, esquerda, acima ou abaixo). O usuário foi instruído a olhar para o estímulo excêntrico o mais rápido possível e continuar fixando-o até ele desaparecer. Logo depois, o ponto de fixação foi mostrado novamente no centro do monitor para começar um novo teste.

A configuração experimental é mostrada na figura 3.4. Os estímulos visuais consistiram em discos de 1 grau de diâmetro mostrados sobre o fundo preto com $R G B=(0,0,0)$. Os discos tinham um ponto no centro para ajudar o usuário a manter o olhar no centro dos estímulos. A distância entre os olhos dos participantes e o monitor foi de aproximadamente $60 \mathrm{~cm}$. Um apoio de queixo foi utilizado para reduzir os movimentos de cabeça dos participantes, com o objetivo de minimizar o 
ruído e a perda da calibração durante o rastreamento do olhar. A distância entre o ponto de fixação e o estímulo excêntrico foi de 10 graus.

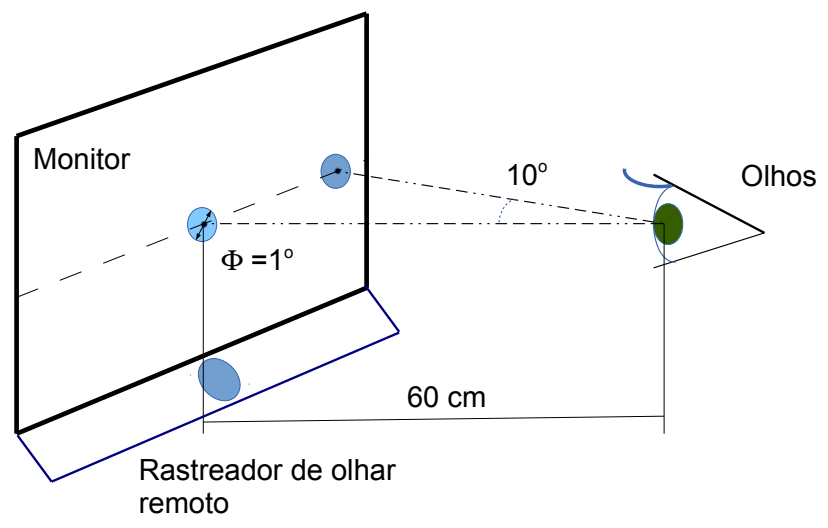

Figura 3.4: Configuração utilizada durante o experimento.

No começo do experimento cada participante assinou o Termo de Consentimento Livre e Esclarecido, recebeu instruções e fez uma pequena sessão de treinamento. As condições do estudo foram obtidas de um design fatorial, combinando as variáveis independentes que foram o valor de warning $(0,200$ e $400 \mathrm{~ms}$ ) e o tipo de teste (controle, gap ou gradiente). O estudo foi projetado como intra-sujeito (within subjects), sendo que cada participante executou todas as condições em ordem aleatória.

O software para mostrar os estímulos visuais e gravar os dados dos movimentos oculares foi implementado na linguagem Python com a biblioteca PsychoPy (Peirce, 2009). Durante o experimento, o software foi capaz de detectar alguns problemas e tentar corrigi-los, como perda da calibração, piscadas ou fixações incompletas.

A análise dos dados foi feita off-line. O SRT foi calculado como sendo o intervalo desde que o estímulo excêntrico foi apresentado até que o usuário iniciou a sacada em direção a esse estímulo. Para detectar sacadas utilizamos o algoritmo baseado na velocidade do olhar, de Salvucci e Goldberg (2000). Testes nos quais os participantes piscaram depois da apresentação do estímulo excêntrico ou fizeram a sacada em uma direção diferente ao estímulo excêntrico, foram desconsiderados da análise.

\section{Resultados e discussão}

Os resultados experimentais de 8 participantes são apresentados na figura 3.5. A condição de controle mostrou o maior $S R T$ dentre todas as condições, enquanto que o efeito gap para warning $=200 \mathrm{~ms}$ apresentou o menor SRT. Um teste pareado de Student emparelhando os participantes com o $S R T$ mostrou que o efeito gap com warning $=200 \mathrm{~ms}$ foi significativamente menor que o controle, $\mathrm{t}(7)=2.76, \mathrm{p}=0.028$, coeficiente $\mathrm{d}$ de Cohen $=0.97$. Rodamos também um teste pareado de Student para comparar o efeito gap gradiente para warning=200 com o controle e encontramos uma diferença significativa, $\mathrm{t}(7)=3.12, \mathrm{p}=0.017$, coeficiente $\mathrm{d}$ de Cohen $=1.1$.

Como pode ser observado na figura 3.5, a diferença entre o efeito gap e o gradiente foi muito pequena. Um teste ANOVA de medições repetidas comparando método (gap, gradiente) $\times$ warning (200, 400 ms) não mostrou efeito principal significativo nem para método, $\mathrm{F}(1,7)=0.06, \mathrm{p}=0.81$, 
$\eta_{p}^{2}=0.0089$, nem para warning, $\mathrm{F}(1,7)=0.04, \mathrm{p}=0.86, \eta_{p}^{2}=0.005$. Também não encontramos interação entre os dois fatores, $\mathrm{F}(1,7)=0.89, \mathrm{p}=0.38, \eta_{p}{ }^{2}=0.11$.

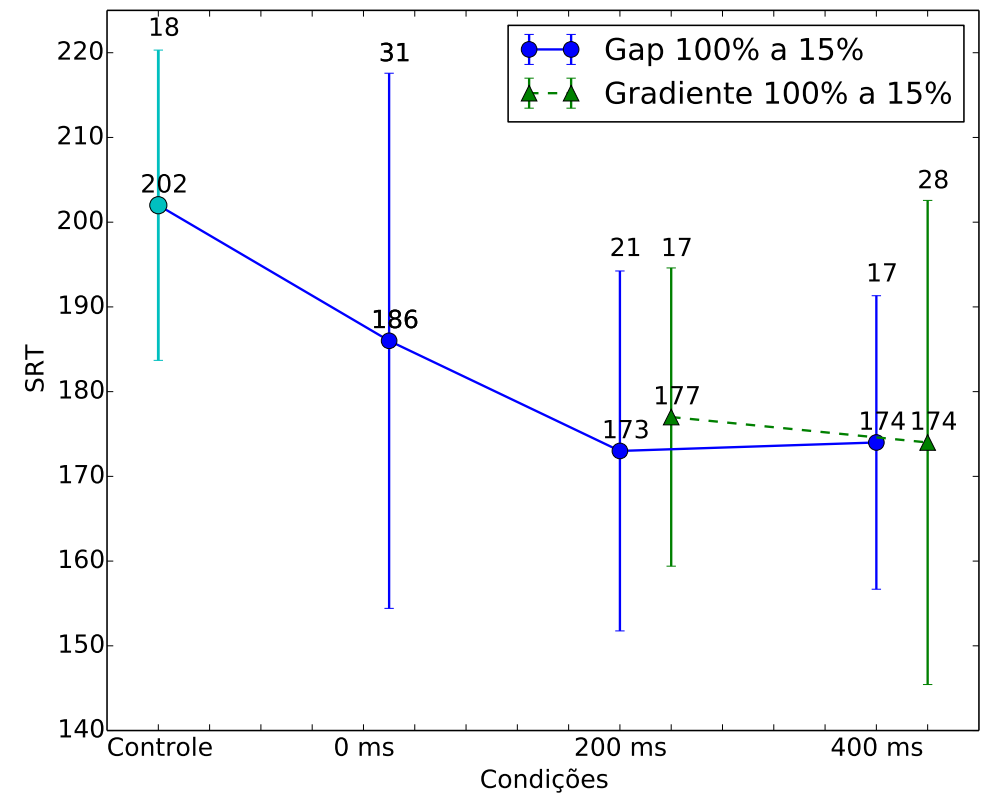

Figura 3.5: Média e 1 desvio padrão do SRT para 8 participantes, para o efeito gap e o efeito gap gradiente. Para gap $=0$ existe apenas uma condição.

De forma similar a vários estudos na literatura (Pratt et al., 2006; Reuter-Lorenz et al., 1991; Saslow, 1967), nós observamos uma redução no SRT para valores de warning de 200 e 400 ms comparado com a condição de controle. Para warning $=0$ o $S R T$ foi menor que no controle, porém maior que para o gap de $200 \mathrm{~ms}$. Esse resultado também se corresponde com o gap zero no estudo de Pratt et al. (2006). Em nosso experimento o estímulo fixado não foi apagado completamente (pois FB foi igual a 15\%), como no estudo original de Saslow (1967). Uma pergunta que surgiu nesse experimento é como o brilho final do ponto de fixação influencia na magnitude do efeito gap.

Dos resultados podemos concluir que o efeito gap gradiente produz uma redução no $S R T$ similar ao efeito gap quando o brilho do estímulo fixado é reduzido, para valores de warning (gap) de 200 e $400 \mathrm{~ms}$. Isto implica que o modelo de feedback usando o efeito gap gradiente poderia ser utilizado em interfaces que utilizam tempos de latência entre 200-400 ms para facilitar o movimento sacádico até o próximo alvo. Esse tempo de latência é um parâmetro importante nas interfaces controladas pelo olhar, pois define a duração da fixação para realizar uma seleção. Para determinadas tarefas esse tempo poderia ser maior ou menor, mas ele depende também das características dos usuários. Por exemplo, usuários experts poderiam usar um tempo de latência curto para ganhar em desempenho, enquanto que usuários inexperientes precisam de um tempo de latência maior para não cometer muitos erros.

\subsubsection{Comparação entre o gradiente descendente e ascendente}

Em um segundo experimento, calculamos o tempo de reação sacádico no gradiente descendente para vários níveis de brilho final do ponto de fixação, além de estabelecer uma comparação com o gradiente ascendente. As condições experimentais foram similares ao experimento 1, contando 
com 8 voluntários, alguns dos quais participaram no primeiro estudo. Para o gradiente descendente, o valor de $I B$ foi $100 \%$ e os valores de $F B$ foram $0 \%$ (estímulo apagado), $15 \%$ e 30\%. Já para o gradiente ascendente, tivemos apenas uma condição com $I B=15 \%$ e $F B=100 \%$. O brilho padrão dos estímulos foi $50 \%$. A ordem de apresentação das condições foi aleatória para cada participante.

\section{Resultados e discussão}

A figura 3.6a mostra os resultados da comparação entre os vários níveis de brilho final no gradiente descendente. Como pode ser observado, o SRT para o brilho final $30 \%$ foi superior aos demais níveis de brilho final, para valores de warning de 0 e 200 ms. Já para o warning de 400 ms a diferença no $S R T$ entre os três níveis de brilho foi muito pequena. Um teste ANOVA de medições repetidas comparando warning $(0,200,400 \mathrm{~ms}) \times$ brilho final $(0,15,30 \%)$ mostrou um efeito principal para warning, $\mathrm{F}(2,14)=10.6, \mathrm{p}=0.0016$, mas não para o brilho final (embora muito perto do limiar de significância), $\mathrm{F}(2,14)=3.45, \mathrm{p}=0.06$. Não houve interação entre os dois fatores, $\mathrm{F}(4,28)=0.63, \mathrm{p}=0.65$. Uma análise post-hoc com correção de Bonferroni mostrou uma diferença significativa entre os valores de warning de 0 e $200 \mathrm{~ms}, \mathrm{p}=0.014$, e também entre os valores de 0 e $400 \mathrm{~ms}, \mathrm{p}=0.02$.

A figura 3.6b mostra a comparação entre os gradientes descendente e ascendente. Podemos ver que o $S R T$ no gradiente descendente foi menor que no ascendente para todos os valores de warning. Um teste ANOVA de medições repetidas comparando warning $(0,200,400 \mathrm{~ms}) \times$ gradiente (ascendente, descendente) mostrou um efeito principal tanto para warning, $\mathrm{F}(1.19,8.31)=8.24$, $\mathrm{p}=0.017$, quanto para gradiente, $\mathrm{F}(1,7)=8.1, \mathrm{p}=0.025$. Não houve interação significativa entre os dois fatores, $\mathrm{F}(2,14)=0.41, \mathrm{p}=0.67$. A análise post-hoc com correção de Bonferroni mostrou que o warning de $0 \mathrm{~ms}$ foi significativamente maior que $200 \mathrm{~ms}, \mathrm{p}=0.039$, e também significativamente maior que $400 \mathrm{~ms}, \mathrm{p}=0.021$. Não houve diferença significativa entre os valores de warning de 200 e $400 \mathrm{~ms}$.

Dos resultados desse experimento podemos concluir que a redução no SRT observada no efeito gap gradiente descendente existe para diferentes níveis de brilho final do ponto de fixação. Isto implica que no modelo de feedback para interfaces controladas pelo olhar, o brilho do estímulo fixado deve ser reduzido para facilitar o movimento sacádico até o próximo alvo (tecla), mas o estímulo ainda pode ficar visível no monitor. Um outro resultado interessante é que o gradiente ascendente produz um tempo de reação maior que o descendente. Isto tem implicações importantes no design do feedback visual nas interfaces, pois ao invés de realçar o objeto selecionado, ele deve ter seu brilho reduzido para facilitar a próxima sacada.

Os resultados dos dois primeiros experimentos foram apresentados na $17^{a}$ Conferência Europeia sobre Movimentos do Olhar (ECEM 2013) em forma de pôster, intitulado Gap effect by gradual brightness reduction (Tula et al., 2013b).

\subsection{Experimento usando um teclado virtual controlado pelo olhar}

Com o objetivo de avaliar o modelo de feedback que explora o efeito gap gradiente em uma interface real de interação pelo olhar, fizemos um experimento para comparar o desempenho e conforto do modelo proposto com um modelo de feedback tradicional encontrado na literatura. Nesse estudo usamos um teclado virtual baseado no tempo de latência, mostrado na figura 3.7. 


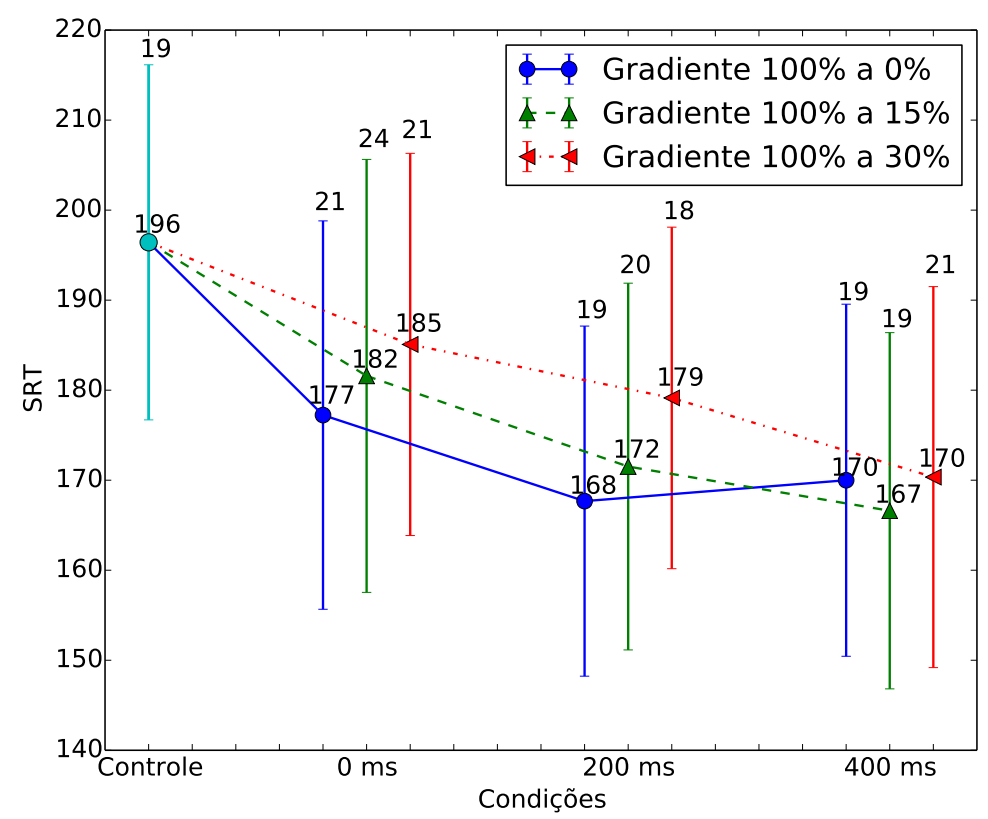

a) Comparação entre vários níveis de brilho final no gradiente descendente.

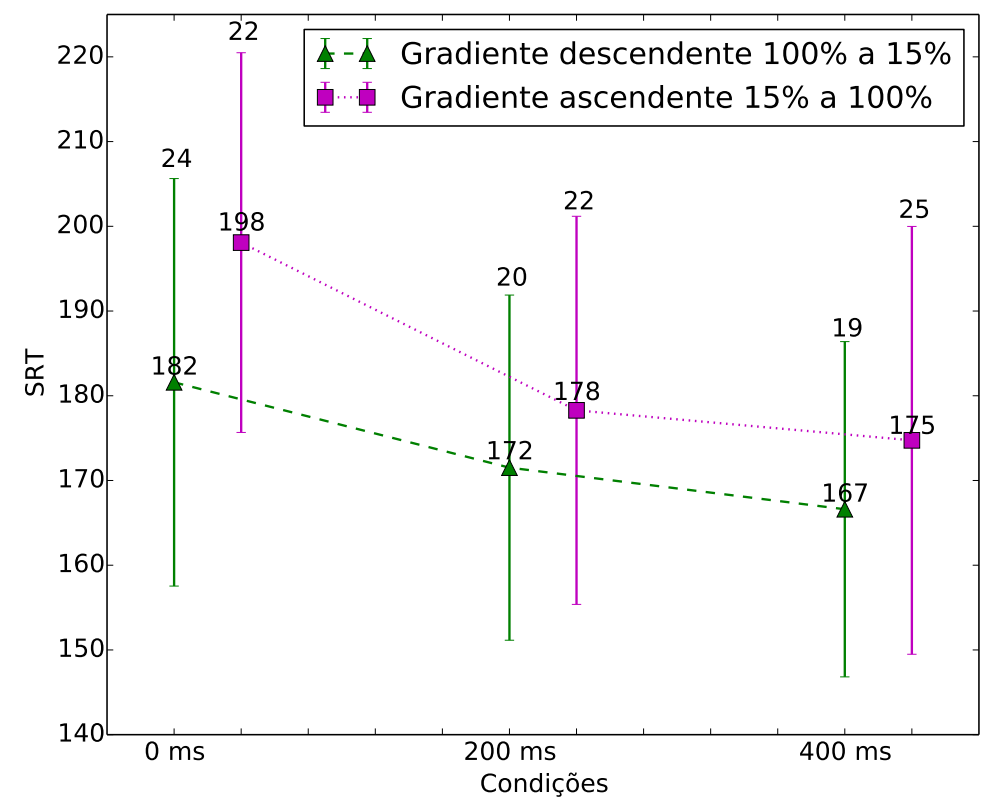

b) Comparação entre os gradientes descendente e ascendente.

Figura 3.6: Média e 1 desvio padrão do SRT para 8 participantes, para o efeito gap gradiente descendente $e$ ascendente.

Um total de 6 voluntários participaram do estudo, todos fisicamente capazes, com visão normal ou corrigida para normal usando lentes de contato ou óculos, com idades entre 22-45 anos (média de 28 anos). Cinco deles não tinham experiência em digitação pelo olhar. Todos os participantes estavam familiarizados o leiaute QWERTY e tinham pelo menos 10 anos de experiência utilizando computadores.

O experimento esteve formado por 5 sessões com duração de 5 minutos cada, nas quais os parti- 


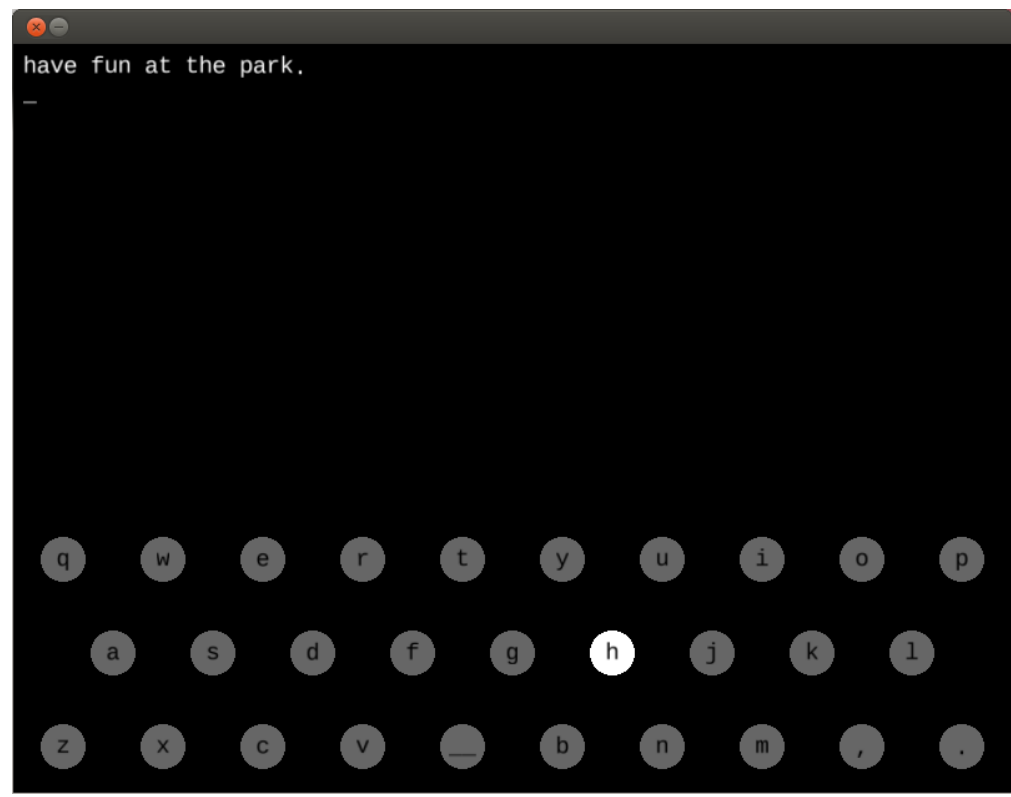

Figura 3.7: Teclado virtual usado no experimento de entrada de texto pelo olhar.

cipantes digitaram frases curtas usando cada método. As frases foram escolhidas de forma aleatória do conjunto de frases sugerido por MacKenzie e Soukoreff (2003), traduzidas para o português. Em cada sessão, os usuários alternaram a ordem em que os métodos foram utilizados, segundo um design de quadrado latino. O método baseado no efeito gap gradiente descendente utilizou o modelo mostrado na figura 3.8a. Já o método tradicional utilizou como feedback um círculo animado que vai desde a borda até o centro da tecla durante o tempo de latência, mostrado na figura 3.8b, similar ao usado no sistema ERICA (Lankford, 2000) e também por Majaranta et al. (2006).

O tempo de latência usado nesse experimento foi de $500 \mathrm{~ms}$, valor usual encontrado na literatura (Majaranta e Räihä, 2007). Como mostrado na figura 3.8a, o tempo de latência de $500 \mathrm{~ms}$ foi dividido em $50 \mathrm{~ms}$ para pré-foco, $200 \mathrm{~ms}$ para foco e $250 \mathrm{~ms}$ de warning. Durante o pré-foco a tecla ficou com o brilho inicial, que foi de $50 \%$ do brilho máximo do monitor. No período de foco, a tecla ficou com $100 \%$ do brilho, indicando que o usuário está fixando nela. Durante o warning o brilho da tecla foi reduzido de forma gradual de $100 \%$ até $15 \%$. No fim do warning, a tecla foi selecionada e um "click" foi tocado na caixa de som para indicar a seleção. A tecla selecionada ficou com $15 \%$ do brilho durante $400 \mathrm{~ms}$, ou até que o usuário olhou para fora da tecla.

No método de animação, mostrado na figura 3.8b, o tempo de latência foi também de $500 \mathrm{~ms}$, mas o brilho da tecla ficou sempre em $50 \%$. No começo do período de warning, um círculo foi desenhado perto da borda da tecla, cujo diâmetro foi reduzido de forma gradual ao longo do warning. No fim do warning a tecla foi selecionada, e um "click" foi tocado na caixa de som para indicar a seleção. Em ambos os métodos, para cancelar uma seleção em andamento o usuário tinha que olhar para fora da tecla antes de acabar o warning.

A diferença para outros estudos na literatura (Majaranta, 2009) é que nesse experimento utilizamos digitação guiada, na qual a próxima tecla a ser digitada é realçada. Assim, os usuários apenas precisam seguir com o olhar a tecla realçada, reduzindo a carga cognitiva de memorizar a frase a ser escrita. Isto fez com que todos os usuários virassem "experts" na entrada de texto, portanto o efeito do feedback visual sobre o comportamento do olhar deveria ser mais evidente.

O desempenho foi medido em palavras por minuto, sendo que uma palavra está formada por 5 


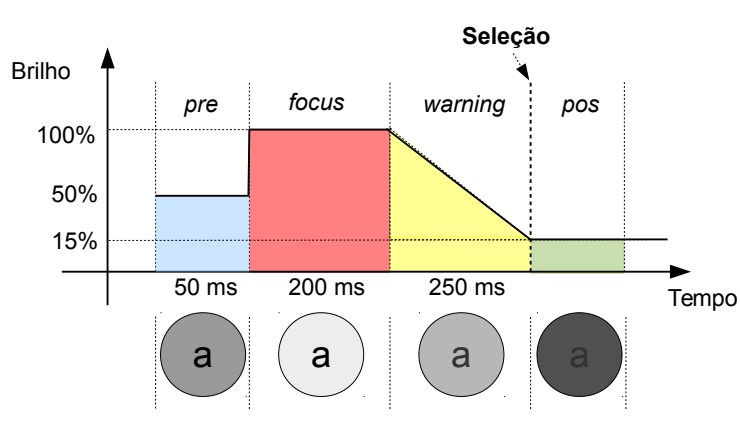

a) Modelo de feedback baseado no efeito gap gradiente.

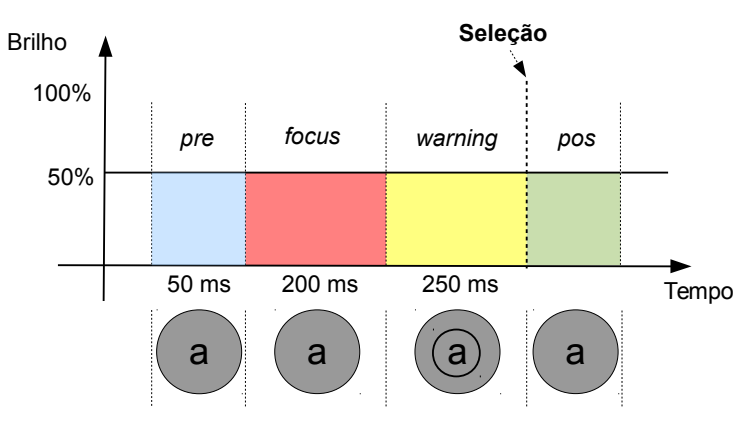

b) Modelo de feedback baseado em um círculo animado da borda até o centro da tecla.

Figura 3.8: Modelos de feedback usados no experimento de digitação pelo olhar.

caracteres sem espaços (Arif e Stuerzlinger, 2009). A taxa de erros foi calculada usando a distância mínima entre cadeias, como sugerido por Soukoreff e MacKenzie (2001). Além disso, no final do experimento cada participante preencheu um questionário para avaliar subjetivamente os métodos de feedback utilizados.

Os resultados do desempenho obtido com cada método pelos 6 participantes são mostrados na figura 3.9a, em forma de gráficos de caixa (box plot). O eixo $x$ corresponde às 5 sessões de digitação com cada método. Para cada sessão, o gráfico mostra o desempenho mínimo e máximo como sendo os extremos da linha tracejada, os quartis inferior e superior como os extremos da caixa sombreada, a mediana como uma linha dentro da caixa e a média como um círculo também dentro da caixa.

Como pode ser observado na figura 3.9a, o modelo de feedback baseado no efeito gap gradiente mostrou um desempenho superior (média de $16.01 \mathrm{ppm}$ ) comparado com o modelo usando animação (média de $15.49 \mathrm{ppm}$ ). Um teste pareado de Student mostrou uma diferença significativa entre ambos métodos, $\mathrm{t}(5)=4.35, \mathrm{p}=0.008$, coeficiente $\mathrm{d}$ de Cohen $=1.94$.

A taxa de erros nos dois métodos foi muito parecida, abaixo de 4\%, como mostrado na figura 3.9b. Os resultados são mostrados também como um gráfico de caixas. Um teste pareado de Student mostrou que não houve diferença significativa, $\mathrm{t}(5)=0.9, \mathrm{p}=0.41$, coeficiente $\mathrm{d}$ de Cohen $=0.4$, o que implica que ambos os métodos mostraram uma taxa de erros similar.

O questionário mostrou que 5 dos 6 participantes acharam o método baseado no efeito gap gradiente mais fácil e confortável de usar. Além disso, três participantes acharam o efeito gap gradiente mais rápido, 1 achou o método usando animação mais rápido, enquanto que os outros dois não perceberam diferença entre os dois métodos. Um dos participantes achou que o método usando efeito gap gradiente requereu de um esforço menor, sendo mais fácil ir até a próxima tecla.

Os resultados desse estudo foram publicados como um resumo expandido na ACM SIGCHI Conference on Human Factors in Computing Systems (CHI 2013), sob o título Facilitating Gaze Interaction Using the Gap and Overlap Effects (Tula et al., 2013a). 


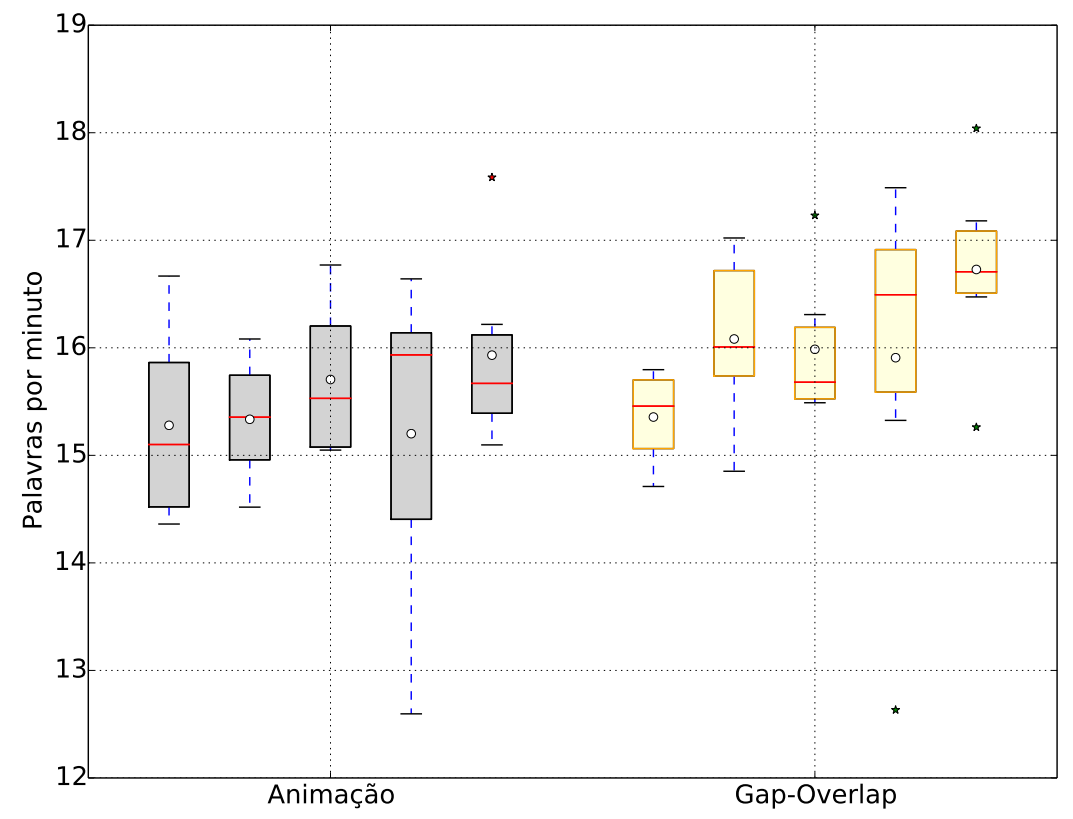

a) Desempenho durante 5 sessões para cada modelo de feedback. Os dados correspondem a 6 participantes.

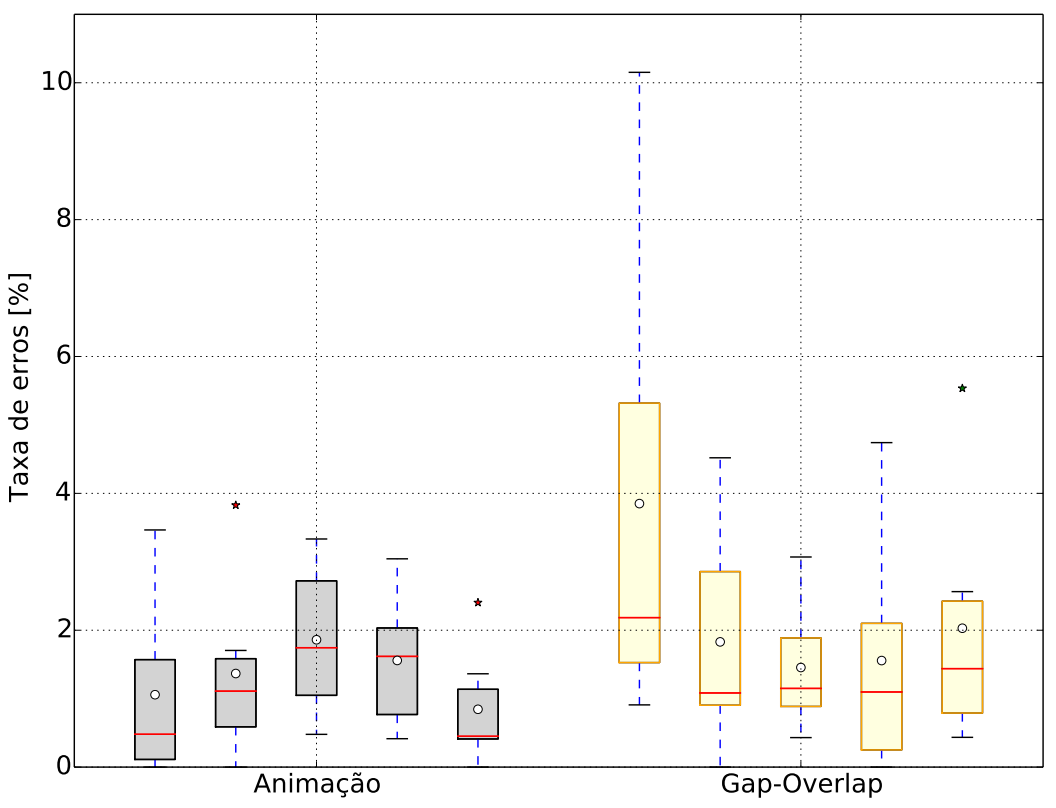

b)Taxa de erros durante 5 sessões para cada modelo de feedback. Os dados correspondem a 6 participantes.

Figura 3.9: Resultados de 5 sessões do experimento de digitação pelo olhar comparando o modelo de feedback baseado no efeito gap gradiente com o modelo de animação. Os valores minimo e máximo correspondem aos extremos da linha tracejada, os quartis inferior e superior aos extremos da caixa sombreada, a mediana à linha dentro da caixa e a média ao círculo também dentro da caixa. 


\section{Capítulo 4}

\section{Modelo matemático do tempo de reação sacádico em função do ganho de brilho}

O modelo de feedback que propomos no capítulo 3 mostrou que é possível aplicar o efeito gap gradiente para melhorar o conforto e o desempenho durante a digitação pelo olhar. Isto nos motivou a realizar um estudo mais detalhado da literatura sobre o efeito gap. Descobrimos que, até o presente, não existem estudos que relacionem o tempo de reação sacádico com mudanças arbitrárias no brilho do estímulo fixado. Uma melhor compreensão dessa relação ajudaria a definir, com uma base mais fundamentada, as manipulações visuais para a interação pelo olhar.

Os resultados do estudo descrito no presente capítulo foram publicados no periódico internacional Attention, Perception, 8 Psychophysics, em um artigo intitulado A mathematical model of saccadic reaction time as a function of the fixation point brightness gain (Diaz-Tula et al., 2015).

\subsection{Modulação do engajamento da atenção no efeito gap}

No capítulo 3 descrevemos o efeito gap, que consiste na redução do $S R T$ quando o estímulo sob fixação é apagado ou, como mostramos nesse capítulo, seu brilho é reduzido, antes de mostrar o estímulo excêntrico, para o qual o usuário tem que olhar o mais rápido possível (Saslow, 1967). O efeito gap tem sido bastante estudado na literatura, como mostramos a seguir.

\subsubsection{Resumo de alguns trabalhos sobre o efeito gap}

Reuter-Lorenz et al. (1991) estudaram o efeito de dois níveis de luminância do estímulo excêntrico (claro e escuro) e reportaram que estímulos mais brilhantes produzem tempos de reação mais curtos, e que esse efeito é aditivo com a redução pelo apagamento do ponto de fixação. Bell et al. (2006) também descobriram que estímulos excêntricos mais brilhantes produzem tempos de reação mais curtos em macacos.

Reulen (1984) calculou o SRT para três níveis de brilho diferentes (alto, médio e baixo) do ponto de fixação, mantendo o estímulo excêntrico com brilho constante (sempre alto). Os resultados de Reulen mostraram uma relação inversa entre o tempo de reação sacádico e o brilho do ponto de fixação: níveis de brilho maiores produzem tempos de reação mais curtos. Reulen concluiu que só uma redução significativa no brilho do ponto de fixação é capaz de reduzir o $S R T$, porém sem definir a magnitude de tal redução. 
Ao invés de brilho, Pratt et al. (2000) manipularam a área do ponto de fixação. No estudo, os autores incluíram um aviso sonoro antes de manipular a área do ponto de fixação em metade dos testes. Pratt et al. descobriram uma redução no $S R T$ de $67 \mathrm{~ms}$ na ausência de aviso sonoro e de 40 ms na presença do aviso sonoro, confirmando assim que o estado de alerta modula o efeito gap.

Jin e Reeves (2009) avaliaram várias teorias do efeito gap e concluíram que o desengajamento da atenção tem um grande impacto na redução do $S R T$, enquanto que a liberação oculomotora tem um impacto menor. No estudo, os autores incluíram a condição de gap escuro (dim gap trial), na qual o brilho do ponto de fixação foi reduzido, e a condição de gap claro (white gap trial), na qual o brilho do ponto de fixação foi aumentado. Embora as condições de gap claro e escuro foram incluídas com o intuito de fornecer o mesmo nível de aviso, o $S R T$ foi menor na condição de gap escuro do que no gap claro. Jin e Reeves assumiram que esse resultado é devido a que quando o brilho do ponto de fixação é reduzido a atenção é desengajada, enquanto que o aumento no brilho segura a atenção no ponto de fixação.

\subsubsection{Hipótese sobre a modulação do engajamento da atenção no efeito gap}

Todos esses resultados podem ser explicados em termos da teoria da atenção bottom-up. De acordo com essa teoria, a alocação da atenção é guiada pela saliência dos estímulos, como o movimento, contraste e sonoridade (Awh et al., 2012). Um exemplo de controle bottom-up da atenção pode ser encontrado no "paradigma de dicas" (cueing paradigm). Nesse paradigma, os sujeitos tem que fixar o olhar em um estímulo central e então achar um outro estímulo que é mostrado em uma de várias posições possíveis (Fuchs e Ansorge, 2012). Uma pista ou "dica" exógena e irrelevante para a tarefa, mostrada antes do aparecimento do estímulo, facilita a tarefa se a localização da dica coincide com a localização onde o estímulo vai ser mostrado. Essa facilitação suporta a ideia que a atenção é capturada pela dica.

Alguns autores têm proposto que dicas com maior contraste capturam mais a atenção que dicas com contraste menor (Fuchs e Ansorge, 2012; Fuller et al., 2009; Kean e Lambert, 2003). Além disso, Fuller et al. (2009) mostraram que a atenção é modulada pelo contraste das dicas, concluindo que embora a alocação da atenção seja um processo automático e inconsciente, o processo de atenção é gradual.

Assim, é plausível assumir que em estudos do efeito gap nos quais a tarefa não inclui a manipulação da atenção de forma explícita, como em Bell et al. (2006); Jin e Reeves (2009); Pratt et al. (2000); Reuter-Lorenz et al. (1991), a atenção é guiada principalmente pela saliência dos estímulos. Considerando o papel da atenção no efeito gap e as evidências do paradigma de dicas de que a atenção é modulada pelo contraste das dicas, nós definimos como hipótese que o componente de engajamento da atenção no efeito gap pode ser modulado por mudanças perceptuais no ponto de fixação.

Se nossa hipótese for correta, então é esperado que o $S R T$ possa ser expressado por uma lei psicofísica, como a lei de Weber-Fechner (Fechner, 1860). Tal lei tem sido utilizada em modelos de $S R T$ para codificar a diferença no brilho do estímulo excêntrico, em casos em que o estímulo excêntrico está presente ou não (Carpenter, 2004) ou quando o seu brilho muda de um nível inicial para um nível final (Taylor et al., 2006).

Na próxima seção descrevemos o modelo matemático proposto que expressa o $S R T$ em função do logaritmo de ganho de brilho, que é a razão entre o brilho final e inicial do ponto de fixação. 


\subsection{Modelo matemático do tempo de reação sacádico}

Vamos supor que a intensidade inicial do ponto de fixação é $I B$ e, um certo tempo (gap) antes de apresentar o estímulo excêntrico, muda para um valor de intensidade final $F B$. Vamos assumir também que o fundo onde os estímulos são mostrados é preto (luminância $0 \mathrm{~cd} / \mathrm{m}^{2}$ ), similar a outros estudos sobre o efeito gap (Jin e Reeves, 2009; Pratt et al., 2000; Reuter-Lorenz et al., 1995, 1991), e que a iluminação ambiente é $L_{a}$. Então a intensidade da luz que chega aos olhos do observador é $I B+L_{a}$ e $F B+L_{a}$ para os valores de intensidade inicial e final do ponto de fixação respectivamente.

A lei de Weber-Fechner (Fechner, 1860) estabelece que a sensação subjetiva de um estímulo é proporcional ao logaritmo de sua magnitude física. De acordo com essa lei, a sensação subjetiva produzida pela intensidade inicial e final do ponto de fixação seria $\log \left(I B+L_{a}\right)$ e $\log \left(F B+L_{a}\right)$ respectivamente. Portanto, podemos definir a diferença subjetiva dada pela mudança no brilho do ponto de fixação (de $I B$ para $F B$ ) como:

$$
\log \left(F B+L_{a}\right)-\log \left(I B+L_{a}\right)=\log \left(\frac{F B+L_{a}}{I B+L_{a}}\right)
$$

É importante notarmos que o argumento do logaritmo na equação 4.1 é independente das unidades utilizadas para expressar a intensidade do ponto de fixação. Por isso temos chamado essa razão de ganho de brilho ( $B G$, do inglês brightness gain). Baseados na equação 4.1, propomos a seguinte expressão matemática para o tempo de reação sacádico:

$$
S R T=\alpha \cdot \log (B G)+\beta
$$

onde $\alpha$ e $\beta$ são constantes numéricas calculadas de forma empírica pelo método de regressão linear, a partir de dados coletados experimentalmente. $\mathrm{O}$ valor de $\alpha$ é definido como sendo o fator de engajamento da atenção e representa a inclinação da curva lin-log do $S R T$ em função do $\log (B G)$. Uma inclinação maior significa que o $S R T$ é muito sensível a variações no ganho de brilho, enquanto que uma inclinação menor implica que o tempo de reação varia pouco, inclusive para grandes mudanças no brilho.

O valor de $\beta$ é definido como o $\boldsymbol{S R T}$ sem modulação, pois ele representa o tempo de reação sacádico quando não há manipulação visual do ponto de fixação (condição de controle). Observe que quando o ganho de brilho é igual a $1, \log (B G)$ é zero e o parâmetro $\beta$ é igual ao $S R T$ observado na condição de controle.

Quando o ganho de brilho é menor que $1, \log (B G)$ é negativo e o engajamento da atenção é reduzido, facilitando assim a sacada, ou seja, o $S R T$ vai ser menor que $\beta$. Por outro lado, quando o ganho de brilho é maior que $1, \log (B G)$ é positivo e o engajamento da atenção é reforçado (o $S R T$ vai ser maior que $\beta$ ).

\subsection{Experimento psicofísico para validar o modelo de tempo de reação sacádico}

Para validar o modelo proposto do tempo de reação sacádico, projetamos um experimento mais abrangente, com vários níveis de brilho inicial e final do ponto de fixação e dois valores de gap. Durante a realização desse estudo contamos com a colaboração do Professor Dr. Ronald Ranvaud 
do Departamento de Fisiologia e Biofísica do Instituto de Ciências Biomédicas da Universidade de São Paulo, que possui experiência na área de estudos psicofísicos utilizando rastreadores de olhar.

\subsubsection{Design experimental e método}

A configuração experimental utilizada nesse estudo foi similar ao experimento 1 , descrito na seção 3.4 do capítulo 3. Para este experimento definimos quatro condições: controle, apagamento, menor brilho e maior brilho. Na condição de controle, mostrada na figura 4.1a, o brilho no ponto de fixação foi mantido constante, similar aos experimentos 1 e 2 da seção 3.4. Na condição de apagamento, como exemplificado na figura 4.1b, o ponto de fixação foi apagado antes de apresentar o estímulo excêntrico. Na condição de menor brilho o ponto de fixação teve seu brilho reduzido até um nível visível, maior que zero, como observado na figura 4.1c. Já na condição de maior brilho, como mostrado na figura 4.1d, o ponto de fixação teve seu brilho incrementado.

O valores de gap utilizados foram 0 e $200 \mathrm{~ms}$, que são os mais comuns na literatura. Os níveis de $I B$ foram $\mathrm{H}$ ( $100 \%$ do brilho máximo do monitor), M (50\% do brilho máximo do monitor) e L (5\% do brilho máximo do monitor), enquanto que os níveis de $F B$ foram os mesmos $\mathrm{H}, \mathrm{M}$, L e Z (0\% do brilho máximo do monitor).

O design do experimento foi intra-sujeito, fatorial e completamente aleatório, com um total de 2 gap $\times 3$ IBs $\times 4$ FBs $=12$ configurações experimentais. Cada condição foi repetida 20 vezes, em 10 delas o estímulo excêntrico foi mostrado à direita do ponto de fixação, enquanto que nas outras 10 repetições o estímulo excêntrico apareceu à esquerda do ponto de fixação, sempre em ordem aleatória.

Para que o experimento seja replicável por outros pesquisadores, o monitor foi calibrado com um fotômetro J1803 Tektronix LumaColor ${ }^{T M}$. Para obter a curva de luminância do monitor, anotamos os valores em $\mathrm{cd} / \mathrm{m}^{2}$ para vários níveis de brilho (tuplas RGB). Com esses valores ajustamos a curva de luminância do monitor, que é dada pela expressão $y=249.9 x^{2.26}$ com um coeficiente de determinação $R^{2}=0.99$, onde $x$ é a porcentagem do brilho (expressado como uma fração, ou seja, para um brilho de $100 \%$ o valor de $x$ é 1 ) e $y$ é a luminância em $\mathrm{cd} / \mathrm{m}^{2}$. Os níveis $\mathrm{H}, \mathrm{M}, \mathrm{L}$ e Z foram convertidos para cd $/ \mathrm{m}^{2}$, cujos valores são mostrados na tabela 4.1 .

A luminância do ambiente foi calculada colocando o fotômetro aproximadamente na mesma posição dos olhos dos participantes, apontando para o centro do monitor, que ficou desligado durante esse procedimento. A luminância ambiente foi anotada depois que a leitura do fotômetro ficou estável em $4 \mathrm{~cd} / \mathrm{m}^{2}$.

Tabela 4.1: Conversão dos niveis de brilho usados no experimento para valores de luminância. Os níveis de brilho são expressados como porcentagens do brilho máximo do monitor RGB (255, 255, 255).

\begin{tabular}{ccc}
\hline Nível & Porcentagem do brilho & Luminância $\left(\mathrm{cd} / \mathrm{m}^{2}\right)$ \\
\hline $\mathrm{H}$ & 100 & 249.9 \\
$\mathrm{M}$ & 50 & 52.0 \\
$\mathrm{~L}$ & 5 & 0.28 \\
$\mathrm{Z}$ & 0 & 0 \\
\hline
\end{tabular}

O presente estudo teve algumas diferenças comparado com os experimentos descritos na seção 3.4 do capítulo 3. No começo de cada teste o ponto de fixação foi mostrado com o valor de $I B$, ou seja, o intervalo de pre não foi incluído nesse experimento. Além disso, depois da manipulação visual 
no ponto de fixação, ele manteve o valor de $F B$ durante o resto do teste, portanto não houve efeito distrator no ponto de fixação. Uma outra diferença foi o uso de um som curto de $100 \mathrm{~ms}$ antes do começo do intervalo de gap (0 ou $200 \mathrm{~ms}$ ), similar a vários estudos na literatura (Craig et al., 1999; Pratt et al., 2006; Reuter-Lorenz et al., 1991). O objetivo desse som é balançar o efeito de alerta produzido pela mudança no brilho nas condições de apagamento, menor brilho e maior brilho com a condição de controle, na qual não existe tal alerta visual. Finalmente, o estímulo excêntrico apenas apareceu à direita ou esquerda do estímulo fixado (aleatoriamente), com o objetivo de reduzir a duração total do experimento.

Dezesseis voluntários participaram do experimento (3 mulheres) com idade entre 21 e 50 anos (média 28.6土8). Todos tinham visão normal ou corrida para normal. Os dados de um dos participantes foram desconsiderados da análise devido a que esse participante tentou adivinhar o lado onde apareceria o estímulo excêntrico, produzindo uma taxa de erros muito grande e tempos de reação muito curtos.

\subsubsection{Resultados}

A seguir apresentamos um resumo dos resultados experimentais. Os resultados nas condições de apagamento, menor brilho e maior brilho foram comparados com o grupo de controle usando testes de Student. Já dentro de cada condição, testes ANOVA foram utilizados para avaliar o efeito do gap e das manipulações visuais do ponto de fixação. Cada teste ANOVA reportado a seguir foi precedido por um teste de esfericidade de Mauchly. Nos casos de violação da condição de esfericidade, os graus de liberdade e o valor de $\mathrm{p}$ foram corrigidos pelo método de Greenhouse-Geisser, pois em tais casos a estimação da esfericidade $(\epsilon)$ foi sempre menor que 0.75 . Maiores detalhes sobre os testes estatísticos podem ser encontrados em Diaz-Tula et al. (2015).

Para facilitar a apresentação dos resultados, cada configuração será representada por três letras, sendo que a primeira é o intervalo de gap (0 ou 2), a segunda é o nível de $I B$ e a terceira o nível de $F B$. Por exemplo, o código $2 \mathrm{HZ}$ representa a configuração com gap $=200 \mathrm{~ms}, I B=\mathrm{H}$ e $F B=\mathrm{Z}$, correspondendo à condição de apagamento $(F B=\mathrm{Z}$ implica que o ponto de fixação é apagado). Quando apenas duas letras forem usadas sem o dígito no começo, significa a média das configurações para os dois valores de gap.

Os resultados experimentais são mostrados como gráficos de caixa (box plot) na figura 4.2a para $g a p=0 \mathrm{~ms}$ e na figura $4.2 \mathrm{~b}$ para $g a p=200 \mathrm{~ms}$. Para cada condição é mostrado o SRT mínimo e máximo como sendo os extremos da linha tracejada, os quartis inferior e superior como os extremos da caixa sombreada, a mediana como uma linha dentro da caixa e a média como um círculo também dentro da caixa. Os valores da média e um desvio padrão são mostrados acima de cada caixa, e os outliers são mostrados com uma estrela. 


\section{Condição de controle}

Os resultados mostraram que na condição de controle, na qual o brilho do ponto de fixação não muda, não há diferença significativa no $S R T$ para os três níveis de brilho $\mathrm{H}, \mathrm{M} \mathrm{e} \mathrm{L}, \mathrm{F}(2,28)=1.56$, $\mathrm{p}=0.23, \eta_{p}{ }^{2}=0.1$. O intervalo gap teve um efeito significativo, $\mathrm{F}(1,14)=66.69, \mathrm{p}<0.001$, $\eta_{p}{ }^{2}=0.83$, sendo que a média do $S R T$ das configurações para gap $=0 \mathrm{~ms}$ foi $201( \pm 29)$ ms e para gap $=200 \mathrm{~ms}$ foi $169( \pm 24) \mathrm{ms}$, resultando em uma diferença de $32 \mathrm{~ms}$.

\section{Condição de apagamento}

Na condição de apagamento, na qual o ponto de fixação é apagado da tela, nossos resultados mostraram que há uma relação inversamente proporcional entre o valor de $I B$ e o $S R T$ : quanto maior o nível de $I B$, menor o SRT. Isto confirma o resultado de Reulen (1984) que reportou a mesma relação em seu experimento. Similar à condição de controle, a variável gap teve um efeito significativo, $\mathrm{F}(1,14)=169.24, \mathrm{p}<0.001, \eta_{p}{ }^{2}=0.92$, sendo que a média do $S R T$ para as configurações com gap $=0 \mathrm{~ms}$ foi $190( \pm 22) \mathrm{ms}$, enquanto que a média para as configurações com gap $=200 \mathrm{~ms}$ foi $152( \pm 20) \mathrm{ms}$

Para verificar a existência de um "efeito gap", comparamos as configurações da condição de apagamento com o grupo de controle. Para gap $=0$ ms a configuração 0LZ não apresentou redução significativa no $S R T$ quando comparada com a condição de controle. Já para as outras condições 0HZ e 0MZ observamos uma redução significativa no SRT. Para gap = $200 \mathrm{~ms}$ houve uma redução significativa no $S R T$ para todos os níveis de $I B$ (ou seja, para as configurações $2 \mathrm{HZ}, 2 \mathrm{MZ}$ e $2 \mathrm{LZ}$ ). Essa redução significativa está em correspondência com a obtida na condição de apagamento do experimento 2 na seção 3.4 .

$\underline{\text { Condição de menor brilho }}$

Na condição de menor brilho, o ponto de fixação teve seu brilho reduzido para um nível perceptível, maior que zero. Os resultados mostraram que as configurações HL e ML tiveram SRTs similares, porém a configuração HM teve um SRT significativamente maior que as duas primeiras. Similar às condições de controle e apagamento, a variável gap teve um efeito significativo, $\mathrm{F}(1,14)=85.96$, $\mathrm{p}<0.001, \eta_{p}{ }^{2}=0.86$, sendo que a média do $S R T$ para $g a p=0 \mathrm{~ms}$ foi maior que a média do $S R T$ para gap $=200 \mathrm{~ms}$.

Um resultado interessante é que os tempos de reação observados nas configurações HL e ML foram similares aos das configurações $\mathrm{HZ}$ e MZ na condição de apagamento, o que implica que se o ponto de fixação não for apagado, mas seu brilho for reduzido para um nível baixo, o SRT é similar a quando o estímulo é apagado. Isto confirma os resultados do experimento 2 na seção 3.4, nos quais não houve diferença significativa quando o ponto de fixação foi apagado ou teve o brilho reduzido para $15 \%$. Porém, não toda redução no brilho reduziu o $S R T$, como no caso da configuração HM.

\section{Condição de maior brilho}

Na condição de maior brilho o ponto de fixação teve seu brilho incrementado. Nossos resultados mostraram que os tempos de reação de todas as configurações nessa condição foram maiores que na condição de controle. Isto implica que incrementar o brilho produz um incremento no SRT. Porém, o incremento não foi igual em todas as configurações. A configuração MH (na qual o brilho 
do ponto de fixação é incrementado de $\mathrm{M}$ para $\mathrm{H}$ ) teve um $S R T$ significativamente menor que as configurações LH e LM.

Uma observação é que os resultados obtidos no presente estudo foram diferentes dos obtidos no experimento 2 na seção 3.4, com o gradiente ascendente. Naquele experimento, quando o brilho foi aumentado de $15 \%$ para $100 \%$, os tempos de reação não foram maiores que na condição de controle. No entanto, essa diferença nos resultados pode ser explicada pela presença do aviso sonoro no presente experimento. Na ausência do aviso sonoro, qualquer mudança no brilho do ponto de fixação (sem importar se for aumentado o reduzido) funciona como um sinal exógeno sobre o aparecimento do estímulo excêntrico, o que pode reduzir o SRT comparado com a condição de controle, na que não existe tal sinal. Já na presença do aviso sonoro, todas as condições tem o mesmo sinal exógeno sobre o aparecimento do estímulo excêntrico, portanto a diferença no $S R T$ entre a condição de controle e as outras condições nas quais o brilho é manipulado é menor. Em outras palavras, o uso do aviso sonoro permite balançar o efeito de alerta em todas as condições e, portanto, reduz a diferença entre o controle e as outras condições, como apontado por Reuter-Lorenz et al. (1995).

O intervalo gap teve um efeito significativo, $\mathrm{F}(1,14)=22.55, \mathrm{p}<0.001, \eta_{p}{ }^{2}=0.62$, similar a todas as condições anteriores, sendo que a média do $S R T$ para gap $=0 \mathrm{~ms}$ foi de $223( \pm 34) \mathrm{ms}$, enquanto que para gap $=200 \mathrm{~ms}$ foi de $185( \pm 38)$.

\subsubsection{Análise do modelo matemático do tempo de reação sacádico}

Um dos principais objetivos desse experimento é avaliar o modelo matemático do $S R T$ em função do ganho de brilho. Lembrando que o modelo tem a forma $S R T=\alpha \cdot \log (B G)+\beta$, onde $\alpha$ e $\beta$ são constantes determinadas de forma empírica por meio de regressão linear, a partir de dados coletados experimentalmente.

A figura 4.3 mostra os resultados da regressão para os dois valores de gap (0 e $200 \mathrm{~ms}$ ). O eixo horizontal inferior representa o logaritmo base 10 do ganho de brilho, enquanto que o eixo vertical representa o $S R T$ em milisegundos. Cada ponto usado na regressão corresponde à média dos 15 participantes para cada configuração experimental. Devido a que na condição de controle se cumpre que $B G=1$ para todas as intensidades do ponto de fixação, usamos a média dos três níveis (H, M e L) como um único ponto na regressão. Assim, ao total 10 pontos foram usados na regressão.

Para gap $=0$ ms o modelo predisse o $S R T$ significativamente, $\mathrm{F}(1,8)=135.96$, p $<0.001$, $R^{2}=0.94$. O valor estimado de $\alpha$ foi $13.9 \mathrm{~ms} / \log _{10}(B G)$ e teve um efeito significativo, $\mathrm{t}(8)=$ 11.66, $\mathrm{p}<0.001$, enquanto que o valor estimado de $\beta$ foi $205.1 \mathrm{~ms}$.

Para gap $=200 \mathrm{~ms}$ o modelo também predisse o $S R T$ significativamente, $\mathrm{F}(1,8)=66.67$, $\mathrm{p}<0.001, R^{2}=0.89$. O valor estimado de $\alpha$ foi $12.1 \mathrm{~ms} / \log _{10}(B G)$ e teve um efeito significativo, $\mathrm{t}(8)=8.17, \mathrm{p}<0.001$, enquanto que o valor estimado de $\beta$ foi de $167.6 \mathrm{~ms}$.

\subsubsection{Comparação dos resultados experimentais com estudos na literatura}

A maior redução no SRT que observamos nesse experimento foi de $22 \mathrm{~ms}$ na condição de apagamento, para o nível de brilho $\mathrm{H}$ do ponto de fixação. Essa redução é compatível com estudos sobre o efeito gap existentes na literatura, que usaram um aviso sonoro similar a nosso estudo, como Pratt et al. (2000) e Reuter-Lorenz et al. (1995).

Embora nos experimentos de Reulen (1984) não tenha sido utilizado um aviso sonoro, Reulen descobriu uma relação inversa entre a intensidade do ponto de fixação e o tempo de reação sacádico. 
Nosso experimento incluiu três configurações nas quais o ponto de fixação foi apagado (níveis H, M e L) e observamos uma relação inversa similar: níveis de brilho maiores no ponto de fixação produziram SRTs mais curtos.

Jin e Reeves (2009) também não incluíram um aviso sonoro nos seus experimentos, mas como eles informaram os valores de intensidade usados nas condições de gap escuro e gap claro, podemos usar esses valores para estimar a diferença entre essas duas condições segundo o nosso modelo. Na condição de gap escuro, Jin e Reeves reduziram a intensidade do ponto de fixação de $80.1 \mathrm{~cd} / \mathrm{m}^{2}$ até $4.2 \mathrm{~cd} / \mathrm{m}^{2}$, enquanto que no gap claro a intensidade foi aumentada de $80.1 \mathrm{~cd} / \mathrm{m}^{2}$ para $117 \mathrm{~cd} / \mathrm{m}^{2}$. Os valores de $B G$ para as condições de gap escuro e claro são 0.1 e 1.44 respectivamente. De acordo com nosso modelo, o SRT no gap escuro seria de $155 \mathrm{~ms}$, enquanto que no gap claro seria de $170 \mathrm{~ms}$. Portanto, a diferença entre essas duas condições, segundo estimada por nosso modelo, é de $15 \mathrm{~ms}$, similar ao resultado obtido por Jin e Reeves nos seus experimentos.

\subsubsection{Discussão sobre o modelo e implicações para o efeito gap}

Os resultados obtidos nesse experimento mostraram que o tempo de reação sacádico pode ser expressado pelo modelo matemático introduzido na equação 4.2. Lembrando que $B G$ é o ganho de brilho, definido como a razão entre o brilho final e inicial do ponto de fixação (considerando a iluminação ambiente), $\alpha$ é o fator de engajamento da atenção, $\beta$ é o $S R T$ sem modulação, e a base do logaritmo escolhida é 10 (sem perder generalidade). Os valores positivos de $\alpha$ observados para os dois intervalos de gap (0 e $200 \mathrm{~ms}$ ) implicam que aumentar a saliência do ponto de fixação produz $S R T$ s maiores, enquanto que reduzir a saliência produz SRTs menores.

Baseados nesses resultados, podemos responder a questão de Reulen (1984) sobre qual seria a magnitude da redução no brilho do ponto de fixação para produzir uma redução significativa no $S R T$. O brilho final do ponto de fixação deveria ser 10 vezes menor que o brilho inicial para reduzir o $S R T$ em aproximadamente $13 \mathrm{~ms}$, na presença de um aviso sonoro. O modelo proposto poderia ser estendido para considerar outros fatores que influenciam no efeito gap, como a intensidade do fundo e a excentricidade dos estímulos.

Finalmente, cabe discutir sobre nossa hipótese de que o engajamento da atenção no efeito gap é modulado por mudanças perceptuais no ponto de fixação. No presente experimento a atenção não foi manipulada de forma explícita, portanto não podemos afirmar que a atenção tenha sido modulada.

Uma explicação alternativa seria por meio de processos de baixo nível que afetam o tempo de reação sacádico. Por exemplo, mudanças perceptuais no ponto de fixação poderiam influenciar o sistema oculomotor que controla a execução das sacadas no colículo superior, pois o colículo recebe entrada direta da retina e os neurônios coliculares são muito sensíveis à intensidade do estímulo visual (Liversedge et al., 2011). Sendo verdadeira essa hipótese alternativa, então os neurônios no colículo superior que controlam a execução das sacadas seriam modulados por mudanças perceptuais no ponto de fixação. Para verificar essa hipótese seria necessário medir a atividade desses neurônios enquanto a saliência do ponto de fixação é manipulada.

Em favor da nossa hipótese sobre a modulação da atenção, o modelo proposto corroborou que o nível de engajamento da atenção, ao invés de ter apenas dois estados (engajado ou desengajado), muda de forma contínua com as mudanças perceptuais do estímulo fixado. Diferente dos resultados de Fuller et al. (2009), que reportaram que o contraste das dicas modula a atenção, o efeito descrito 
nesse capítulo acontece no ponto de fixação, onde o usuário já está prestando atenção, com maior potencial de aplicação no design de interfaces de usuário. Uma possível aplicação seria aumentar o contraste da área observada para "segurar" a atenção do usuário, por exemplo no caso de aeronaves voando muito próximas entre si em um painel de controlador de voo. Caso a informação observada for pouco relevante, o contraste pode ser reduzido para liberar a atenção do usuário, permitindo que ele olhe mais rápido para outras partes da interface. 


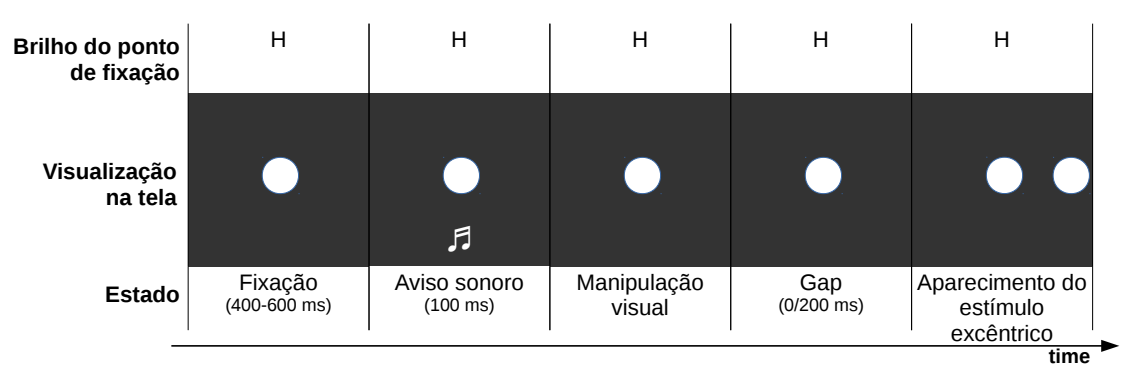

a) Condição de controle em que o brilho do ponto de fixação não muda (fica com valor $\mathrm{H}$ ) durante o teste inteiro.

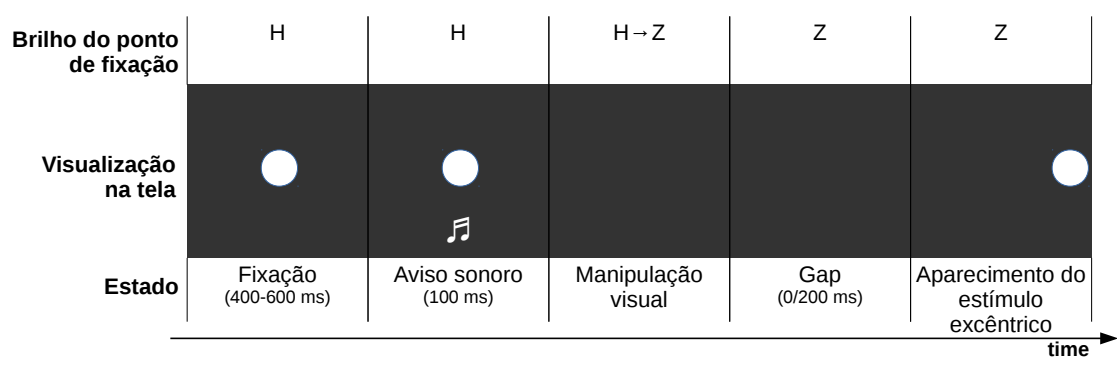

b) Condição de apagamento em que o brilho do ponto de fixação muda de $\mathrm{H}$ para Z, com um gap de 0 ou $200 \mathrm{~ms}$.

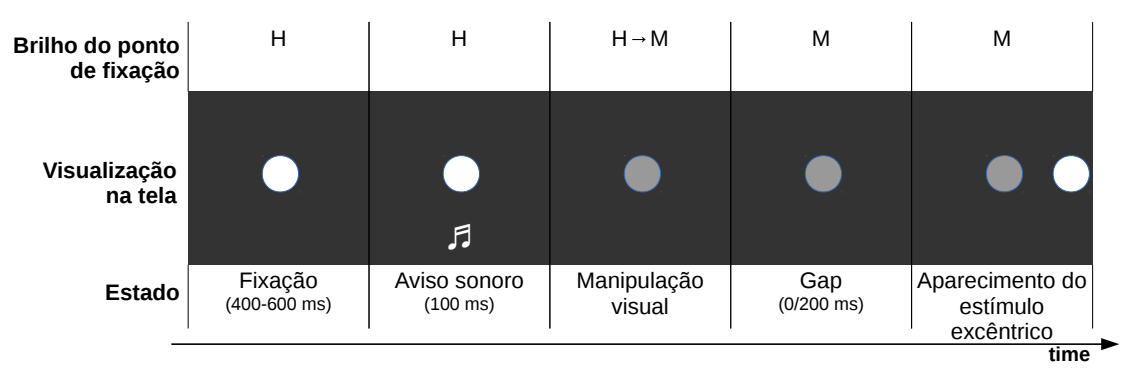

c) Condição de menor brilho, em que o brilho final do ponto de fixação é menor que o brilho inicial (no caso muda de $\mathrm{H}$ para $\mathrm{M}$ ).

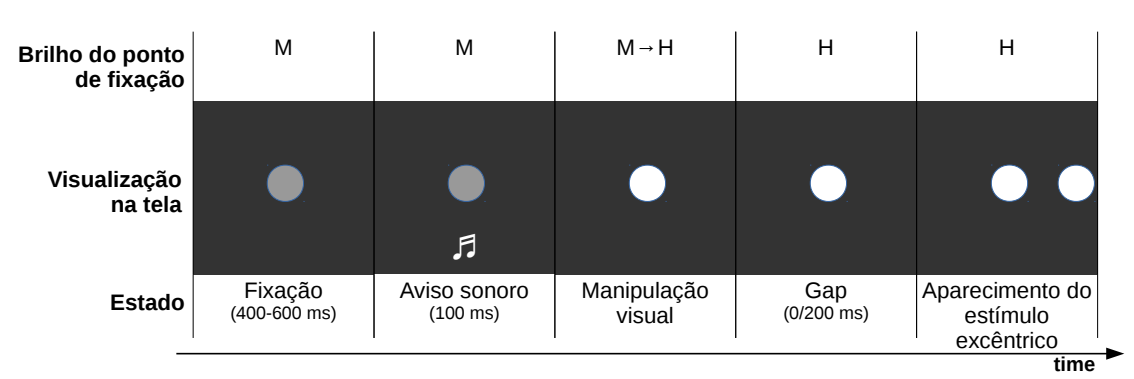

d) Condição de maior brilho, em que o brilho do ponto de fixação é aumentado (no caso muda de $\mathrm{M}$ para $\mathrm{H}$ ).

Figura 4.1: Condições de controle, apagamento, menor brilho e maior brilho usadas no experimento 


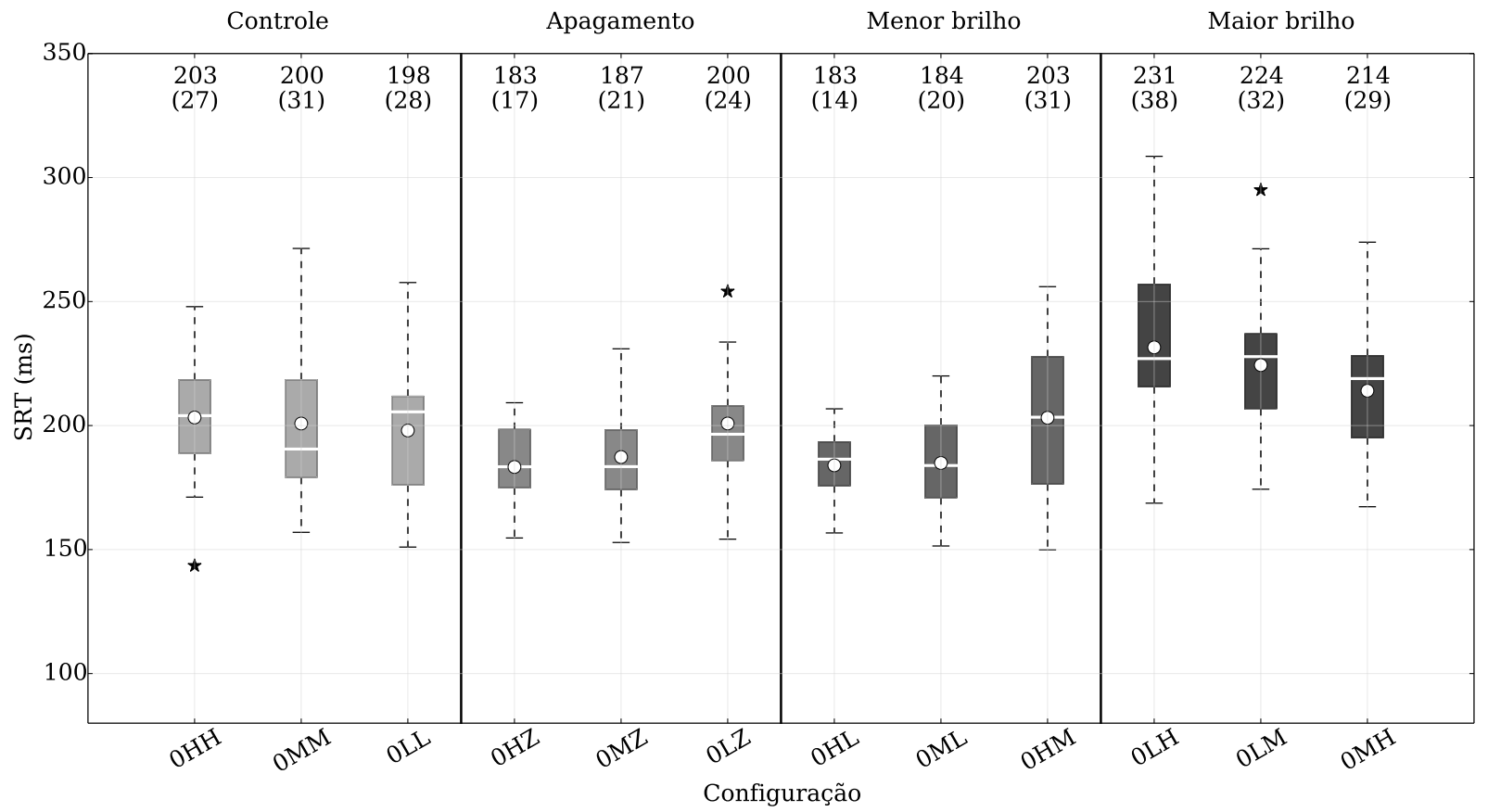

a) Resultados experimentais para o gap de $0 \mathrm{~ms}$.

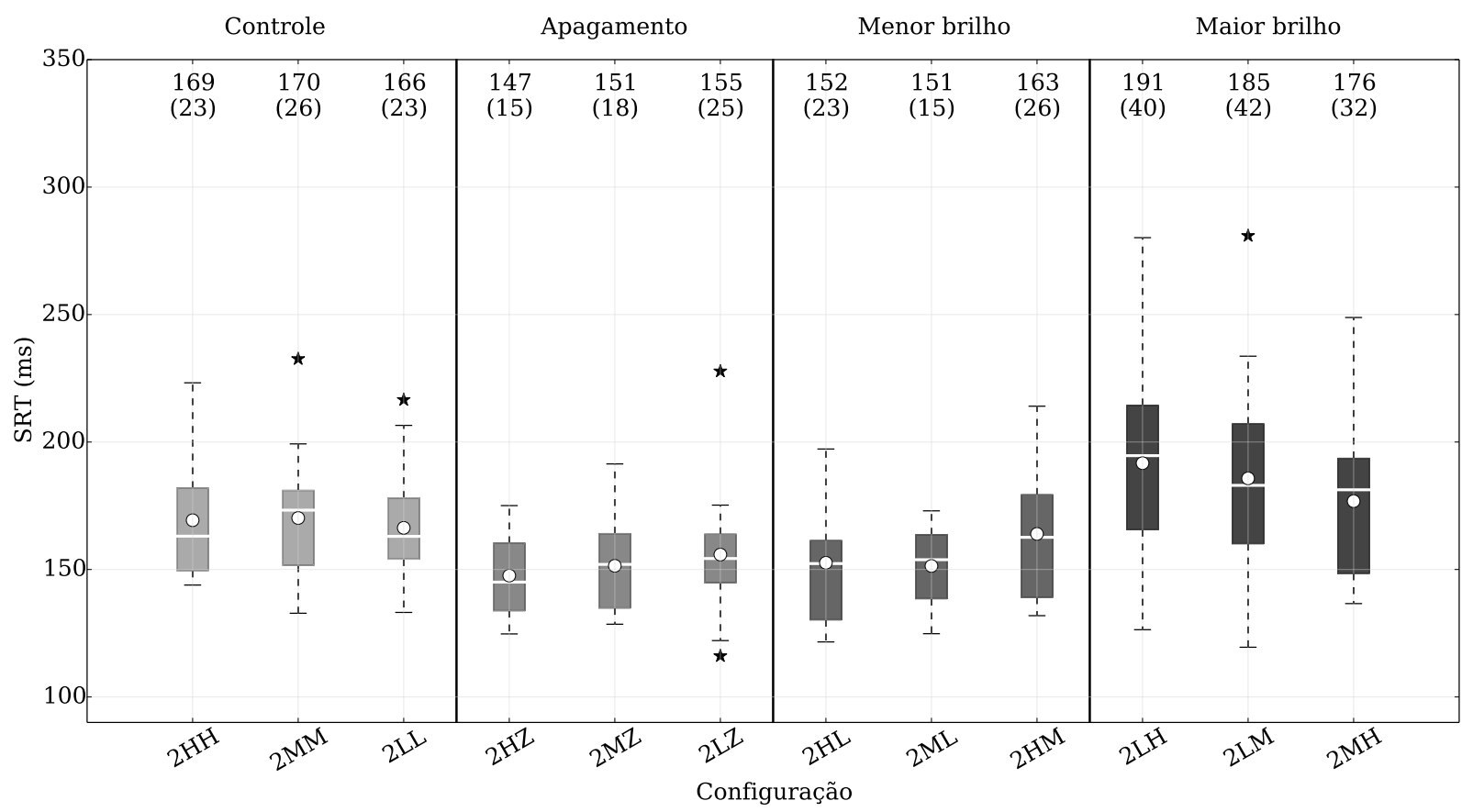

b) Resultados experimentais para o gap de $200 \mathrm{~ms}$.

Figura 4.2: Resultados experimentais para os dois valores de gap (0 e $200 \mathrm{~ms}$ ). Para cada condição é mostrado o SRT minimo e máximo como sendo os extremos da linha tracejada, os quartis inferior e superior como os extremos da caixa sombreada, a mediana como uma linha dentro da caixa e a média como um círculo também dentro da caixa. Os valores da média e um desvio padrão são mostrados acima de cada caixa, e os outliers são mostrados com uma estrela. 


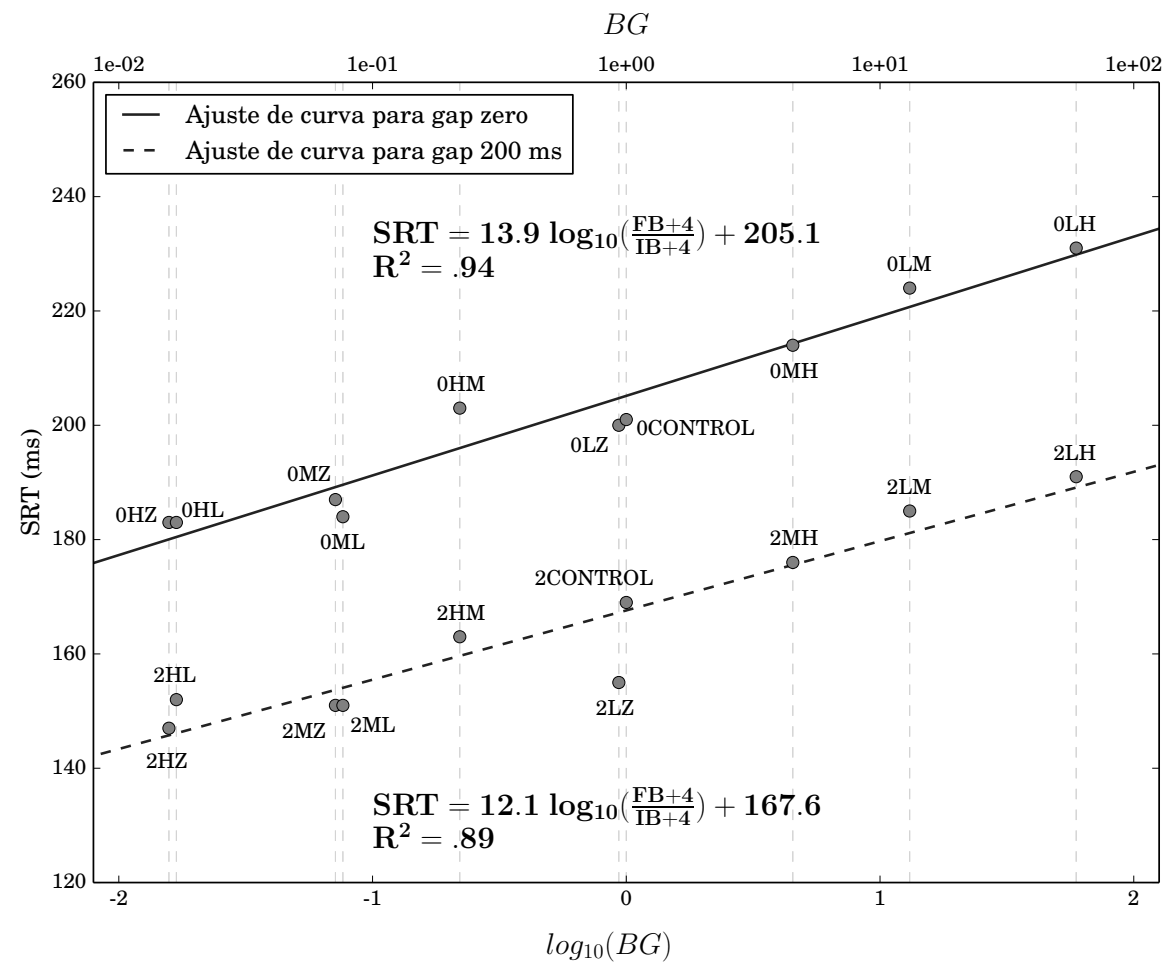

Figura 4.3: Resultados da regressão para calcular os parâmetros da equação 4.2 para os valores de gap de 0 e $200 \mathrm{~ms}$. Note que o eixo x possui uma escala logarítmica. 


\section{Capítulo 5}

\section{Estudo e extensão da alternância entre contextos}

Como descrito na introdução, um dos principais problemas na interação pelo olhar é o toque de Midas. Na ativação por tempo de latência o toque de Midas é mais frequente, pois o olhar não pode descansar em uma tecla por muito tempo sem selecioná-la. Em alguns estudos que compararam digitação por tempo de latência com outras técnicas, como Wobbrock et al. (2008) e Bee e André (2008), os participantes acharam o tempo de latência mais cansativo e estressante devido ao toque de Midas.

Nesse sentido, a alternância entre contextos é uma técnica muito promissora, pois a seleção só é feita quando o usuário faz uma troca de contextos. Assim, o usuário é livre de explorar o conteúdo da interface sem o estresse do toque de Midas. Nesse capítulo apresentamos a descrição e avaliação de duas extensões para a alternância entre contextos.

\subsection{Mudança dinâmica no tamanho dos contextos}

Uma característica da alternância entre contextos é a utilização de uma área grande da tela para a exibição de dois contextos idênticos, por exemplo, dois teclados como em Morimoto e Amir (2010). No experimento de Morimoto e Amir, um leiaute de três linhas e nove colunas foi utilizado, para tolerar a baixa precisão do rastreador de olhar de aproximadamente $1^{o}$ de ângulo visual. Um maior número de teclas permitiria digitar mais caracteres, como sinais de pontuação e números.

Para aproveitar melhor a área útil do monitor, nós propomos a mudança dinâmica dos tamanhos dos contextos, sendo que o contexto com o foco do usuário é maior do que o outro contexto. Assim que o usuário trocar de contextos para fazer uma seleção, o contexto que ganha o foco é maximizado, enquanto que o outro é reduzido. A técnica é chamada de "alternância entre contextos dinâmicos" (Dynamic Context Switching).

Para avaliar essa nova técnica, desenvolvemos um protótipo de teclado para navegação e seleção de objetos, mostrado na figura 5.1. A figura 5.1a mostra uma configuração com tamanho fixo, na qual os dois contextos possuem as mesmas dimensões, cada um contendo duas colunas e cinco linhas de teclas. Na área central entre os dois contextos são mostradas as seleções feitas. A figura 5.1b mostra uma configuração com três colunas e cinco linhas, ou seja, $50 \%$ de teclas a mais que na configuração com tamanho fixo. Já a figura 5.1c mostra uma configuração com quatro colunas e cinco linhas, 
representando $100 \%$ de teclas a mais que na configuração com tamanho fixo. Escolhemos alinhar os contextos de forma horizontal ao invés de vertical como em Morimoto e Amir (2010), devido a que as sacadas horizontais são mais naturais e rápidas do que as verticais (Collewijn et al., 1988).

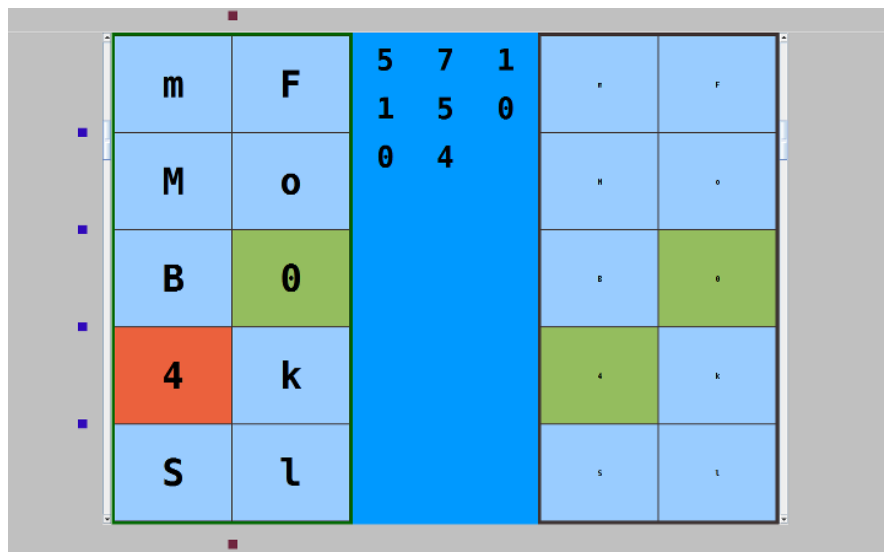

a) Contextos de tamanho fixo com 2 colunas e 5 linhas de teclas em cada contexto

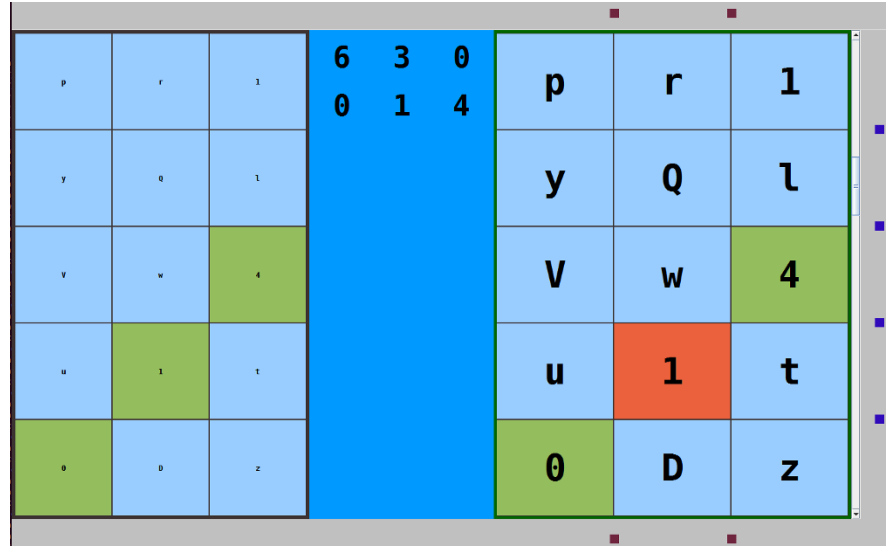

b) Contextos dinâmicos com 3 colunas e 5 linhas de teclas em cada contexto

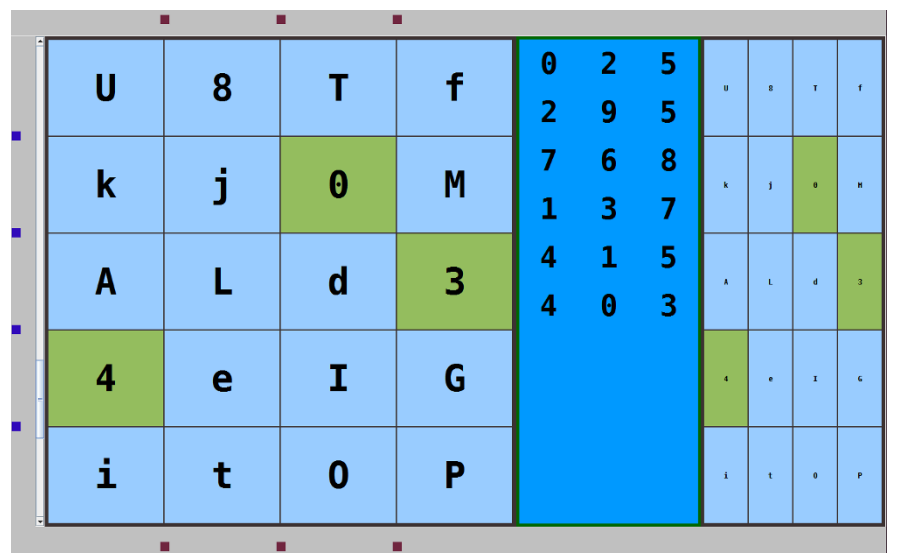

c) Contextos dinâmicos com 4 colunas e 5 linhas de teclas em cada contexto

Figura 5.1: Três interfaces baseadas na alternância entre contextos de tamanho fixo e dinâmicos. Em todas as configurações a ponte (área azul) separa os dois contextos. 


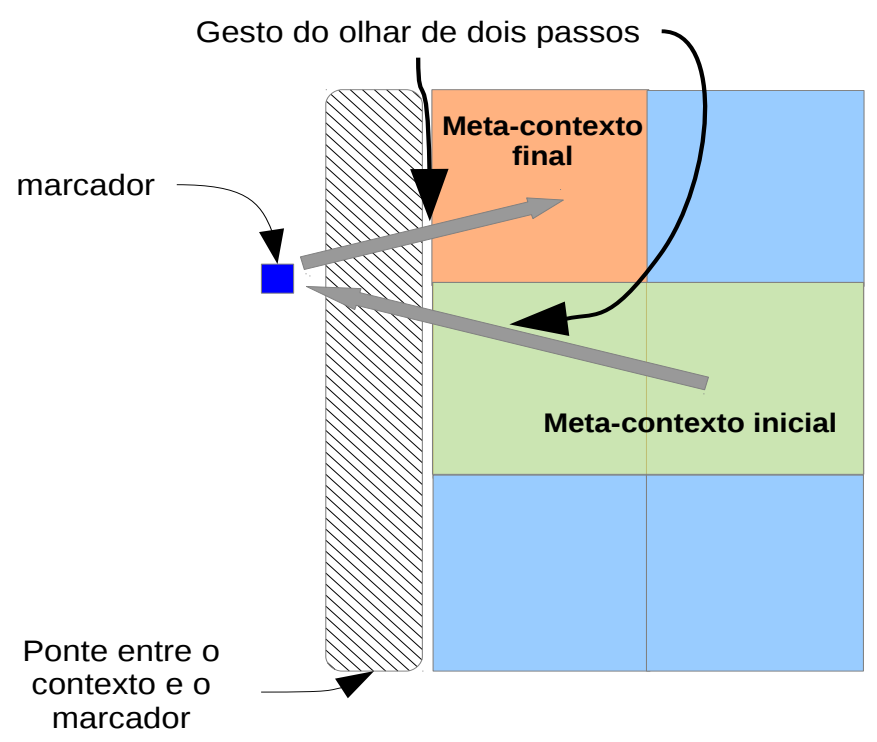

Figura 5.2: Representação gráfica de um meta-key. O gesto de dois passos feito com o olhar começa em um meta-contexto, depois vá até o marcador (quadrado azul) e finalmente volta para um meta-contexto vizinho, cruzando a ponte duas vezes.

\subsubsection{Uma segunda extensão: meta-keys}

Embora a alternância entre contextos dinâmicos permita aproveitar melhor o espaço útil no monitor, ainda podem existir casos em que espaço adicional é necessário. Por exemplo, mudar o layout do teclado virtual para digitar caracteres especiais e/ou acentos, fazer operações sobre arquivos (abrir, salvar, fechar), gerenciar conteúdo multimídia, entre outras atividades. Para isso propomos o uso de meta-keys.

Porta e Turina (2008) proporam o uso de gestos do olhar para executar comandos de propósito geral. No entanto, gestos complexos como os utilizados por Wobbrock et al. (2008) e Porta e Turina (2008) podem ser difíceis de aprender e provocar cansaço visual. Por outro lado, gestos de um passo (formados por apenas uma sacada), como os propostos por Møllenbach et al. (2013), poderiam ser ativados por acidente enquanto o usuário está explorando a interface.

Para a ativação dos meta-keys nós propomos usar gestos do olhar de dois passos, ou seja, gestos formados por duas sacadas curtas. Os meta-keys são colocados do lado de fora dos contextos, a uma certa distância das suas bordas exteriores, deixando um espaço entre o contexto e o marcador, que funciona como uma "ponte" entre o contexto e o meta-key. Além disso, sub-regiões dentro dos contextos (como uma linha ou coluna) são usadas como meta-contextos para iniciar e finalizar os gestos.

Para ativar um meta-key o usuário precisa começar em um meta-contexto, depois olhar para o marcador correspondente ao meta-key, e finalmente olhar de volta para um outro meta-contexto. A figura 5.2 mostra uma representação gráfica do funcionamento dos meta-keys.

Para comparar o desempenho dos contextos de tamanho fixo com os dinâmicos e com a seleção por tempo de latência, além de avaliar o uso dos meta-keys, realizamos dois experimentos que são descritos nas próximas seções. 


\subsection{Experimento 1: Comparação entre contextos com tamanho fixo e dinâmicos}

O objetivo do experimento 1 é comparar o desempenho dos contextos com tamanho fixo com os contextos dinâmicos em uma tarefa de seleção múltipla, comum em aplicações da vida real, como seleção de imagens ou multimídia. Um outro objetivo é avaliar o uso de meta-keys para navegação e ativação de comandos, em uma tarefa que requer navegar por várias páginas de objetos.

\subsubsection{Método}

\section{Participantes}

Nesse experimento contamos com 6 participantes, todos do sexo masculino, capazes, com visão normal ou corrigida para normal usando óculos ou lentes de contato. Dois deles nunca antes tinham usado um rastreador de olhar, outros dois já tinham participado em pelo menos um estudo com rastreadores de olhar, e os outros dois já tinham experiência no desenvolvimento de rastreadores de olhar e interfaces controladas pelo olhar. Todos os participantes eram estudantes ou pesquisadores da Universidade de São Paulo, com idades entre 21 a 45 anos de idade. Todos tinham pelo menos 10 anos de experiência usando computadores.

\section{Materiais e equipamentos}

O experimento foi realizado com um rastreador de olhar de baixo custo, desenvolvido por Morimoto et al. (1999). O rastreador roda a $30 \mathrm{~Hz}$ e possui uma precisão espacial de aproximadamente $1^{o}$ de ângulo visual. Um apoio de queixo foi utilizado para reduzir os movimentos de cabeça dos participantes, com o objetivo de minimizar o efeito do ruído na estimação do olhar, assim como evitar a perda da calibração durante o experimento.

A figura 5.1 mostra as três interfaces que foram desenvolvidas para o experimento, todas baseadas no paradigma da alternância entre contextos, com os contextos arranjados de forma horizontal e separados pela ponte. As configurações consistem em 2 colunas (2C) de teclas em ambos contextos, como mostrado na figura 5.1a, 3 colunas (3C) de teclas em ambos contextos, como mostrado na figura 5.1b, e 4 colunas (4C) de teclas em ambos contextos, como mostrado na figura 5.1c. Todas as configurações possuem 5 linhas de teclas. Assim, a configuração 2C tem 10 teclas em cada contexto, a configuração $3 \mathrm{C}$ tem 15 teclas em cada contexto (50\% a mais que $2 \mathrm{C}$ ) e a configuração $4 \mathrm{C}$ tem 20 teclas em cada contexto ( $100 \%$ a mais que $2 \mathrm{C}$ ).

Na configuração 2C o tamanho dos contextos foi mantida constante. Já nas configurações 3C e $4 \mathrm{C}$ o contexto com o foco do usuário foi desenhado em tamanho completo, enquanto que outro contexto foi minimizado. As teclas do contexto com o foco do usuário e a ponte ficaram com tamanho constante ao longo do experimento todo. A ponte foi utilizada para mostrar os caracteres alfanuméricos selecionados.

As teclas ganhavam o foco quando o usuário fixava o olhar nelas por pelo menos $150 \mathrm{~ms}$. O tempo máximo para trocar de contexto (ou seja, a duração máxima da transição de um contexto para o outro) foi de $450 \mathrm{~ms}$ nas configurações 2C e 3C e de $550 \mathrm{~ms}$ na configuração 4C (devido a que na média essa configuração requer de sacadas mais longas para trocar de contextos).

O contexto com o foco do usuário foi desenhado com uma borda verde. As teclas não selecionadas 


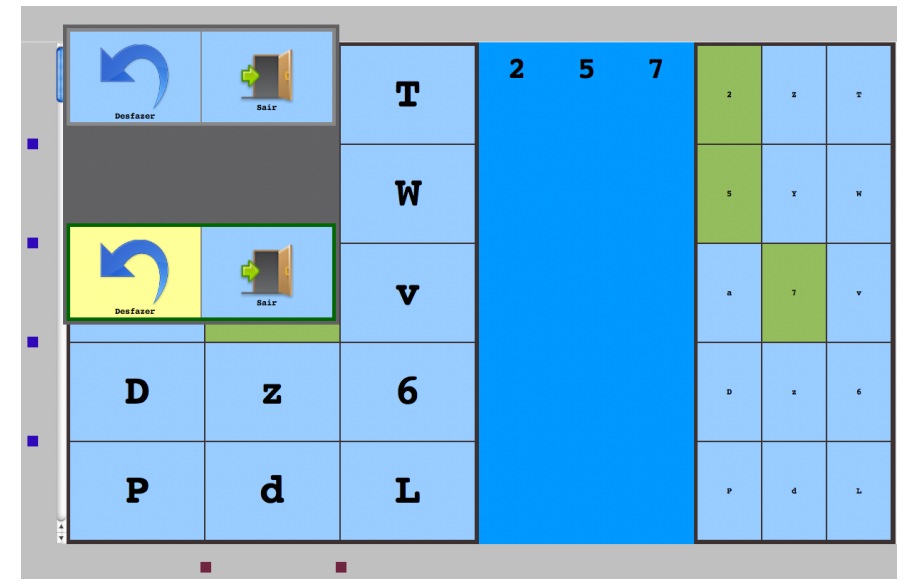

Figura 5.3: Menu ativado meta-keys localizados à direita ou esquerda dos contextos para iniciar e finalizar cada teste, e também para desfazer a última seleção.

foram desenhadas com um fundo azul claro. Uma tecla azul virava amarela quando recebia o foco do usuário, indicando que podia ser selecionada. As teclas selecionadas eram desenhadas com um fundo verde. Para apagar uma seleção incorreta, o usuário precisava apenas selecionar a mesma tecla de novo. Uma tecla selecionada como o foco do usuário era desenhada com um fundo laranja, indicando que era possível apagá-la.

Meta-keys colocados a esquerda e a direita dos contextos foram usadas para ativar um menu secundário para iniciar/finalizar o experimento e também para desfazer a última seleção, como mostrado na figura 5.3. Já os meta-keys colocados acima e abaixo dos contextos foram usados para navegar pelas páginas da interface. Por exemplo, para ir até a página anterior o participante começava olhando dentro de um dos contextos, depois olhava para um dos marcadores acima do contexto, e na sequência olhava de volta para o mesmo contexto, mas dessa vez para uma coluna vizinha da que iniciou o gesto. Os marcadores mudavam de cor quando o usuário olhava para eles, como forma de feedback visual.

\section{Design experimental}

O estudo foi intra-sujeito, pois todos os participantes usaram cada uma das três configurações definidas. A ordem de apresentação das interfaces para cada participante foi variada de acordo com um design de quadrado latino. A tarefa foi selecionar todos os dígitos existentes em um conjunto de caracteres alfanuméricos (letras maiúsculas e minúsculas do alfabeto inglês). A tarefa foi escolhida assim para reduzir a carga cognitiva dos participantes durante o experimento, de forma que eles pudessem se focar na interação.

Cada teste foi formado por um total de 120 caracteres alfanuméricos. Para fazer os participantes navegarem todas as páginas usando meta-keys, o número total de dígitos em cada teste foi escolhido de forma aleatória no intervalo [18, 28], correspondente a 15\%-25\% do total de caracteres alfanuméricos no conjunto.

Antes de começar o experimento todos os participantes assinaram o termo de consentimento livre e esclarecido e depois foram introduzidos ao experimento. Logo após a introdução houve uma sessão de treinamento de 10 minutos. Os participantes foram instruídos a selecionar todos os dígitos o mais rápido possível, cuidando sempre de não deixar dígitos sem selecionar. Cada sessão, incluindo 
o treinamento, foi iniciada com a calibração do rastreador de olhar. O processo de calibração foi repetido até conseguir uma precisão razoável, a nosso critério.

Após a sessão de treinamento, os participantes fizeram 6 sessões de aproximadamente 15 minutos cada. Em cada sessão os participantes fizeram 9 testes, 3 para cada configuração $(2 \mathrm{C}, 3 \mathrm{C}$ e $4 \mathrm{C})$. Entre uma sessão e a próxima houve um descanso de pelo menos 30 minutos, portanto a maioria dos participantes levaram entre 2 e 3 dias para completar todas as sessões. Nos casos de perda da calibração, o rastreador foi recalibrado e o teste repetido. No fim do experimento os participantes preencheram um questionário para recolher as suas avaliações subjetivas.

\section{Análise dos dados}

A precisão e a revocação são métricas usadas para avaliar o cuidado com que os participantes realizam uma tarefa de busca. Para cada teste do experimento, seja TP o conjunto de dígitos selecionados (verdadeiros positivos), FP o conjunto de letras (não dígitos) que foram selecionados (falsos positivos) e $F N$ o conjunto de dígitos que foram esquecidos (falsos negativos). A precisão e a revocação são definidos como sendo:

$$
\begin{aligned}
\text { precisão } & =\frac{|T P|}{|T P|+|F P|} \cdot 100 \\
\text { revocação } & =\frac{|T P|}{|T P|+|F N|} \cdot 100
\end{aligned}
$$

O desempenho global de cada método pode ser comparado usando o tempo total da tarefa, que é calculado desde a seleção da tecla "Começar" até a seleção da tecla "Fim". Como cada teste tem um número aleatório de dígitos, esse tempo é dividido pelo total de dígitos selecionados no teste, sem considerar os falsos positivos. O tempo médio de tarefa (ATT, do inglês average task time) é definido como:

$$
A T T=\frac{\text { tempo total da tarefa }}{|T P|}
$$

Como os usuários tinham que navegar por várias páginas durante cada teste, podemos assumir que a duração de um teste é igual a soma do tempo dedicado a selecionar os dígitos mais o tempo que levou para mudar de páginas. Portanto, é possível separar o tempo de seleção do tempo de navegação.

Seja $V P$ o conjunto de páginas visitadas durante um dado teste. Para cada página em $V P$, o tempo de seleção é definido desde o instante em que a página foi mostrada até a última seleção dentro dessa página. Como dentro de cada página podemos ter um número diferente de seleções, então definimos o tempo de seleção por dígito ( $S T P D$, do inglês selection time per digit) como sendo o tempo de seleção dividido pelo número de dígitos selecionados dentro de cada página, sem considerar os falsos positivos. O tempo médio de seleção ( $A S T$, do inglês average selection time), ou seja, o tempo necessário para fazer apenas uma seleção (sem considerar o tempo de navegação) para cada método do experimento é definido como:

$$
A S T=\frac{1}{|\mathrm{VP}|} \sum_{p \in \mathrm{VP}} S T P D_{p}
$$




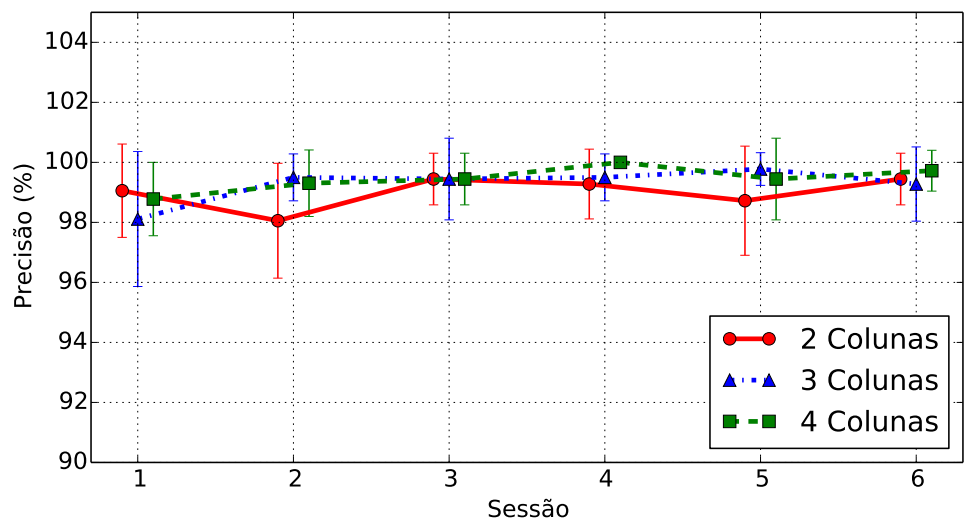

Figura 5.4: Média e um desvio padrão de 6 participantes para precisão, para as configurações $2 C, 3 C$ e 4 C.

Para cada página em $V P$, o tempo de navegação é calculado desde a última seleção dentro da página até a execução do meta-key para mudar de página. O tempo médio de navegação ( $A P T$, do inglês average paging time), ou seja, o tempo médio utilizado para navegar por todas as páginas para cada método, é definida como:

$$
A P T=\frac{1}{|\mathrm{VP}|} \sum_{p \in \mathrm{VP}} \text { tempo de navegação } \mathrm{o}_{p}
$$

\subsubsection{Resultados do experimento 1}

Cada teste ANOVA reportado a seguir foi precedido por um teste de esfericidade de Mauchly. Nos casos de violação da condição de esfericidade, os graus de liberdade e o valor de $\mathrm{p}$ foram corrigidos pelo método de Greenhouse-Geisser, pois em tais casos a estimação da esfericidade $(\epsilon)$ foi sempre menor que 0.75 .

Os resultados para precisão e revocação são mostrados na figuras 5.4 e 5.5 respectivamente. Para cada sessão (eixo horizontal) calculamos a média utilizando os dados dos 6 participantes para cada configuração (2C, 3C e 4C), mostrando também o erro equivalente a um desvio padrão.

A média da precisão ficou acima de $98 \%$ enquanto que a média de revocação ficou acima de $94 \%$ ao longo de todas as sessões para todos os métodos. Um teste ANOVA de medições repetidas não mostrou diferenças significativas entre as três configurações nem para precisão, $\mathrm{F}(1.08,5.4)=1.55$, $\mathrm{p}=0.27$, nem para revocação, $\mathrm{F}(2,10)=0.39, \mathrm{p}=0.68$.

A média do tempo médio de navegação para os 6 participantes é mostrada na figura 5.6. Como pode ser observado, a configuração $4 \mathrm{C}$ teve um $A P T$ maior que $2 \mathrm{C}$ e $3 \mathrm{C}$. Um teste ANOVA de medições repetidas mostrou um efeito principal significativo de configuração no $A P T$, $\mathrm{F}(2,10)=18.9, \mathrm{p}<0.001$. Um teste post-hoc com correção Bonferroni mostrou que o APT na configuração $4 \mathrm{C}$ foi significativamente maior que nas configurações $2 \mathrm{C}$ e $3 \mathrm{C}$, com valores de $\mathrm{p}$ de 0.023 e 0.0074 respectivamente. Não houve diferença significativa entre $2 \mathrm{C}$ e $3 \mathrm{C}, \mathrm{p}=0.31$.

A figura 5.7 mostra o tempo médio de seleção, calculado a partir dos dados dos 6 participantes para as três configurações. Como pode ser observado, a configuração $4 \mathrm{C}$ teve um $A S T$ maior que as outras duas configurações, enquanto que $2 \mathrm{C}$ e $3 \mathrm{C}$ tiveram $A S T$ s similares. Um teste ANOVA de medições repetidas mostrou um efeito principal significativo de configuração no $A S T$, $\mathrm{F}(1.08,5.4)=19.6, \mathrm{p}=0.0054$. Um teste post-hoc com correção Bonferroni mostrou que o AST na 


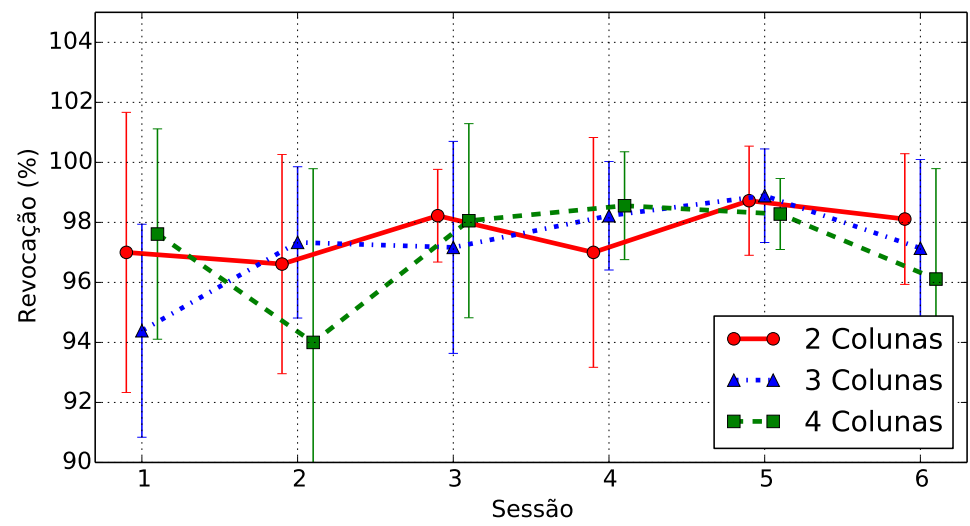

Figura 5.5: Média e um desvio padrão de 6 participantes para revocação, para as configurações $2 C$, 3C e $4 C$.

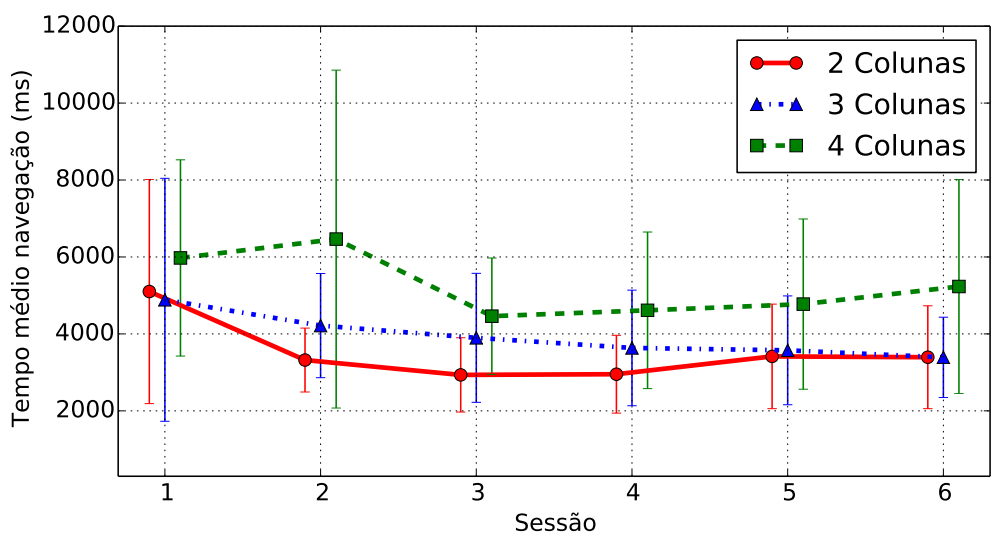

Figura 5.6: Média e um desvio padrão de 6 participantes para tempo médio de navegação, para as configurações $2 C, 3 C$ e $4 C$.

configuração 4C foi significativamente maior que nas configurações $2 \mathrm{C}(\mathrm{p}=0.028)$ e $3 \mathrm{C}(\mathrm{p}<0.001)$. Não houve diferença significativa entre $2 \mathrm{C}$ e $3 \mathrm{C}, \mathrm{p}=1.0$.

Em relação ao tempo médio de tarefa, a média e um desvio padrão dos seis participantes para as três configurações é mostrada na figura 5.8. A configuração $2 \mathrm{C}$ mostrou o maior ATT em 4 das 6 sessões, enquanto que a configuração $3 \mathrm{C}$ teve o menor $A T T$ em todas as 6 sessões. Um teste ANOVA de medições repetidas mostrou um efeito principal significativo de configuração no $A T T, \mathrm{~F}(2,10)$ $=13.6, \mathrm{p}=0.0014$. Um teste post-hoc com correção Bonferroni mostrou que o ATT a configuração $3 \mathrm{C}$ foi significativamente menor que nas configurações $2 \mathrm{C}(\mathrm{p}=0.0096)$ e $4 \mathrm{C}(\mathrm{p}=0.02)$. Não houve diferença significativa entre as configurações $2 \mathrm{C}$ e $4 \mathrm{C}, \mathrm{p}=0.64$.

\subsubsection{Discussão do experimento 1}

Os resultados de precisão e revocação mostram que os participantes foram igualmente cuidadosos com todas as configurações durante o experimento, como pode ser observado nas figuras 5.4 e 5.5 respectivamente. Os valores de precisão muito perto de $100 \%$ implica que durante o experimento a maioria das teclas selecionadas foram dígitos. O erro mais frequente foi a letra "a" minúscula, tendo sido selecionada 2 vezes pelo participante 2 e uma vez pelo participante 4 respectivamente. Os valores de revocação foram um pouco inferiores aos de precisão, o que implica que durante o 


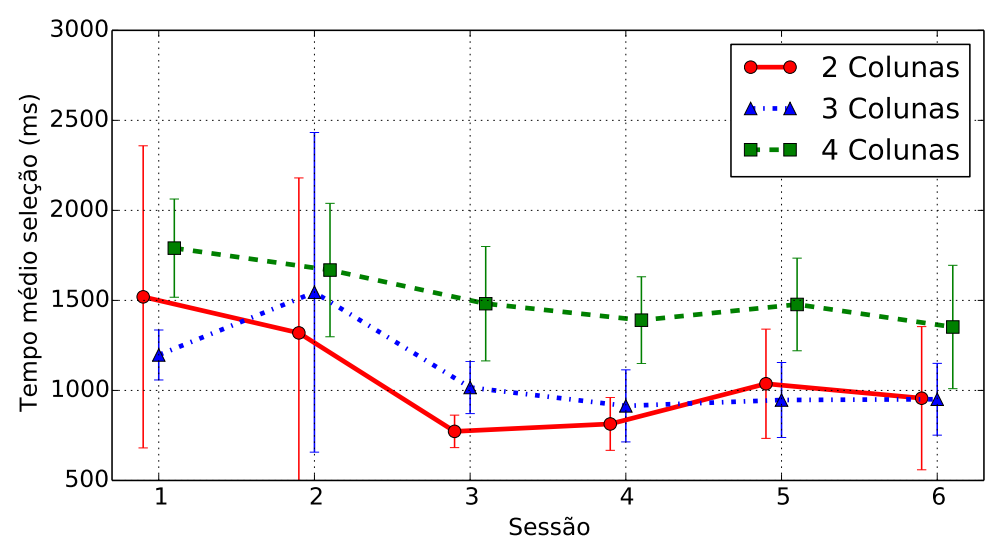

Figura 5.7: Média e um desvio padrão de 6 participantes para tempo médio de seleção, para as configurações $2 C, 3 C$ e $4 C$.

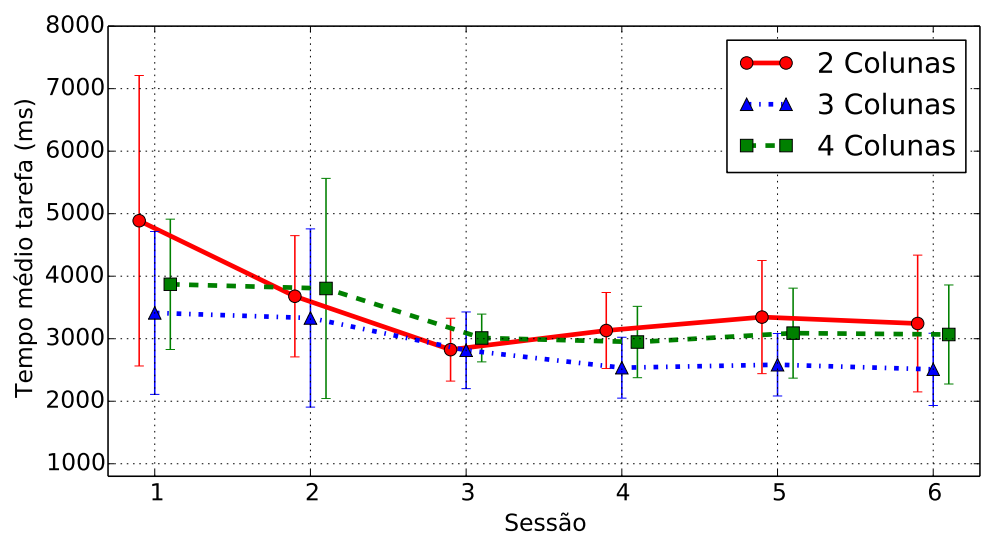

Figura 5.8: Média e um desvio padrão de 6 participantes para tempo médio de tarefa, para as configurações $2 C, 3 C$ e $4 C$.

experimento foi mais fácil esquecer um dígito do que selecionar uma letra.

Como pode ser observado na figura 5.6, nas configurações $2 \mathrm{C}$ e $3 \mathrm{C}$ os participantes demoraram entre 3.5-4 seg para mudar de página, enquanto que na configuração $4 \mathrm{C}$ esse tempo foi de aproximadamente 5 segundos. Devido a que o tempo de navegação foi calculado desde a última seleção dentro de cada página até a ativação do meta-key, esse diferença no APT é esperada pois os participantes geralmente faziam uma última varredura antes de mudar de página, buscando dígitos não selecionados. Portanto, nas configurações $2 \mathrm{C}$ e $3 \mathrm{C}$ os participantes podiam usar a visão periférica para varrer o contexto de uma passada só, o que não pôde ser feito com $4 \mathrm{C}$, devido ao maior número de colunas.

Se considerarmos apenas o tempo necessário para fazer uma seleção, os valores de $A S T$ para $2 \mathrm{C}$ e $3 \mathrm{C}$ foram significativamente menores que para $4 \mathrm{C}$, como pode ser observado na figura 5.7. Essa diferença é esperada devido a que na configuração 4C são necessárias sacadas mais longas para trocar de contextos. Esse resultado também é consistente com as entrevistas. Como mostrado na tabela 5.1, 3 participantes escolheram as configurações $2 \mathrm{C}$ e $3 \mathrm{C}$ como as mais rápidas. Podemos observar também que a configuração $2 \mathrm{C}$ foi considerada a mais confortável por 4 participantes e a $3 \mathrm{C}$ por dois participantes. A configuração $2 \mathrm{C}$ foi percebida como a mais simples de usar dentre as três. 
Tabela 5.1: Impressões subjetivas dos participantes em relação a velocidade percebida e conforto

\begin{tabular}{cccc}
\hline \hline & 2 colunas & 3 colunas & 4 colunas \\
\hline Percebido como mais rápido & 3 & 3 & 0 \\
Mais confortável & 4 & 2 & 0 \\
\hline
\end{tabular}

A métrica do tempo médio de tarefa reflete o desempenho global dos participantes, considerando o tempo de seleção e de navegação. A figura 5.8 mostra que a configuração $3 \mathrm{C}$ teve um ATT menor que as outras duas configurações. A configuração 3C apresenta um melhor balanço entre número de teclas em cada contexto e número de mudanças de página necessárias para navegar a coleção inteira. Isso indica que o balanceamento desses dois fatores poderia resultar em um melhor desempenho em tarefas de navegação e busca, similares à usada nesse experimento.

\section{Avaliação subjetiva da alternância entre contextos dinâmicos e dos meta-keys}

No fim do experimento os participantes responderam quão fácil foi selecionar por troca de contextos e ativar os meta-keys. Em uma escala de Likert de 1 (muito difícil) até 5 (muito fácil), a média para seleção foi de 4.7, ou seja, os participantes acharam muito fácil fazer seleções pela alternância entre contextos. Nenhum dos participantes mostrou desorientação pela mudança dinâmica dos contextos, o que poderia ser explicado pelo mecanismo de supressão sacádico (Bridgeman et al., 1975). Tal mecanismo estabelece que durante uma sacada, os olhos não percebem se um estímulo visual se deslocou do seu lugar ou não.

A ativação de meta-keys na direção vertical recebeu 2.8 para cima e 3.0 para baixo, portanto a maioria dos participantes acharam razoável ou fácil de usar. Já os meta-keys feitos para a direita receberam 2.4 e para a esquerda 2.6. A melhor pontuação dos meta-keys para navegação pode ser devido a que os participantes os usaram com mais frequência, portanto tiveram mais tempo para aprender a executá-los.

Os participantes também deram sua impressão subjetiva sobre as interfaces usadas no experimento. Um participante, sem experiência na área de interação pelo olhar, disse que as vezes ele tinha que olhar para fora da tela para ativar os meta-keys. Para facilitar a seleção dos meta-keys, a distância entre os marcadores e o contexto (ou seja, a ponte) poderia ser maior, para tolerar melhor o erro na estimação do olhar do rastreador.

Outro participante, experiente nas áreas de rastreamento de olhar e interação pelo olhar, disse que as configurações com duas e três colunas foram mais confortáveis que com 4 colunas. Ele mencionou também que a busca por dígitos com $4 \mathrm{C}$ é menos eficiente, pois com $2 \mathrm{C}$ e $3 \mathrm{C}$ é possível usar a visão periférica para explorar rapidamente o conteúdo das teclas. Em relação aos meta-keys, esse participante disse que no começo sentiu alguma dificuldade, mas depois das primeiras sessões aprendeu a executar os gestos normalmente. Ele também mencionou o fato da distância entre os contextos e os marcadores ser relativamente pequena, o que requer de uma calibração mais precisa para ativar os meta-keys. 


\subsection{Experimento 2: comparando os contextos com tamanho fixo e dinâmico com seleção por tempo de latência}

Os resultados do experimento 1 mostraram que a alternância entre contextos dinâmicos pode melhorar o desempenho em tarefas de navegação e busca, devido ao melhor aproveitamento da área último do monitor. O experimento mostrou também que sacadas muito longas podem não ser confortáveis, como na configuração com 4 colunas.

O objetivo do experimento 2 é avaliar o uso de seleção por tempo de latência na mesma tarefa de seleção e navegação, para comparar os resultados com a alternância entre contextos dinâmicos em termos de desempenho e taxa de erros.

\subsubsection{Método}

\section{Participantes}

Um total de 5 voluntários participaram nesse experimento, todos capazes, com visão normal ou corrigida para normal usando óculos ou lentes de contato. Dos 5 voluntários, 3 participaram no experimento 1 , enquanto que os outros 2 nunca tinham participado em estudos usando rastreadores de olhar. Todos os voluntários eram estudantes ou pesquisadores da Universidade de São Paulo, com idades entre 30 e 47 anos e pelo menos 10 anos de experiência usando computadores.

\section{Equipamentos}

O rastreador de olhar utilizado nesse estudo foi o SMI RED500, com uma frequência de $500 \mathrm{~Hz}$ e uma acurácia entre 0.5-1 grau de ângulo visual. Similar ao experimento 1, um apoio de queixo foi usado para reduzir os movimentos de cabeça dos participantes.

O experimento teve apenas uma configuração baseada no tempo de latência, com um contexto contendo 6 colunas e 5 linhas de teclas, como mostrado na figura 5.9. Essa configuração tem o dobro de teclas que a configuração de contextos dinâmicos com 3 colunas, que mostrou o melhor desempenho no experimento 1. As teclas tinham o mesmo tamanho que no experimento 1.

Inicialmente fizemos alguns testes para escolher o tempo de latência para selecionar as teclas. Os testes iniciais mostraram que um tempo de latência de $500 \mathrm{~ms}$, que é muito comum na literatura (Majaranta e Räihä, 2007), era muito curto para executar os meta-keys sem selecionar outras teclas no contexto. Assim, escolhemos um tempo de latência de $700 \mathrm{~ms}$.

$\mathrm{Na}$ tecla com o foco do usuário foi desenhada uma barra de progresso para indicar o andamento da seleção. Quando a barra chega no fim, a tecla é selecionada (ou apagada, caso já tivesse sido selecionada antes). Para interromper uma seleção em andamento, o usuário tinha que olhar para uma outra tecla ou para fora do contexto. A navegação usando meta-keys foi feita de forma similar ao experimento 1 .

\section{Design experimental}

A tarefa foi similar ao experimento 1: os participantes tinham que selecionar todos os dígitos o mais rápido e com a maior precisão possível. Com 5 linas e 6 colunas, todos os 120 caracteres alfanuméricos foram distribuídos em 4 páginas de 30 caracteres cada. Igual ao experimento 1, o número de dígitos em cada teste foi escolhido de forma aleatória no intervalo [18, 28]. 


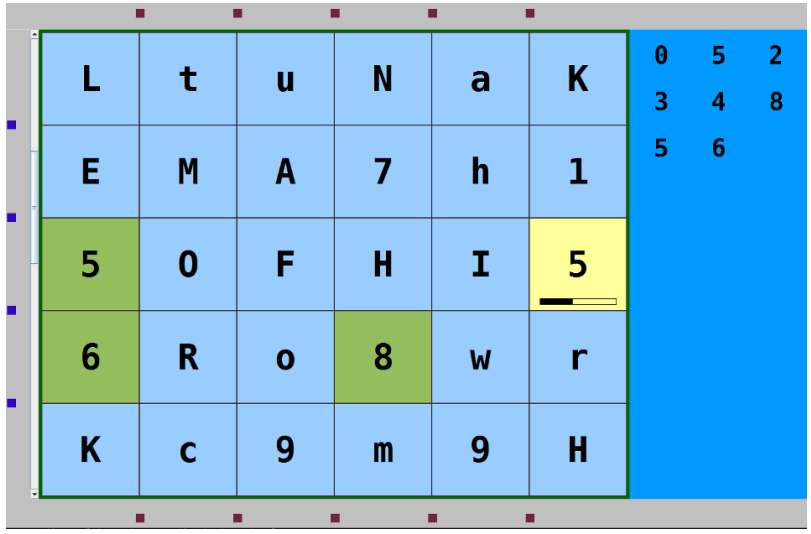

Figura 5.9: Interface baseada no tempo de latência usada no experimento 2.

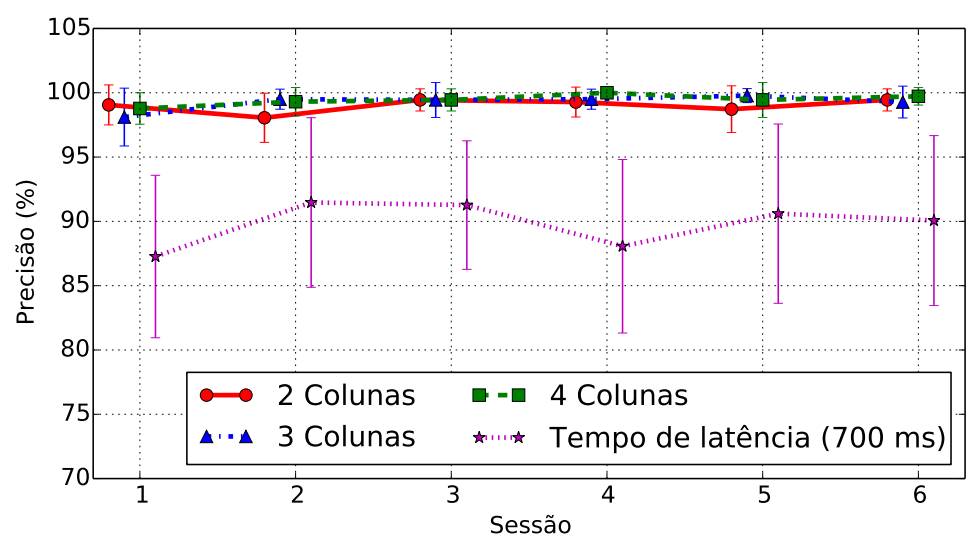

Figura 5.10: Média e um desvio padrão para precisão, para o tempo de latência e a alternância entre contextos dinâmicos.

Todos os participantes completaram as 6 sessões no mesmo dia. Em cada sessão os participantes executaram 3 testes, com um descanso de pelo menos 5 minutos entre cada sessão.

\subsubsection{Resultados do experimento 2}

As figuras 5.10 e 5.11 mostram os resultados para precisão e revocação, respectivamente. Para cada sessão (eixo horizontal) calculamos a média dos 5 participantes para o tempo de latência, mostrando também o erro equivalente a um desvio padrão. Os resultados do experimento 1 foram incluídos nesses gráficos para fins de comparação.

Como pode ser observado na figura 5.10, a precisão no tempo de latência foi consistentemente menor que em todas as configurações baseadas na alternância entre contextos dinâmicos, ao longo de todas as sessões. Um teste de Welch para dados não emparelhados mostrou uma diferença significativa entre o tempo de latência e $2 \mathrm{C}, \mathrm{t}(4.37)=4.43, \mathrm{p}=0.0093$. Também significativa foi a diferença entre o tempo de latência e $3 \mathrm{C}, \mathrm{t}(4.26)=4.6, \mathrm{p}=0.0087$, e entre o tempo de latência e $4 \mathrm{C}, \mathrm{t}(4.13)=4.72, \mathrm{p}=0.0085$.

O resultado de revocação no tempo de latência também foi inferior à alternância entre contextos dinâmicos, diferença que foi mais pronunciada nas 4 últimas sessões. Um teste de Welch para dados não emparelhados mostrou que a revocação foi significativamente menor no tempo de latência comparado com $2 \mathrm{C}, \mathrm{t}(5.11)=2.98, \mathrm{p}=0.042$. A diferença entre o tempo de latência e $3 \mathrm{C}$ foi 


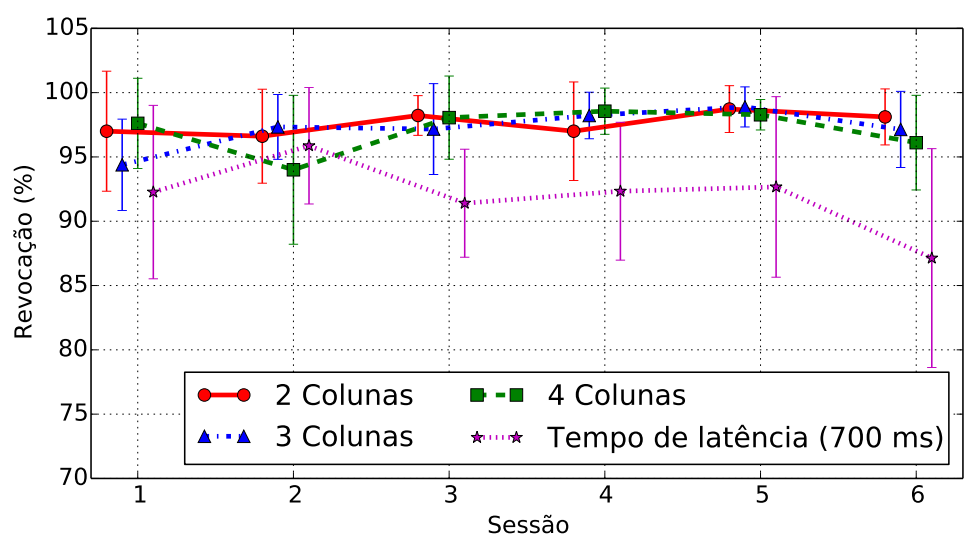

Figura 5.11: Média e um desvio padrão para revocação, para o tempo de latência e a alternância entre contextos dinâmicos.

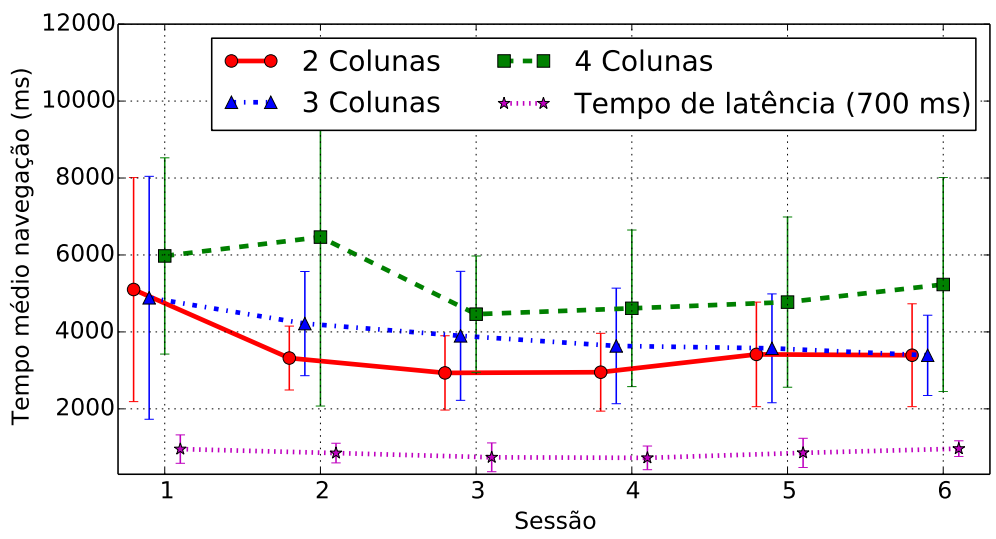

Figura 5.12: Média e um desvio padrão para tempo médio de navegação, para o tempo de latência e a alternância entre contextos dinâmicos.

significativa, mas o valor de $\mathrm{p}$ ficou no limiar de significância estatística, $\mathrm{t}(4.87)=2.52, \mathrm{p}=0.05$. A diferença entre o tempo de latência e $4 \mathrm{C}$ também foi significativa, mas o valor de p ficou no limiar de significância estatística, $\mathrm{t}(5.28)=2.42, \mathrm{p}=0.05$.

Os resultados para o tempo médio de navegação são mostrados na figura 5.12 como uma linha pontilhada. Os resultados do experimento 1 também forma incluídos para comparação. Como pode ser observado nessa figura, o $A P T$ no tempo de latência foi menor que nas configurações baseadas na alternância entre contextos dinâmicos. Um teste de Welch para dados não emparelhados mostrou que essa diferença entre o tempo de latência e $2 \mathrm{C}$ foi significativa, $\mathrm{t}(5.37)=5.57, \mathrm{p}=0.0021$, também entre o tempo de latência e $3 \mathrm{C}, \mathrm{t}(5.2)=4.72, \mathrm{p}=0.0047$, e também entre o tempo de latência e $4 \mathrm{C}, \mathrm{t}(5.12)=5.23, \mathrm{p}=0.0032$.

Os resultados do tempo médio de seleção são mostrados na figura 5.13 como uma linha pontilhada. Também foram incluídos os resultados do experimento 1. Como pode ser observado, no tempo de latência o AST foi maior que nas configurações $2 \mathrm{C}, 3 \mathrm{C}$ e $4 \mathrm{C}$ ao longo de todas as sessões. Um teste Welch para dados não emparelhados mostrou que o $A S T$ foi significativamente maior no tempo de latência comparado com $2 \mathrm{C}, \mathrm{t}(7.07)=3.19, \mathrm{p}=0.015$. A diferença entre o tempo de latência e $3 \mathrm{C}$ também foi significativa, $\mathrm{t}(6.14)=3.26, \mathrm{p}=0.017$. No entanto, a diferença entre o tempo de latência e $4 \mathrm{C}$ não foi significativa, $\mathrm{t}(6)=1.38, \mathrm{p}=0.22$. 


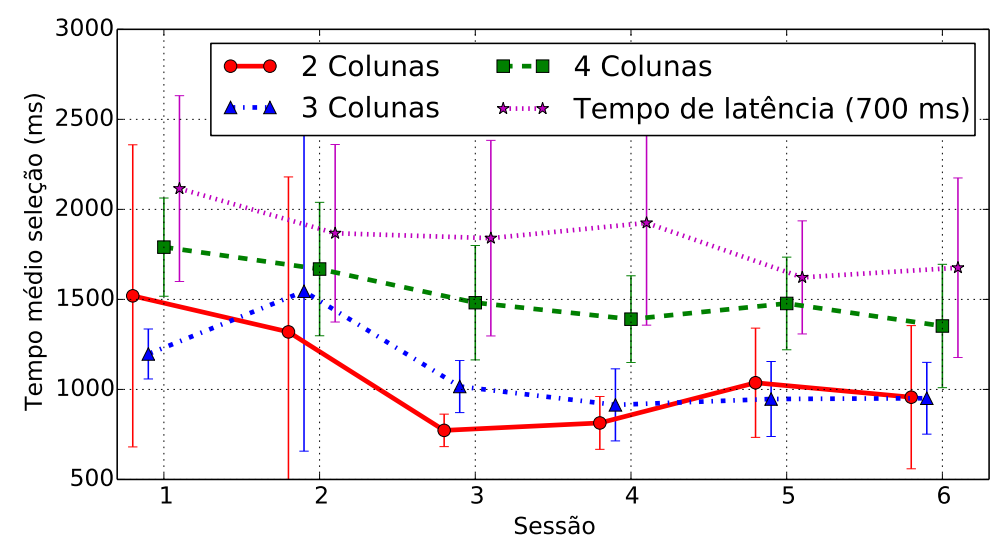

Figura 5.13: Média e um desvio padrão para tempo médio de seleção, para o tempo de latência e a alternância entre contextos dinâmicos.

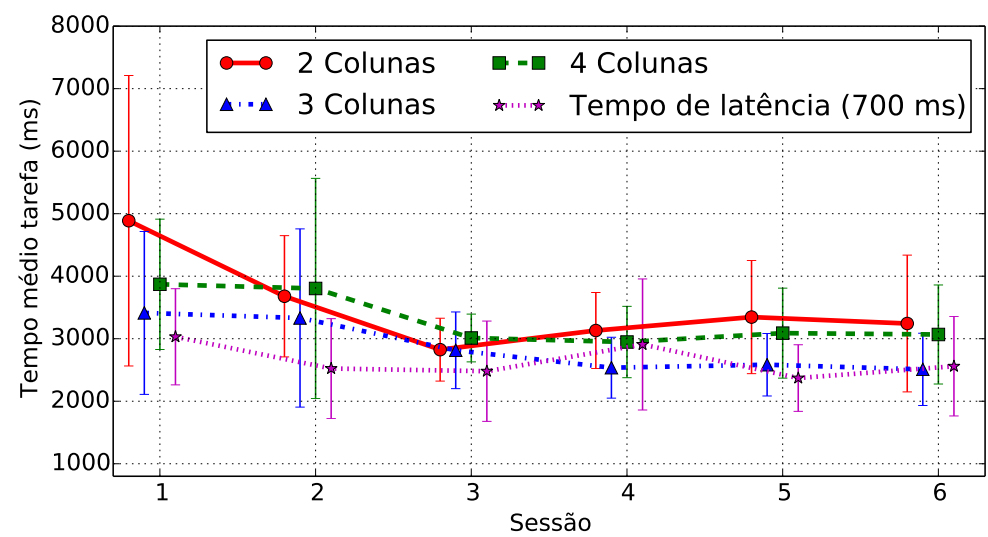

Figura 5.14: Média e um desvio padrão para tempo médio de tarefa, para o tempo de latência e a alternância entre contextos dinâmicos.

Os resultados do tempo médio de tarefa são mostrados na figura 5.14 (linha pontilhada), junto com os resultados do experimento 1. Como pode ser observado, o ATT no tempo de latência foi similar à configuração $3 \mathrm{C}$ e um pouco menor que as configurações $2 \mathrm{C}$ e $3 \mathrm{C}$. Testes Welch para dados não emparelhados não mostraram diferença significativa entre o tempo de latência e $2 \mathrm{C}, \mathrm{t}(8.93)=$ $1.84, \mathrm{p}=0.1$, nem entre o tempo de latência e $3 \mathrm{C}, \mathrm{t}(8.55)=0.55, \mathrm{p}=0.6$, e nem entre o tempo de latência e $4 \mathrm{C}, \mathrm{t}(8.8)=1.56, \mathrm{p}=0.15$.

\subsubsection{Discussão sobre a comparação entre o tempo de latência e a alternância entre contextos dinâmicos}

Os resultados do experimento 2 tem mostrado alguns pontos interessantes quando comparados com os resultados do experimento 1, que são discutidos a seguir.

Os resultados de precisão e revocação significativamente menores no tempo de latência, quando comparados com a alternância entre contextos dinâmicos (figuras 5.10 e 5.11), são resultado do toque de Midas (Jacob, 1990). Durante a execução do experimento percebemos que alguns participantes, usando o tempo de latência, selecionaram letras acidentalmente (reduzindo assim a precisão) ou apagaram dígitos que já tinham sido selecionados (reduzindo a revocação) enquanto exploravam o contexto. Os participantes também cometiam erros durante a seleção dos meta-keys de navegação 
e durante a ativação do menu para encerrar cada teste, o que poderia explicar a menor precisão e revocação comparado com as configurações baseadas na alternância entre contextos. Na alternância entre contextos, o risco de uma seleção acidental é menor, pois para selecionar uma tecla o usuário tem que trocar de contextos, cruzando completamente a ponte.

O tempo médio de seleção maior observado no tempo de latência é esperado, pois os participantes tinham que esperar 700 ms para completar cada seleção. A diferença, na alternância entre contextos dinâmicos não há necessidade de esperar, pois a sacada para o outro contexto pode ser iniciada assim que a tecla observada ganhar o foco (o que demorava apenas $150 \mathrm{~ms}$ ). A latência para iniciar uma sacada, como mostramos no estudo do tempo de reação sacádico no capítulo 4, é em torno de 150-250 ms, e o movimento sacádico demora entre 50-100 ms. Resumindo, o tempo mínimo necessário para fazer uma seleção na alternância entre contextos dinâmicos é menor que o tempo de latência usado nesse experimento. Tempos de latência mais curtos poderiam reduzir o tempo médio de seleção, mas isso iria incrementar também o número de erros pelo toque de Midas.

$\mathrm{Na}$ configuração baseada no tempo de latência os participantes apresentaram um tempo de navegação menor comparado com as configurações baseadas na alternância entre contextos dinâmicos. A princípio esse resultado é inesperado, pois um maior número de teclas no contexto implica que a última varredura para buscar dígitos deveria demorar mais. Uma possível explicação é que durante a ativação dos meta-keys de navegação, os participantes selecionavam teclas por acidente, como descrito no começo dessa discussão. Como o tempo de navegação foi calculado desde a última seleção dentro de cada página até a ativação do meta-key, então uma seleção por acidente justo antes de ativar o meta-key reduziria o tempo de navegação.

Finalmente, é interessante ressaltar que o tempo médio de tarefa foi similar tanto para o tempo de latência quanto para a alternância entre contextos dinâmicos (figura 5.14), pois não houve diferença significativa entre os dois métodos. Isto implica que, embora fazer uma seleção com a alternância entre contextos dinâmicos seja mais rápido que com o tempo de latência, a ativação menos frequente dos meta-keys de navegação no tempo de latência (devido ao maior número de teclas no contexto) acabou influenciando no desempenho global da tarefa.

\subsubsection{Comentários finais sobre alternância entre contextos dinâmicos e meta- keys}

Nesse capítulo propomos e avaliamos a alternância entre contextos dinâmicos para melhorar o uso do espaço no monitor, e também os meta-keys para estender a funcionalidade para outras tarefas, como navegação e ativação de menus secundários, entre outras.

Os resultados dos experimentos mostraram que a mudança dinâmica nos tamanhos dos contextos permite melhorar o desempenho em tarefas de seleção e navegação, sem provocar desorientação aos usuários, devido ao mecanismo de supressão sacádico. Usando contextos dinâmicos é possível colocar um número maior de teclas nos contextos para incluir caracteres adicionais no teclado virtual, como sinais de pontuação, acentos, dígitos entre outros. Além disso, caso a interface for usada com rastreadores de olhar de baixa precisão, as teclas poderiam ser maiores para tolerar melhor o erro na estimação do ponto observado.

Os resultados mostraram também que o uso de sacadas muito longas para alternar entre os contextos não é confortável, podendo inclusive piorar o desempenho, como na configuração com 4 colunas. 
Por outro lado, os meta-keys são extensões da alternância entre contextos que podem ser usados para navegação, mas também para ativação de comandos como gerenciamento de arquivos ou email.

Finalmente, comparamos o uso de contextos dinâmicos com seleção por tempo de latência, que é a forma de interação pelo olhar mais usada na literatura. Os resultados mostraram que para tarefas de busca, o tempo de latência tem um erro maior por causa do toque de Midas. Uma outra sugestão, de acordo com os resultados, é que misturar a seleção por tempo de latência com gestos do olhar pode aumentar o número de erros.

A descrição da alternância entre contextos dinâmicos foi publicada como um artigo resumido, intitulado Dynamic Context Switching for Gaze Based Interaction, no Symposium on Eye Tracking Research and Applications - ETRA 2012 (Tula et al., 2012). A descrição detalhada dos meta-keys foram publicados como artigo completo no XIII Simpósio Brasileiro Sobre Fatores Humanos em Sistemas Computacionais (Tula e Morimoto, 2014), sob o título Meta-keys: extending the functionality of gaze-based interaction. Um artigo estendido, abrangendo tanto os contextos dinâmicos e os meta-keys como a comparação com o tempo de latência, intitulado Dynamic and Meta-Context Switching for Gaze-Based Interaction, foi publicado no periódico SBC Journal on Interactive Systems (Diaz-Tula e Morimoto, 2015). 


\section{Capítulo 6}

\section{AugFix: uma interface para melhorar a velocidade e a experiência do usuário na digitação pelo olhar}

Como mencionado na introdução e na revisão bibliográfica (capítulo 2), um dos problemas na digitação pelo olhar é a baixa velocidade. Embora o uso de predição de palavras tenha o potencial de melhorar a velocidade (pelo fato de selecionar vários caracteres com apenas um toque), a necessidade de alternar o foco entre o teclado e a lista limita bastante o ganho obtido na prática. Além disso, o usuário precisa olhar repetidamente para a área de texto para detectar erros na digitação.

Com o objetivo de melhorar os mecanismos de aceleração em teclados virtuais utilizando predição de palavras, nós propomos um modelo de feedback que consiste em mostrar informação aumentada na tecla com o foco do usuário. O objetivo é que o usuário não precise deslocar o olhar da tecla focada para procurar informação sobre o estado da interface, pois a informação já se encontra na área da tecla focada. Chamamos este método de $\boldsymbol{A u g F i x}$, do inglês Augmented Fixation.

\section{Uso de sufixos}

No modelo proposto, a aceleração funciona como descrito em Majaranta (2009): a lista contem as palavras mais prováveis baseado no texto escrito até o momento. Quando o usuário foca o olhar em alguma tecla, o sistema gera novas predições considerando, além do texto escrito até esse instante, o conteúdo da tecla focada. Essas novas predições, porém, não são mostradas na lista de palavras, mas sim na área ao redor da tecla focada. Dessa forma, o usuário pode saber quais palavras estarão na lista caso a tecla com o foco for selecionada. Para facilitar a leitura das palavras na área focada pelo usuário, apenas os sufixos das palavras são mostrados. Se a tecla focada for selecionada, a lista de palavras é atualizada de acordo com os sufixos. Se a tecla focada não for selecionada, a lista de palavras fica sem mudanças. Assim, com o novo modelo de feedback, o sistema vai um passo a frente para que o usuário saiba como ficará a lista de palavras se a tecla com o foco for selecionada.

\section{Uso de prefixos}

Além dos sufixos, AugFix mostra os últimos caracteres digitados ao redor da tecla com o foco do usuário. Assim, o usuário pode ler esses caracteres para detectar erros na digitação, sem ter 
que olhar repetidamente para a área de texto. Quando o usuário está digitando uma nova palavra, esses caracteres correspondem ao "prefixo" da palavra que está sendo escrita. No caso da tecla de backspace, usada para apagar o último caractere, a interface mostra também os últimos caracteres selecionados, mas realçando os caracteres que serão apagados.

Na próxima sessão descrevemos duas interfaces para entrada de texto pelo olhar baseadas nos paradigmas de tempo de latência e alternância entre contextos com predição de palavras, que utilizam modelo de feedback proposto.

\subsubsection{Teclados virtuais com aceleração para entrada de texto pelo olhar base- ados em AugFix}

A figura 6.1a mostra um teclado controlado por tempo de latência com AugFix, quando o usuário está focando no "t". Durante a fixação no "t", o teclado mostra em laranja o prefixo formado pelos três últimos caracteres digitados (que na figura 6.1a correspondem a " no"). O teclado também mostra, em verde, o sufixo das três palavras que estarão na lista (que na figura 6.1 são "noticia", "noticias" e "na") caso o "t" for selecionado. Assim, durante o tempo de fixação o usuário pode ler a informação aumentada e saber se a palavra desejada estará na lista ou não. Na figura 6.1a a lista de palavras é mostrada do lado direito do teclado, contendo as três palavras mais prováveis segundo o texto escrito, sem considerar o "t". Escolhemos mostrar três palavras na lista de predições devido a limitações no espaço disponível em cada tecla virtual: um número maior de sufixos extrapolaria a área correspondente à tecla com o foco do usuário, aumentando a chance de selecionar teclas vizinhas durante a leitura dos sufixos.

Depois de selecionar o "t", a lista de palavras é atualizada, como mostrado na figura 6.1b. Nesse instante e graças ao sufixo, o usuário já sabe que a palavra "noticias" se encontra na lista, e então desloca o olhar para as predições para completar a palavra. No suposto que a palavra desejada não estivesse na lista, o usuário continuaria para o próximo caractere no teclado sem ter que escanear a lista buscando a palavra, melhorando assim o desempenho e reduzindo a carga cognitiva durante a digitação.

Quando o usuário seleciona uma palavra da lista, o teclado completa a palavra e adiciona automaticamente um espaço no fim da palavra completada. Esse espaço automático pode economizar até $20 \%$ de caracteres no texto, considerando que uma palavra tem na média 5 caracteres (Arif e Stuerzlinger, 2009).

A interface proposta pode ser usada também com a alternância entre contextos (Morimoto e Amir, 2010), como mostrado na figura 6.2. A figura 6.2a mostra o caso em que a tecla "g" tem o foco. Já a figura $6.2 \mathrm{~b}$ mostra o teclado depois que o usuário selecionou o "g" trocando de contextos, e está olhando para a tecla com a palavra "pergunta". Uma nova troca de contextos nesse estado completaria a palavra "pergunta".

\subsection{Experimento de entrada de texto pelo olhar usando AugFix}

Para avaliar o método AugFix proposto, realizamos um experimento de entrada de texto pelo olhar com dois teclados virtuais: tempo de latência e alternância entre contextos, e duas condições: com aceleração e sem aceleração. Nossa hipótese é que com AugFix, os usuários conseguem um maior desempenho e têm uma melhor experiência, comparado com os teclados sem aceleração. 


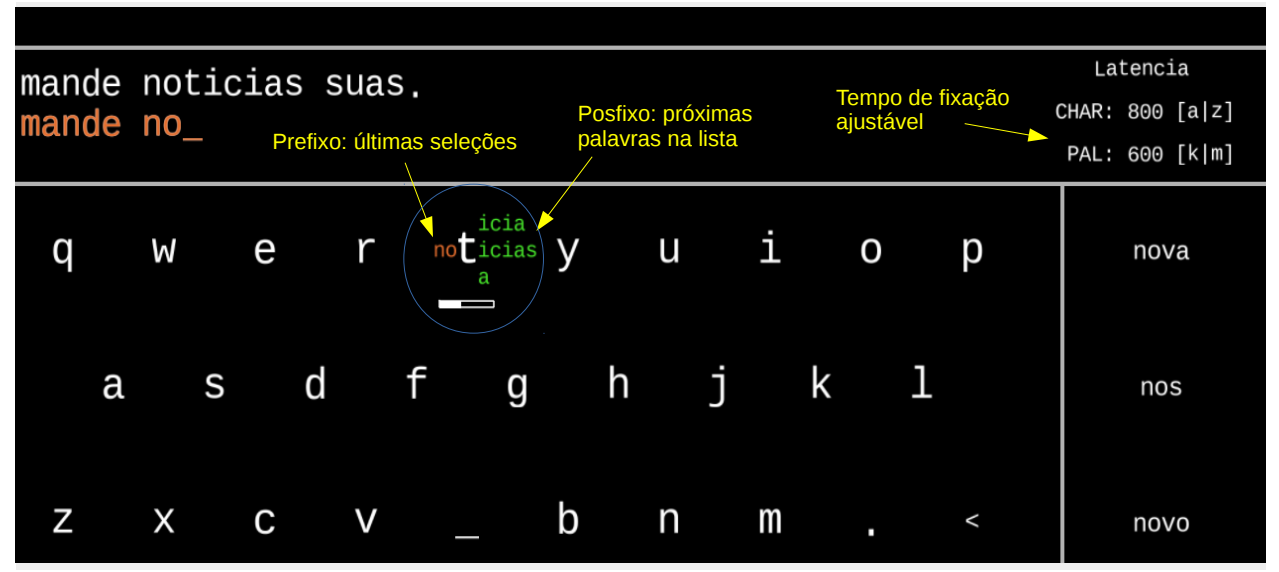

a) Durante a fixação no "t" o teclado mostra o prefixo "no" e as próximas palavras na lista.

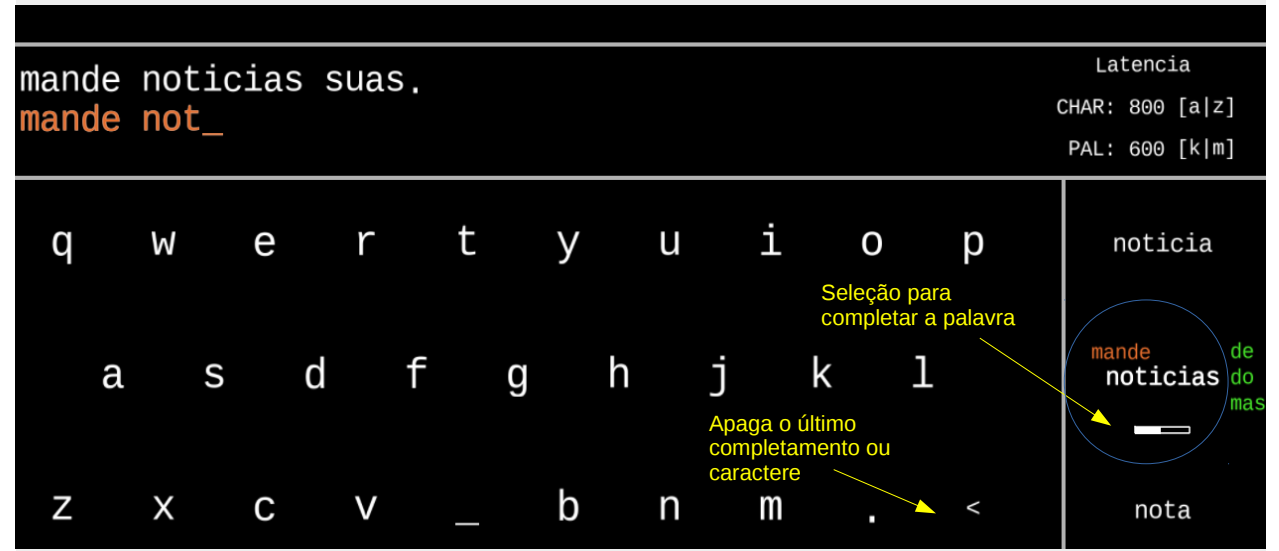

b) Após selecionar o "t" o usuário vá para a lista e completa a palavra "noticias".

Figura 6.1: Teclado virtual baseado no tempo de latência com o prefixo, sufixos e lista de palavras.

Existem vários fatores que podem influenciar os resultados de estudos de digitação pelo olhar. Como apontado por Rough et al. (2014), estudos de digitação pelo olhar precisam ter, além das novas técnicas que irão ser investigadas, uma condição de controle contra a qual comparar os resultados. O aprendizado é um outro fator, pois a diferença entre duas ou mais interfaces pode ficar evidente apenas depois de um certo tempo de uso.

Nos estudos que usam aceleração com modelos de linguagens, a qualidade das predições e o número de palavras mostradas são fatores que têm grande influência no resultado (Rough et al., 2014; Trnka et al., 2009; Tuisku et al., 2008). Por isso, no presente estudo queremos avaliar como o método de feedback baseado em AugFix permite aos usuários explorarem a aceleração, dentro dos limites estabelecidos pelo modelo da linguagem.

\subsubsection{Método}

\section{Participantes}

Sete pessoas participaram no experimento, todos com visão normal ou corrigida para normal usando lentes de contato ou óculos, com idade média de $32( \pm 7)$ anos. Seis participantes são fisicamente capazes, enquanto que um deles sofre de quadriplegia. Dois voluntários tinham participado 


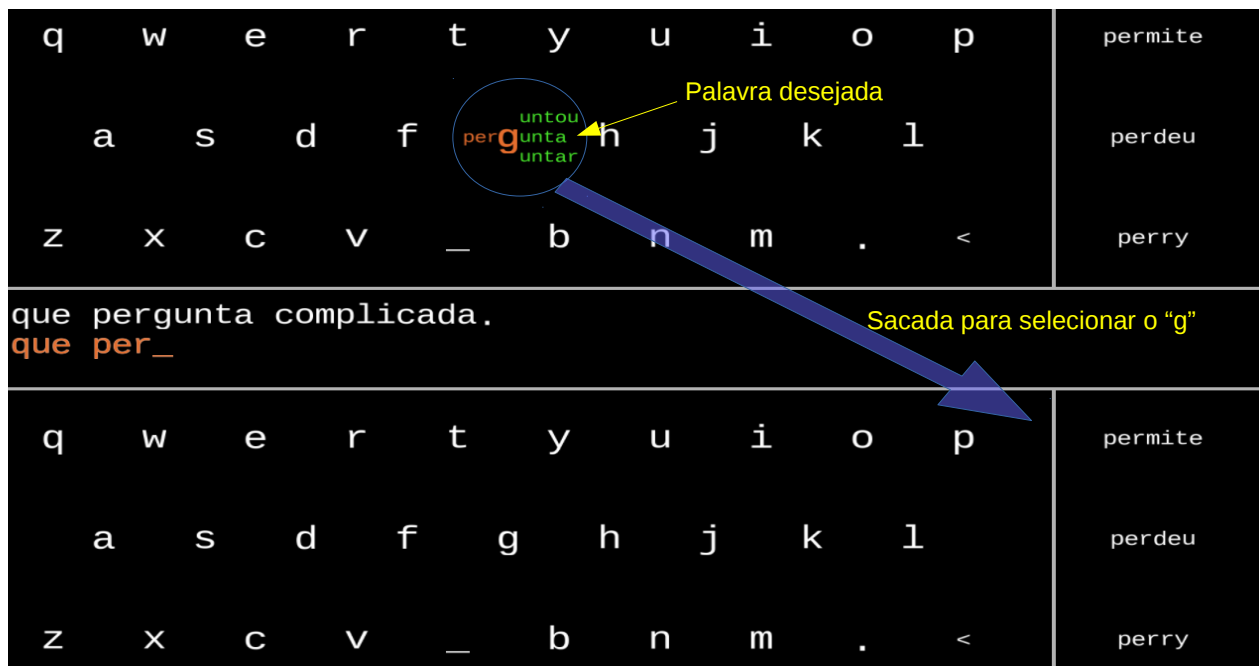

a) O usuário olha para o "g" e o teclado mostra o prefixo "per" e as próximas palavras na lista. A sacada para o outro contexto completa a seleção do "g".

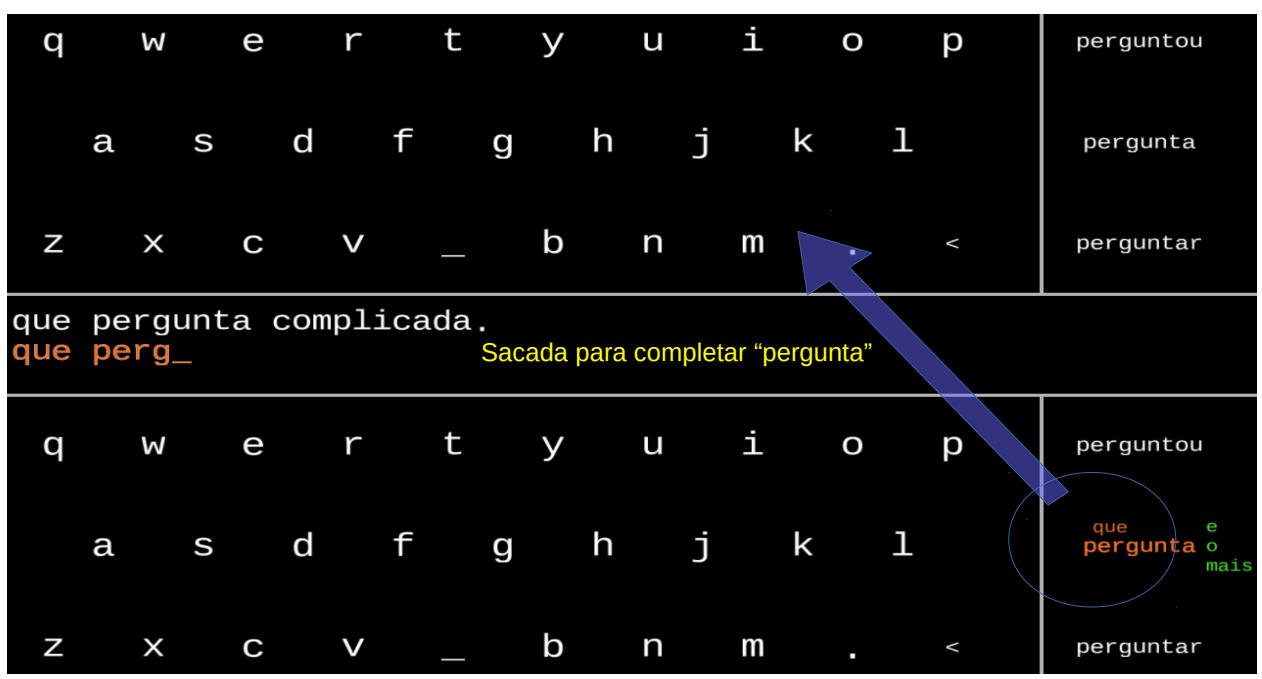

b) Usuário olha para a palavra desejada e troca novamente de contextos para selecioná-la.

Figura 6.2: Teclado virtual baseado na alternância entre contextos com o prefixo, sufixos e lista de palavras.

em outros estudos utilizando rastreadores de olhar, mas não de entrada de texto pelo olhar. O participante com necessidades especiais tinha participado em um experimento com um mouse ocular. Os restantes quatro participantes nunca tinham participado em estudos com rastreadores de olhar. Todos os participantes estavam familiarizados o leiaute QWERTY e tinham pelo menos 10 anos de experiência utilizando computadores. Três participantes têm como língua nativa o português, três o espanhol e um o inglês.

\section{Equipamentos e materiais}

Para rastrear os movimentos oculares usamos o rastreador de olhar remoto SMI RED500, que possui uma frequência de $500 \mathrm{~Hz}$. O rastreador está acoplado abaixo de um monitor LCD de 22 "com uma resolução de $1680 \times 1050$, utilizado para mostrar os teclados virtuais. O monitor foi colocado a aproximadamente $60 \mathrm{~cm}$ de distância dos olhos dos participantes. Um apoio de queixo foi utilizado 
durante o experimento para reduzir os movimentos de cabeça e assim evitar perdas da calibração. O experimento foi realizado em um laboratório com iluminação fluorescente, sem incidência direta da luz solar, como recomendado por Holmqvist et al. (2011).

\section{Implementação do software}

Os teclados virtuais foram desenvolvidos em $\mathrm{C}++$ e OpenGL. O teclado baseado em tempo de latência é mostrado na figura 6.1, enquanto que o teclado baseado na alternância entre contextos é mostrado na figura 6.2. Na versão sem aceleração, os teclados são similares aos mostrados nas figuras 6.1 e 6.2 mas eliminando o prefixo, sufixos e a lista de palavras.

As teclas virtuais têm tamanho $3,2 \times 3,2$ graus de ângulo visual para reduzir o efeito da inacurácia na estimação do olhar. Para facilitar a leitura da informação (prefixo e sufixos) mostrada na área da tecla focada, apenas o caractere de cada tecla foi desenhado, enquanto que as bordas e o interior das teclas foram desenhados com a mesma cor do fundo do teclado.

Em ambas interfaces, uma tecla ganha o foco quando o usuário fixar o olhar nela por pelo menos $50 \mathrm{~ms}$. No tempo de latência, assim que uma tecla ganhar o foco, uma barra de progresso é mostrada para indicar o andamento da fixação, sendo que a tecla é selecionada quando a barra chegar no fim. Nesse instante o caractere muda de cor (laranja) e um "click" é tocado no fone de ouvido. $\mathrm{Na}$ alternância entre contextos, quando uma tecla ganha o foco, ao invés de mostrar a barra de progresso, a tecla vira laranja indicando que é possível selecioná-la fazendo uma troca de contextos. Assim que o teclado detectar a troca de contextos, a tecla é selecionada e um "click" é tocado no fone de ouvido.

O comportamento da tecla backspace é similar em ambos teclados e funciona como descrito a seguir. Se a última ação do usuário foi completar uma palavra, então o backspace apaga o sufixo que foi adicionado ao texto escrito pelo usuário. Em qualquer outro caso, o backspace apaga o último caractere no texto escrito pelo usuário. Como descrito na seção 6, quando focada, a tecla backspace mostra os últimos caracteres selecionados, realçando aqueles que serão apagados.

A área de texto tem altura de 3,2 graus e é utilizada para mostrar a frase a ser escrita e o texto produzido pelo usuário. No teclado da alternância entre contextos, essa área serve como ponte entre os contextos superior e inferior, e deve ser cruzada completamente para fazer uma seleção por troca de contextos.

No teclado baseado em tempo de latência é possível ajustar o tempo de fixação para selecionar caracteres com as teclas "a" e "z" do teclado físico. O tempo de latência para selecionar palavras também é ajustável por meio das teclas "k" e "m" do teclado físico.

Para detectar os eventos do olhar, as aquisições do rastreador de olhar são filtradas usando uma média móvel de tamanho 5. Os dados filtrados são então usados para detectar fixações e sacadas em tempo real, usando um algoritmo baseado em Salvucci e Goldberg (2000). Os eventos do olhar são passados para uma máquina de estados que modela o comportamento do teclado. Tal máquina de estados detecta eventos como foco em uma tecla, seleção por tempo de latência ou por alternância entre contextos, além de reduzir o efeito de aquisições faltantes, inacurácia na estimação do olhar e piscadas do usuário. 


\section{Modelo de predição de palavras}

Para calcular as palavras mais prováveis usamos o software Presage (Vescovi, 2004) (antigamente conhecido como Soothsayer). Presage retorna as palavras mais prováveis combinando os resultados de vários preditores baseados em N-gramas e um texto de treinamento. Presage é capaz de retornar predições inclusive no começo de uma frase e depois de um espaço. O Presage foi configurado para retornar as três palavras mais prováveis baseado no texto escrito pelo usuário. A opção de aprendizado do Presage a partir do texto escrito pelo usuário foi desabilitada, de modo a garantir a mesma probabilidade para todos os usuários ao longo do experimento.

Para o experimento usamos o conjunto de frases em inglês de MacKenzie e Soukoreff (2003). As frases foram traduzidas para português e espanhol, de modo que os participantes fizeram o experimento na sua língua nativa. Cada frase foi apresentada no máximo uma vez durante o experimento. A ordem de apresentação das frases foi aleatória para cada participante. Para fazer as predições consistentes com a linguagem das frases, o Presage foi treinado em inglês, português e espanhol. O texto de treinamento usado está disponível na última versão do Dasher (http://www.inference.phy.cam.ac.uk/dasher/Download.html).

\section{Design e procedimento}

O design do experimento foi intra-sujeito (within-subjects) com duas variáveis independentes: Método (tempo de latência e alternância entre contextos) e Aceleração (com e sem). Como AugFix é uma extensão das técnicas de tempo de latência e alternância entre contextos, usar os teclados com aceleração serve também como treinamento para os teclados sem aceleração. Por isso, nas primeiras seis sessões os participantes treinaram a digitação pelo olhar usando ambos métodos com aceleração. Da sétima à duodécima sessão os participantes usaram ambos métodos, mas nesse caso o uso de AugFix foi alternado entre sessões. Portanto, houveram no total 9 sessões com aceleração e 3 sessões sem aceleração. Assim, ao total o experimento teve 12 sessões.

As 12 sessões foram agrupadas em 5 blocos. Os dois primeiros blocos tiveram três sessões com aceleração cada. Os três blocos restantes tiveram duas sessões cada, uma delas com aceleração e a outra sem aceleração. Entre duas sessões do mesmo bloco houve um descanso de 5 minutos. O intervalo entre dois blocos foi de no mínimo duas horas, sendo que no máximo dois blocos foram executados por dia. A ordem dos métodos em cada sessão foi escolhida de forma aleatória. Além disso, em 6 das 12 sessões os participantes usaram primeiro o tempo de latência e nas outras 6 usaram primeiro a alternância entre contextos.

No início do experimento, os participantes assinaram o termo de consentimento livre e esclarecido e completaram um breve questionário, para coletar dados como experiência com rastreadores de olhar e uso de computadores. Depois explicamos o objetivo do estudo e os participantes leram vários slides que descrevem o funcionamento das interfaces. Depois da leitura dos slides e esclarecimento de dúvidas, os participantes tiveram uma sessão de treinamento. O treinamento foi feito inicialmente com o mouse, durante o qual escreveram algumas frases. Após esse treinamento com o mouse, os participantes calibraram o rastreador olhando para nove pontos no monitor. A seguir, os participantes olharam para os mesmos 9 pontos usados durante a calibração para que avaliássemos a sua acurácia. A calibração foi repetida até que uma acurácia razoável foi atingida, a nosso critério. Depois da calibração, os participantes continuaram o treinamento, dessa vez escrevendo algumas 
frases pelo olhar. No fim do treinamento, começou o primeiro bloco do experimento.

Para começar cada sessão, os participantes apertaram a barra de espaço no teclado físico do computador, como mostrado na figura 6.3a. Nesse instante o teclado mostrou a primeira frase a ser escrita, como exemplificado na figura 6.3b. Os participantes foram instruídos a ler e lembrar a frase, antes de começar a escrevê-la pelo olhar o mais rápido e com o menor número de erros possível. A figura 6.3c mostra o teclado durante a escrita da frase "o objetivo esta claro". Para simplificar a tarefa e reduzir o número de teclas necessárias, os acentos e sinais especiais foram removidos das frases. Cada frase foi encerrada com o ponto final, como mostrado na figura 6.3d. Para mostrar a próxima frase os participantes tinham que apertar a barra de espaço no teclado físico.

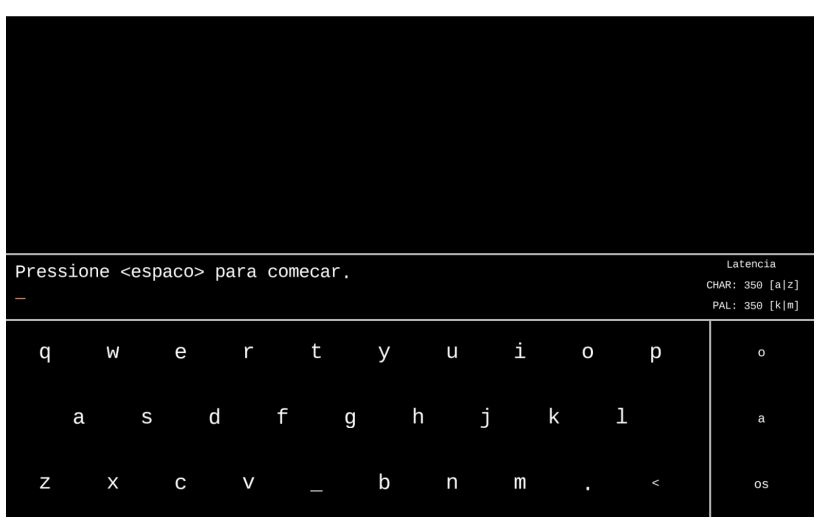

a) Teclado no começo de uma sessão.

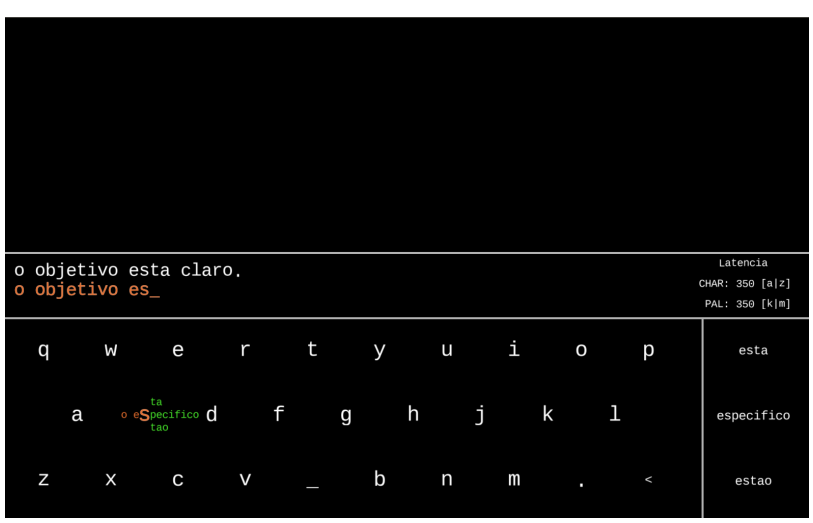

c) Escrevendo uma frase.

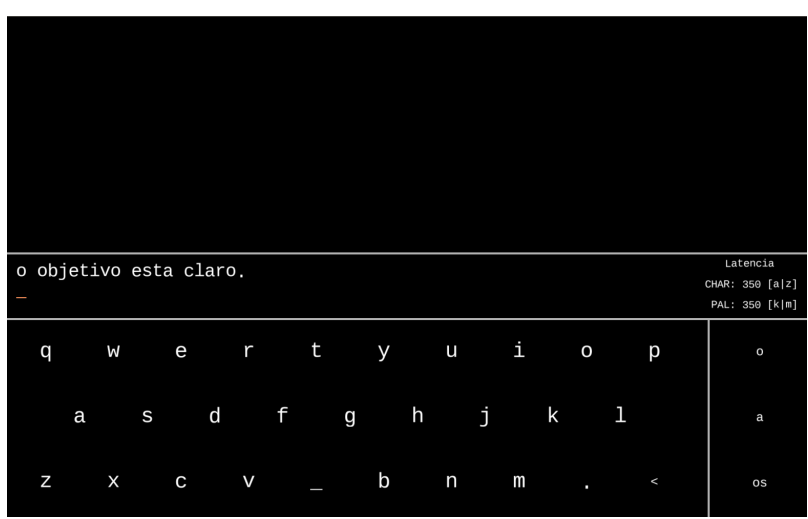

b) Teclado mostrando a frase a ser digitada.

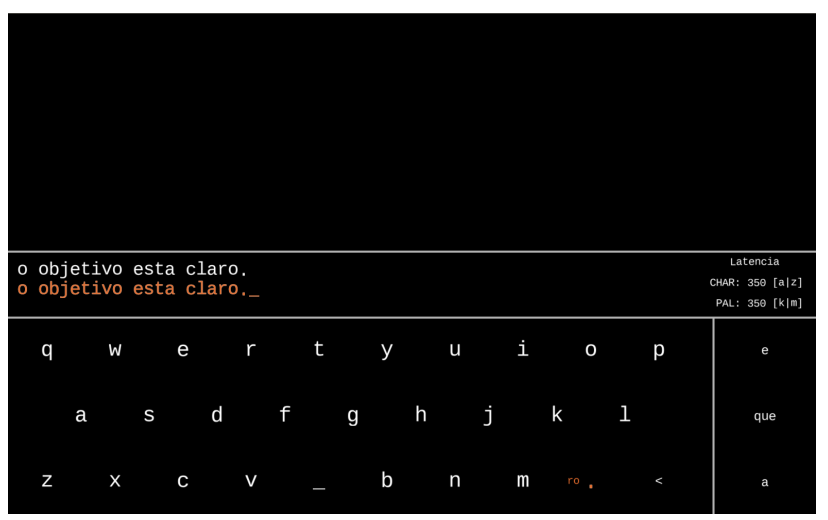

d) Fim da frase com o ponto final.

Figura 6.3: Estados do teclado virtual baseado em tempo de latência durante o experimento.

Durante a execução de cada bloco, o rastreador só foi recalibrado quando a acurácia caiu ao ponto do participante não conseguir selecionar as teclas desejadas. Antes de iniciar cada bateria de frases, a calibração anterior foi carregada e avaliada, e repetida apenas quando necessário, a nosso critério.

\section{Coleta e análise dos dados}

Para cada sessão do experimento, os dados sobre os eventos do teclado (como foco, seleção etc.) foram gravados em arquivos log para serem processados depois. Além disso, foram gravadas outras informações como o ajuste no tempo de latência durante o experimento. As métricas usadas para avaliar os métodos são: 
- Palavras por minuto (ppm): mede o desempenho em número de palavras por minuto, considerando que uma palavra está formada por cinco caracteres, incluindo o espaço (Arif e Stuerzlinger, 2009). É calculada como sendo:

$$
p p m=\frac{\frac{|E|}{5}}{\text { Tempo em minutos }}
$$

onde $E$ é o texto escrito pelo usuário.

- Taxa de erros (TE): porcentagem de erros deixados no texto final (ou seja, erros não corrigidos). A forma mais utilizada é baseada na distância mínima entre cadeias (Soukoreff e MacKenzie, 2001). A taxa de erros é calculada pela fórmula:

$$
T E=\frac{D M C(A, E)}{\overline{S_{A}}} \cdot 100
$$

onde $A$ é o texto apresentado, $E$ é o texto escrito pelo usuário, $D M C$ é a função de distância mínima entre cadeias e $\overline{S_{A}}$ é a média dos tamanhos de todos os alinhamentos ótimos entre $A$ e $E$.

- Seleções de teclas por caractere (Soukoreff e MacKenzie, 2001) (STPC): representa o número de seleções de teclas necessário para produzir um caractere na frase final. É calculado pela fórmula:

$$
S T P C=\frac{\mid \text { Fluxo entrada } \mid}{|E|}
$$

onde o Fluxo de entrada contem todas as teclas selecionadas (incluindo backspace) e $E$ é o texto escrito pelo usuário.

Além dessas métricas tradicionais, para esse estudo definimos a taxa de aceleração $(T A)$, que é definida como sendo:

$$
T A=\frac{\left|E_{a c c}\right|}{|E|} \cdot 100
$$

onde $E$ é o texto escrito pelo usuário e $E_{a c c}$ é a subsequência de $E$ formada pelos caracteres adicionados pela aceleração. Por exemplo, considere a frase "hello world" que foi escrita da seguinte forma: seleção do "h", "e", completamento de "llo ", seleção de "w" e completamento de "orld". A frase possui 11 caracteres, dos quais 8 foram escritos graças à aceleração. Logo, a taxa de aceleração é $\frac{8}{11} \cdot 100=72.7 \%$.

A taxa de aceleração é importante, pois ela é uma boa estimativa do ganho máximo no desempenho que pode ser atingido para um determinado conjunto de frases e modelo de linguagem, comparado com a condição de controle (sem aceleração), na qual cada frase tem que ser digitada letra por letra. Para cada conjunto de frases em português, espanhol e inglês calculamos a taxa máxima de aceleração possível. Os resultados mostraram uma taxa máxima de $55.25 \%$ para português, $50.55 \%$ para espanhol e $59.36 \%$ para inglês.

Para avaliar a experiência dos usuários utilizamos questionários aplicados na $6^{a}$ e $12^{a}$ sessão. Além disso, para medir a carga de trabalho de cada condição experimental, utilizamos o teste de índice de carga de trabalho da NASA (Hart e Stavenland, 1988). 


\subsubsection{Apresentação e discussão dos resultados}

Os valores das métricas foram calculados para cada frase escrita por cada participante. Cada frase foi considerada desde a seleção do primeiro caractere até a seleção do ponto final. De todas as frases coletadas no experimento, apenas duas foram descartadas, uma por não ter o ponto final e a outra por ter mais de um ponto no meio da frase. Para cada sessão e participante, consideramos a média de todas as frases escritas sob cada uma das condições experimentais.

Para avaliar o efeito dos métodos e da aceleração, utilizamos testes ANOVA de medições repetidas. Os valores de p reportados nos resultados foram corrigidos usando o método de GreenhouseGeisser, nos casos de violação da hipótese de esfericidade dos dados.

A seguir apresentamos primeiro os resultados e a discussão das nove sessões dos métodos com aceleração. Depois, apresentamos os resultados das três sessões que comparam os métodos com aceleração e sem aceleração, e finalmente apresentamos uma discussão geral.

\subsubsection{Resultados do estudo longitudinal: tempo de latência e alternância entre contextos com aceleração}

As figuras 6.4, 6.5, 6.6 e 6.7 mostram o resultado para ppm, TE, STPC e TA respectivamente, para os teclados baseados no tempo de latência e na alternância entre contextos, ambos com aceleração, durante 9 sessões. Cada ponto representa a média e um desvio padrão para os sete participantes.

Como podemos observar na figura 6.4, o ppm foi superior com o tempo de latência em todas as 9 sessões, começando em 12 ppm na primeira sessão e chegando até 16 ppm na última. Já na alternância entre contextos o desempenho variou desde 6 ppm na primeira sessão até 11 ppm na última. Em ambos os métodos podemos observar uma curva de aprendizado durante as primeiras 7 sessões. Um teste ANOVA de medições repetidas comparando Sessão (1-9) × Método (tempo de latência, alternância entre contextos) mostrou um efeito principal significativo de Sessão, F $(8,48)=12.18$, p $<0.001$ e também de Método, $\mathrm{F}(1,6)=95.09$, $\mathrm{p}<0.001$. Não houve interação entre Sessão e Método, $\mathrm{F}(8,48)=0.49, \mathrm{p}=0.73$.

Os resultados para TE (figura 6.5) mostram que, ao longo das 9 sessões, os usuários foram muito cuidadosos com os dois métodos. O erro ficou sempre abaixo de $1.3 \%$ e não houve diferença notável entre os dois métodos. Um teste ANOVA de medições repetidas comparando Sessão (1-9) × Método (tempo de latência, alternância entre contextos) confirmou que não houve efeito significativo para Sessão, $\mathrm{F}(8,48)=1.04, \mathrm{p}=0.4$, nem para Método, $\mathrm{F}(1,6)=2.58, \mathrm{p}=$ 0.16. Também não houve interação entre Sessão e Método, $\mathrm{F}(8,48)=1.05, \mathrm{p}=0.39$.

Os resultados para o número de seleções de teclas por caractere, observados na figura 6.5, mostram que no tempo de latência o $S T P C$ foi quase constante ao longo de todas as 9 sessões, ficando sempre abaixo de 1. Já na alternância entre contextos, o STPC foi de 1.59 na primeira sessão, e depois foi baixando ao longo das sessões, até ficar similar ao tempo de latência na última sessão. Um teste ANOVA de medições repetidas comparando Sessão (1-9) × Método (tempo de latência, alternância entre contextos) mostrou um efeito principal significativo de Sessão, $\mathrm{F}(8,48)=5.31$, p $=0.02$, e também de Método, $\mathrm{F}(1,6)=8.05, \mathrm{p}=0.03$. Não houve interação entre Sessão e Método, $\mathrm{F}(8,48)=2.54, \mathrm{p}=0.14$.

Os resultados para $T A$, apresentados na figura 6.7, mostram que no tempo de latência houve 


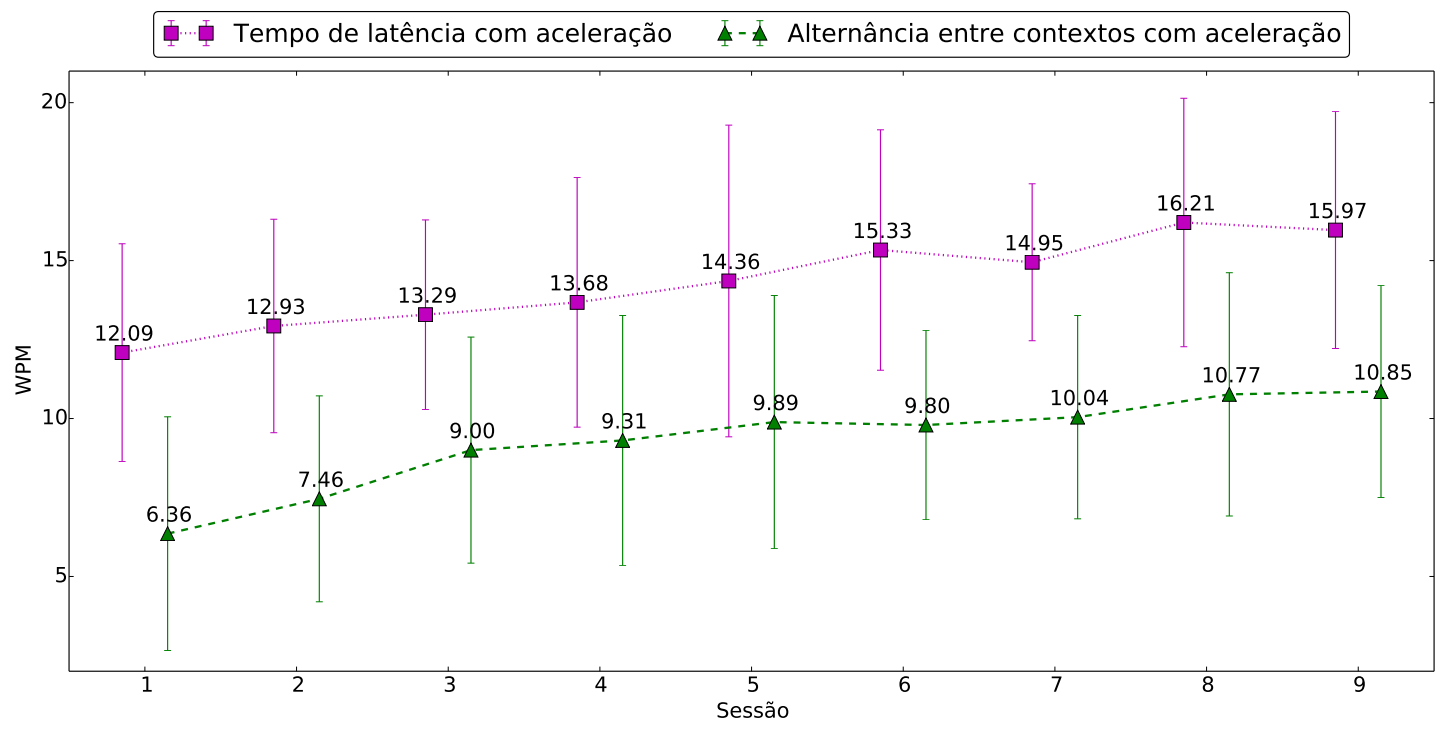

Figura 6.4: Média e um desvio padrão de 7 participantes para ppm, para os dois teclados com aceleração durante 9 sessões.

pouca mudança ao longo das 9 sessões, ficando muito perto de 50\%. Já na alternância entre contextos, o valor de $T A$ começou em 36\%, teve um aumento acentuado nas sessões 2-4 e depois ficou quase constante, com valores muito similares ao tempo de latência. A linha horizontal tracejada na figura 6.7 representa a aceleração máxima possível para o texto de treinamento e as frases usadas no estudo. A aceleração máxima foi calculada como sendo a soma da aceleração máxima para cada linguagem (português, espanhol e inglês) multiplicado pelo número de participantes em cada linguagem, dividido pelo número total de participantes. Um teste ANOVA de medições repetidas comparando Sessão (1-9) × Método (tempo de latência, alternância entre contextos) mostrou um efeito principal significativo (embora muito perto no limiar de significância) de Sessão, $\mathrm{F}(8,48)=4$, $\mathrm{p}=$ 0.04. Não houve efeito significativo de Método, $\mathrm{F}(1,6)=2.38, \mathrm{p}=0.17$, nem interação entre Sessão e Método, $\mathrm{F}(8,48)=2.82, \mathrm{p}=0.09$.

\section{Resultados do questionário 1 sobre os métodos com aceleração}

No fim da $6^{a}$ sessão os participantes preencheram o questionário 1 para avaliar subjetivamente os dois métodos, indicando qual deles achavam que era o mais rápido, com qual cometiam menos erros e qual era o mais confortável (veja o questionário completo no apêndice B). Os resultados do questionário 1 são mostrados na figura 6.8. O tempo de latência recebeu 5 votos para o mais rápido, 7 para o mais confortável, e 6 para o menor número de erros. Já a alternância entre contextos recebeu 2 votos para o mais rápido e 1 voto para o menor número de erros.

\section{Resultados do índice de carga de trabalho para os métodos com aceleração}

Também no fim da $6^{a}$ sessão os participantes preencheram o questionário da NASA, que está formado por duas fases. Detalhes sobre as duas fases do teste podem ser consultados no apêndice C. A partir das respostas do questionário, calculamos o índice de carga de trabalho para ambos métodos com aceleração. A média dos 7 participantes é mostrada na figura 6.9. Para comparar 


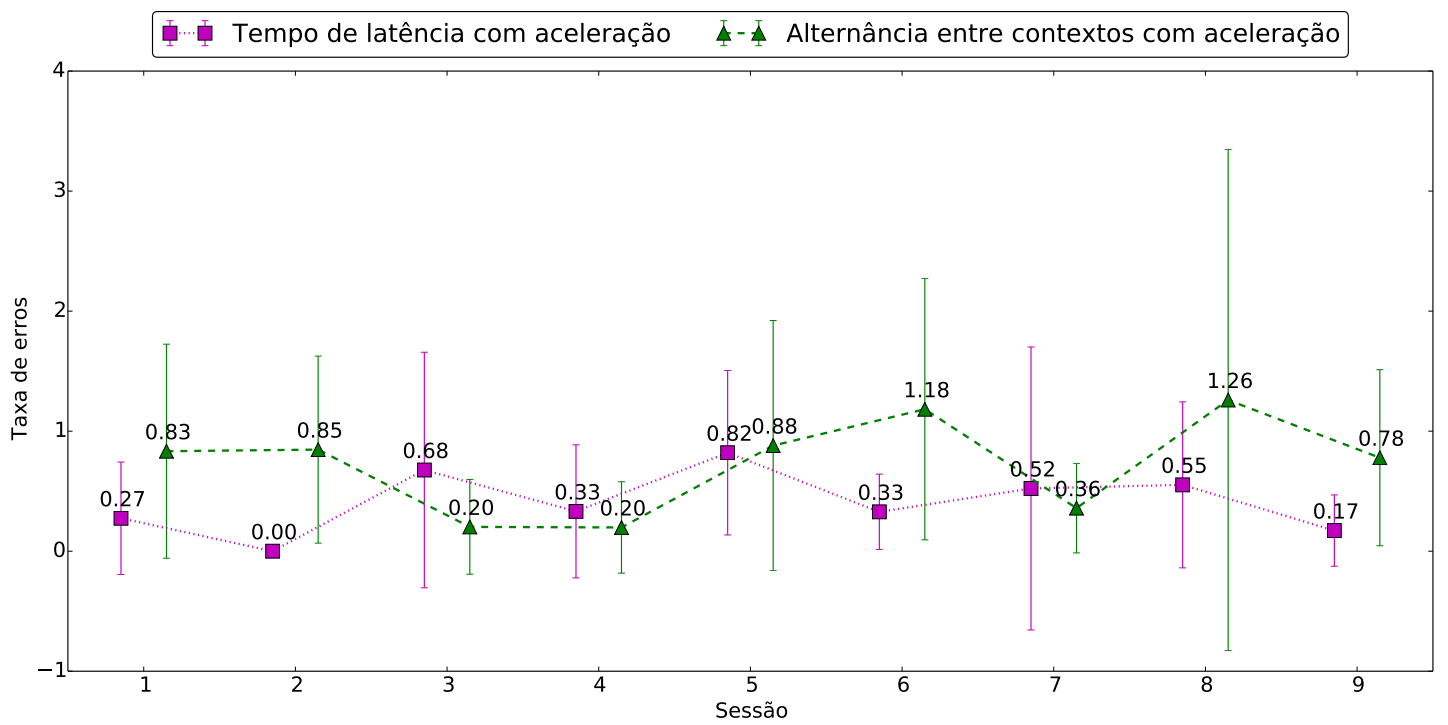

Figura 6.5: Média e um desvio padrão de 7 participantes para TE, para os dois teclados com aceleração durante 9 sessões.

esses resultados, utilizamos o teste de Welch que não assume a normalidade dos dados. $\mathrm{O}$ teste mostrou que a diferença no índice de carga de trabalho entre o tempo de latência e a alternância entre contextos não foi significativa, $\mathrm{t}(11.99)=1.36, \mathrm{p}=0.2$.

\subsubsection{Discussão do estudo longitudinal}

\section{Curvas de aprendizado}

Como pode ser observado na figura 6.4, ao longo das 9 sessões houve um aprendizado significativo. A média dos valores de ppm para cada sessão foram ajustados a uma curva de aprendizado com a forma $y=\alpha_{m} x^{\gamma_{m}}$, onde $x$ é u número da sessão, $y$ é o ppm e $m \in$ \{tempo de latência, alternância entre contextos\}. Os resultados do ajuste, apresentados na figura 6.10, mostram que os dados experimentais seguem a curva de aprendizado com coeficientes de determinação de 0.94 e 0.95 respectivamente. Essas curvas de aprendizado são similares às obtidas por Wobbrock et al. (2008) em um estudo que comparou o desempenho de um método baseado em gestos discretos do olhar (EyeWrite) com um teclado virtual baseado no tempo de latência.

\section{Comparação com estudos correlatos usando predição de palavras}

Os resultados de MacKenzie e Zhang (2008) mostraram um desempenho de 12.3 ppm utilizando predição de palavras. O resultado obtido no nosso experimento após 9 sessões foi superior, chegando até 16 ppm com o teclado baseado em tempo de latência com aceleração. Já com o teclado baseado na alternância entre contextos com aceleração, o desempenho foi um pouco menor, chegando a 12 ppm na nona sessão. Comparando a taxa de erros, MacKenzie e Zhang obtiveram valores entre $8.8 \%$ e $14.8 \%$, enquanto que no nosso experimento a taxa de erro foi sempre menor que $1.26 \%$ ao longo das 9 sessões com ambos os métodos.

Os resultados de Hansen et al. (2004) com o GazeTalk mostraram um desempenho de 5.82 ppm na primeira sessão e $6.61 \mathrm{ppm}$ na segunda sessão. Esse desempenho é inferior comparado com os 


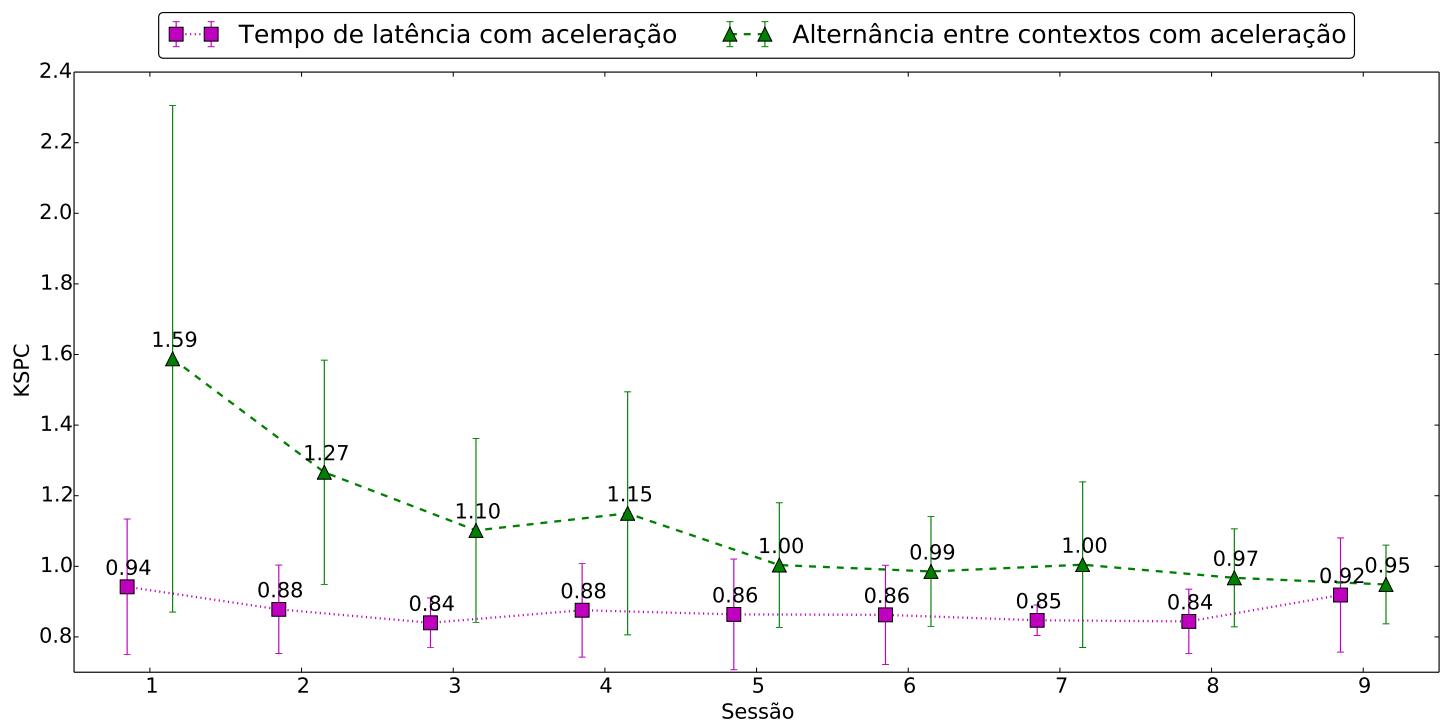

Figura 6.6: Média e um desvio padrão de 7 participantes para STPC, para os dois teclados com aceleração durante 9 sessões.

resultados obtidos em nosso experimento. Uma possível causa é a diferença no número de teclas entre as duas interfaces: com apenas 10 teclas no GazeTalk é impossível mostrar todas as letras. A taxa de erros no experimento de Hansen et al. foi similar à obtida em nosso estudo, o que é esperado devido ao grande tamanho das teclas no GazeTalk.

O resultados de Urbina e Huckauf (2010) com 9 participantes ao longo de 20 sessões mostraram uma média de 13.47 ppm nas três última sessões. Esse resultado é ligeiramente superior ao desempenho obtido na última sessão com a alternância entre contextos com aceleração, porém inferior ao obtido com o tempo de latência com aceleração. A taxa de erros foi similar à obtida no nosso estudo. Comparando o $S T P C$, os resultados de Urbina e Huckauf mostraram valores em torno de 0.7-0.75, enquanto que em nosso experimento foi de 0.84-0.94 com o tempo de latência com aceleração e de 0.95-1.59 com a alternância entre contextos com aceleração. No entanto, Urbina e Huckauf não detalharam como o $S T P C$ foi calculado.

Como podemos observar, o desempenho alcançado com o tempo de latência com aceleração em nosso experimento foi superior ao reportado por estudos usando predição de palavras encontrados na literatura. Já a taxa de erros foi similar aos estudos com o GazeTalk e Pie Menus e inferior à obtida por MacKenzie e Zhang (2008).

Já se compararmos com o trabalho de Pedrosa et al. (2015), nossos resultados com o tempo de latência com aceleração são similares aos obtidos com a interface Filteryedping, que não usa tempo de latência para selecionar os caracteres. Pedrosa et al. também usaram o teste da NASA para calcular o índice de carga de trabalho, que foi de 4.87, similar ao valor obtido em nosso estudo para o tempo de latência com aceleração (4.86).

Comparando nossos resultados com Dasher, o desempenho obtido com o tempo de latência com aceleração nesse estudo (16 ppm) é superior ao obtido por Rough et al. (2014), entre 12-14 ppm, e similar ao desempenho obtido por Tuisku et al. (2008), de 17 ppm. A taxa de erros de ambos métodos (tempo de latência com aceleração e alternância entre contextos com aceleração) foram também similares às taxas de erro desses estudos com o Dasher.

No nosso estudo, um dos participantes se destacou do resto por ter um desempenho muito 


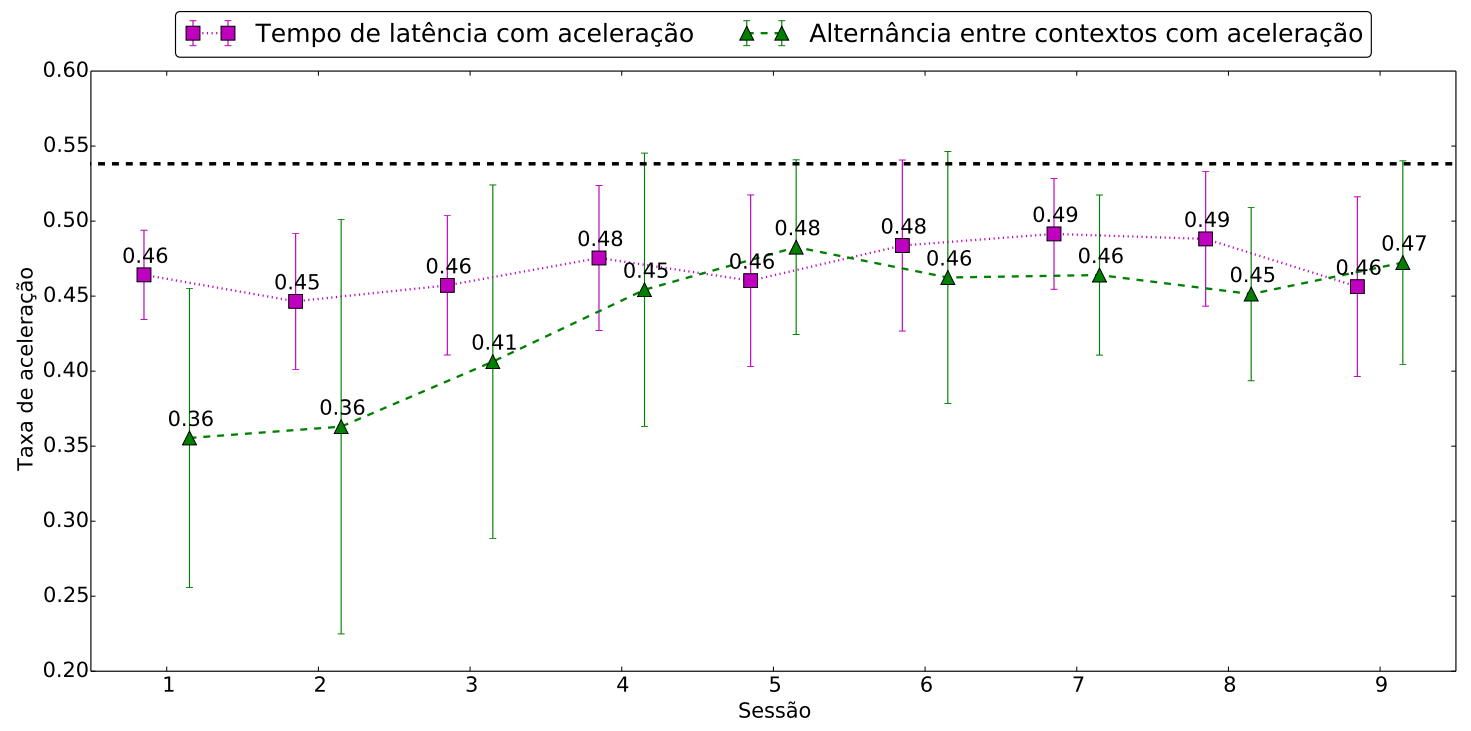

Figura 6.7: Média e um desvio padrão de 7 participantes para TA, para os dois teclados com aceleração durante 9 sessões. A linha horizontal tracejada representa a aceleração máxima possível para o texto de treinamento e as frases usadas no estudo.

superior. Como observado na figura 6.11, esse participante conseguiu digitar acima de $20 \mathrm{ppm}$ com o tempo de latência com aceleração em 6 das 9 sessões. Já com a alternância entre contextos com aceleração, o desempenho também foi muito acima da média dos participantes, ultrapassando 16 ppm em 6 das 9 sessões. Cabe destacar que esse participante não tinha experiência nenhuma em interação pelo olhar. Vale também destacar que o autor da presente tese, que não participou do estudo, é capaz de digitar a uma velocidade de $26 \mathrm{ppm}$ com o tempo de latência com aceleração e 23 ppm com a alternância entre contextos com aceleração, após 5 sessões de treinamento com ambos métodos.

\section{Comparação entre o tempo de latência e a alternância entre contextos com aceleração}

O desempenho (ppm) do tempo de latência com aceleração foi significativamente maior que a alternância entre contextos com aceleração, com uma diferença de 4-6 ppm ao longo das 9 sessões. Uma possível explicação para essa diferença é o maior STPC obtido na alternância entre contextos com aceleração, como mostrado na figura 6.6. Um $S T P C$ maior implica que os participantes precisaram de mais seleções de teclas por cada caractere. Esse número maior de seleções por caractere corresponde a erros que foram corrigidos durante a digitação, portanto os participantes demoravam mais para completar as frases, o que afeta o desempenho. No entanto, como observado na figura 6.6, a diferença no $S T P C$ entre os dois teclados diminuiu a partir da $5^{a}$ sessão, mas a diferença no desempenho foi quase constante durante todas as sessões (figura 6.4). Assim, o maior valor de $S T P C$ na alternância entre contextos com aceleração poderia explicar apenas em parte o menor desempenho comparado com o tempo de latência com aceleração.

Uma outra explicação para a diferença no desempenho é que, como o teclado tem três linhas (para conseguir mostrar 29 teclas), na alternância entre contextos as sacadas são maiores pois o usuário precisa cruzar de um contexto para o outro, atravessando a área de texto. A diferença, no tempo de latência as sacadas são feitas apenas dentro de um mesmo contexto, portanto elas são menores. As sacadas maiores tem também uma duração 


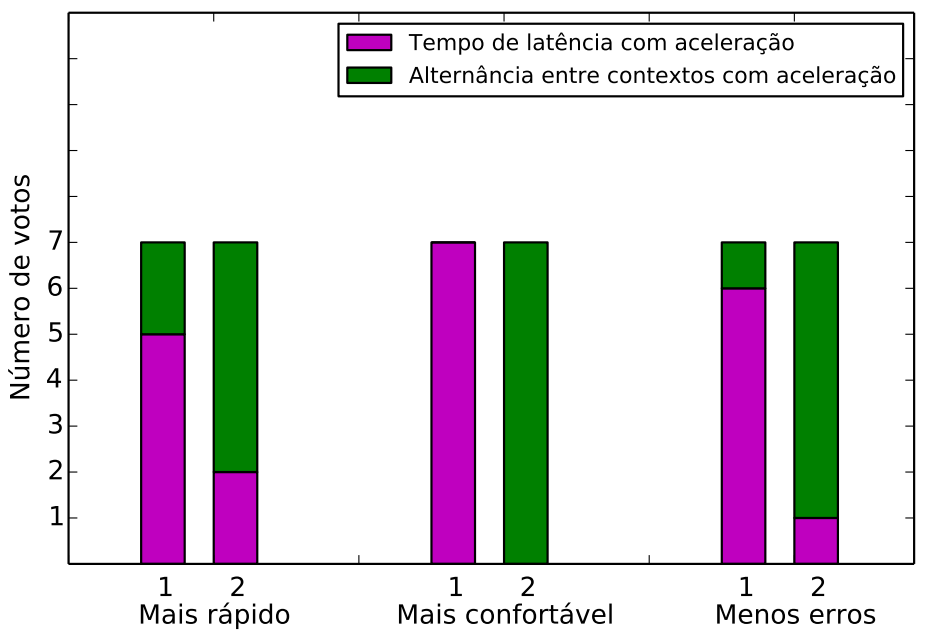

Figura 6.8: Resultados do questionário 1 sobre os métodos com aceleração, em relação ao desempenho, taxa de erros e conforto.

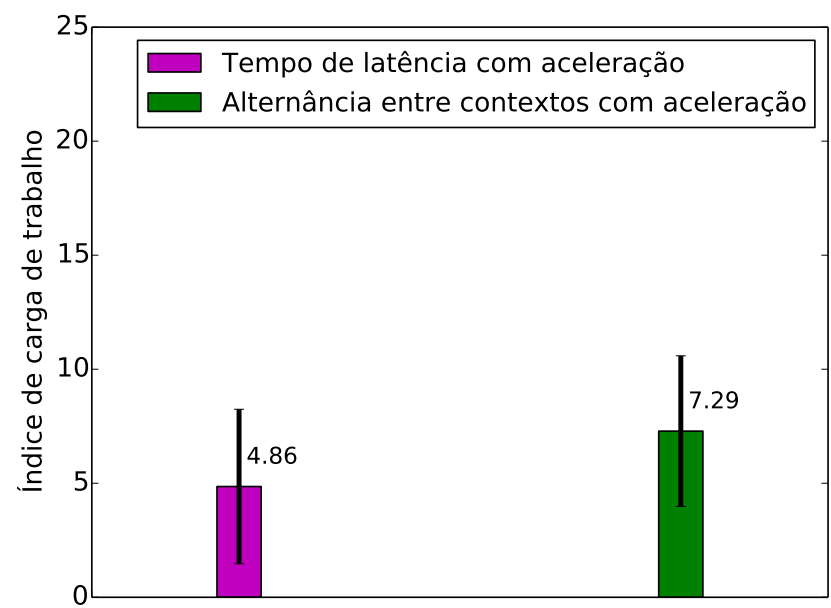

Figura 6.9: Média e um desvio padrão de 7 participantes para o índice de carga de trabalho, para os dois teclados com aceleração.

maior (Baloh et al., 1975), o que poderia explicar essa diferença no desempenho entre os dois métodos. A diferença quantitativa no desempenho entre ambos métodos é consistente com os resultados do questionário 1. Como mostrado na figura 6.8, 5 dos 7 participantes acharam que o desempenho com o tempo de latência com aceleração foi maior que com a alternância entre contextos com aceleração.

A taxa de erros foi similar nos dois métodos, o que indica que os participantes corrigiram a maioria dos erros cometidos. Seis participantes (todos capazes) acharam que com o tempo de latência com aceleração cometeram menos erros, enquanto que o outro participante com necessidades especiais para digitar no computador achou que errava menos com a alternância entre contextos com aceleração. Esse participante argumentou que com o tempo de latência era mais fácil selecionar uma tecla errada, e por isso sempre utilizou um tempo de fixação de $600 \mathrm{~ms}$, valor acima da média geral do tempo de seleção, que foi em torno de 400 ms nas últimas duas sessões. A argumentação desse participante é consistente com o toque de Midas. 


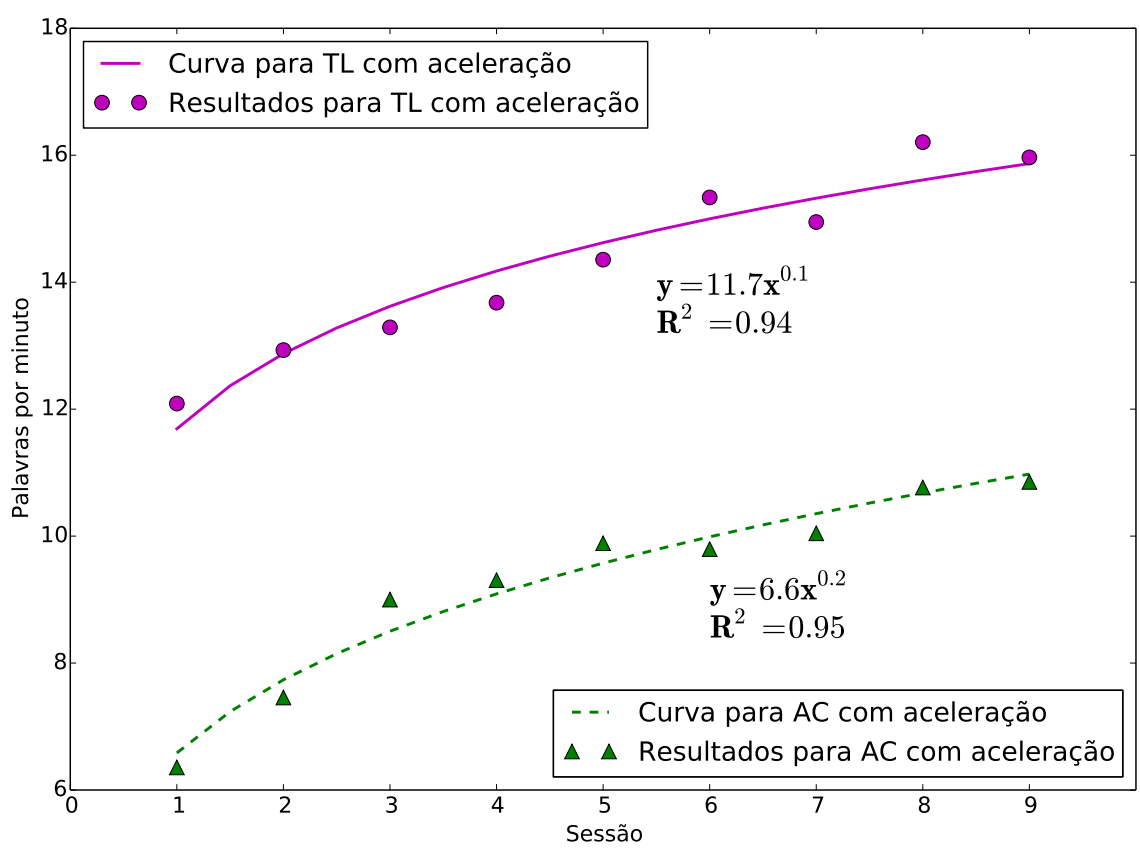

Figura 6.10: Ajuste de curva para a média de ppm ao longo das 9 sessões para os dois métodos com aceleração (TL = tempo de latência, $A C=$ alternância entre contextos). A função tem a forma $y=\alpha_{m} x^{\gamma_{m}}$, onde $x$ é u número da sessão, y é o ppm e $m \in\{T L, A C\}$.

Em termos de conforto, todos os 7 participantes acharam o tempo de latência com aceleração mais confortável. Alguns participantes comentaram que na alternância entre contextos com aceleração era mais difícil focar em alguns caracteres no canto do monitor, onde a acurácia do rastreador é menor. Além disso, para selecionar as teclas mais afastadas da área de texto (a "ponte" entre os dois contextos) eram necessárias sacadas mais longas, o que requer de um esforço maior. Um outro ponto levantado por alguns participantes foi a estratégia usada na alternÂncia entre contextos: eles focavam na tecla desejada e faziam a sacada para o outro contexto na direção da próxima tecla. Se a tecla focada não for selecionada (por causa do erro do rastreador ou porque o teclado não detectou a troca de contextos), o participante tinha que repetir a seleção do mesmo caractere, requerendo um esforço maior pois ele já tinha feito a sacada na direção do próximo caractere.

\section{Discussão sobre a taxa de aceleração}

Como pode ser observado na figura 6.7, a partir da $4^{a}$ sessão aproximadamente metade do texto final foi produzido graças à aceleração de palavras. Devido à falta de diferença significativa entre ambos métodos, a aceleração foi utilizada de forma similar pelos participantes tanto no tempo de latência quanto na alternância entre contextos. É notável também que os valores de $T A$ ficaram próximos do valor máximo possível de $T A$.

\subsubsection{Resultados da comparação entre os teclados com e sem aceleração}

A seguir apresentamos os resultados das últimas 6 sessões do experimento, nas quais os participantes alternaram o uso da aceleração. Como os participantes sempre fizeram uma sessão com e outra sem aceleração na mesma visita ao laboratório, agrupamos essas últimas 6 sessões em três, 


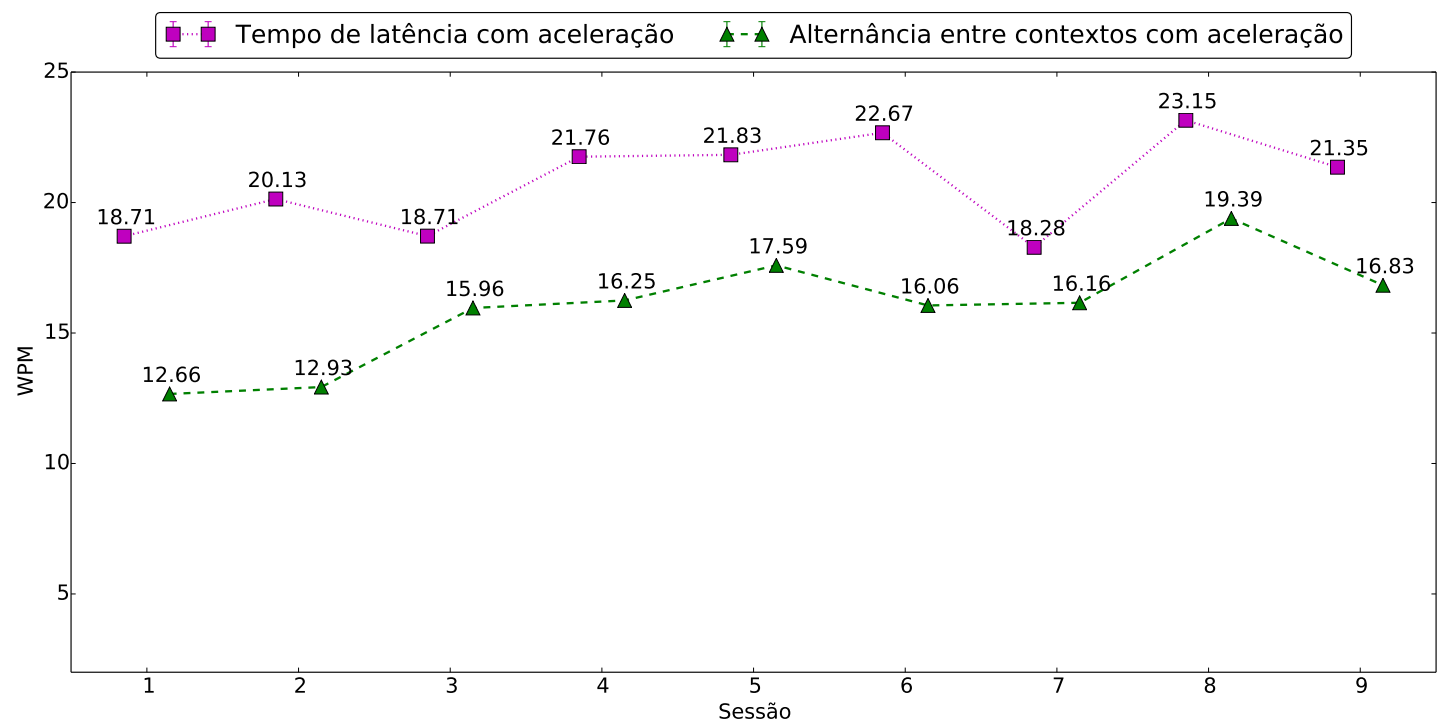

Figura 6.11: Média de um dos participantes para ppm, para os dois teclados com aceleração durante 9 sessões.

considerando 4 métodos em cada uma dessas três sessões: tempo de latência com e sem aceleração, e alternância entre contextos com e sem aceleração. Tal agrupamento facilitará a apresentação e análise dos resultados.

As figuras 6.12, 6.13 e 6.14 mostram o resultado para ppm, TE e $S T P C$ respectivamente, para os teclados baseados no tempo de latência e na alternância entre contextos, com e sem aceleração, para as 3 sessões analisadas. Na sessão 1 os participantes usaram pela primeira vez os métodos sem aceleração, portanto ela será considerada sendo de treinamento. Assim, a análise estatística apresentada a seguir é baseada apenas nas duas últimas sessões.

Como podemos observar na figura 6.12, sem o uso da aceleração o tempo de latência apresentou um desempenho maior que a alternância entre contextos. Além disso, o uso da aceleração permitiu melhorar o desempenho para ambos os métodos. Um teste ANOVA de medições repetidas comparando Método (tempo de latência, alternância entre contextos) $\times$ Aceleração $(\mathrm{com}$, sem $) \times$ Sessão $(2,3)$ mostrou um efeito principal significativo de Método, $\mathrm{F}(1,6)=56.44, \mathrm{p}<0.001, \eta_{p}^{2}=0.9$, e também de Aceleração, $\mathrm{F}(1,6)=38.74, \mathrm{p}<0.001, \eta_{p}^{2}=0.87$. Não houve efeito significativo principal de Sessão, $\mathrm{F}(1,6)=0.18, \mathrm{p}=0.69$. Não houve interação significativa entre nenhum dos fatores.

Os resultados para $T E$, apresentados na figura 6.13, mostram que nas duas últimas sessões a taxa de erros foi levemente inferior para o tempo de latência comparado com a alternância entre contextos. Além disso, os métodos com aceleração apresentaram um erro levemente inferior aos métodos sem aceleração. Na comparação dos métodos utilizando o teste ANOVA, obtivemos valores de p no limiar de significância estatística. Um teste ANOVA de medições repetidas comparando Método (tempo de latência, alternância entre contextos $) \times$ Aceleração $(\mathrm{com}$, sem $) \times$ Sessão $(2,3)$ mostrou um efeito principal significativo de Método, $\mathrm{F}(1,6)=6.15, \mathrm{p}=0.05, \eta_{p}^{2}=0.51$, e também de Aceleração, $\mathrm{F}(1,6)=7.55, \mathrm{p}=0.03, \eta_{p}^{2}=0.56$. Não houve efeito significativo principal de Sessão, $\mathrm{F}(1,6)=0.0015, \mathrm{p}=0.97$. Não houve interação significativa entre nenhum dos fatores.

Os resultados para $S T P C$, apresentados na figura 6.13, mostram que os métodos sem aceleração 


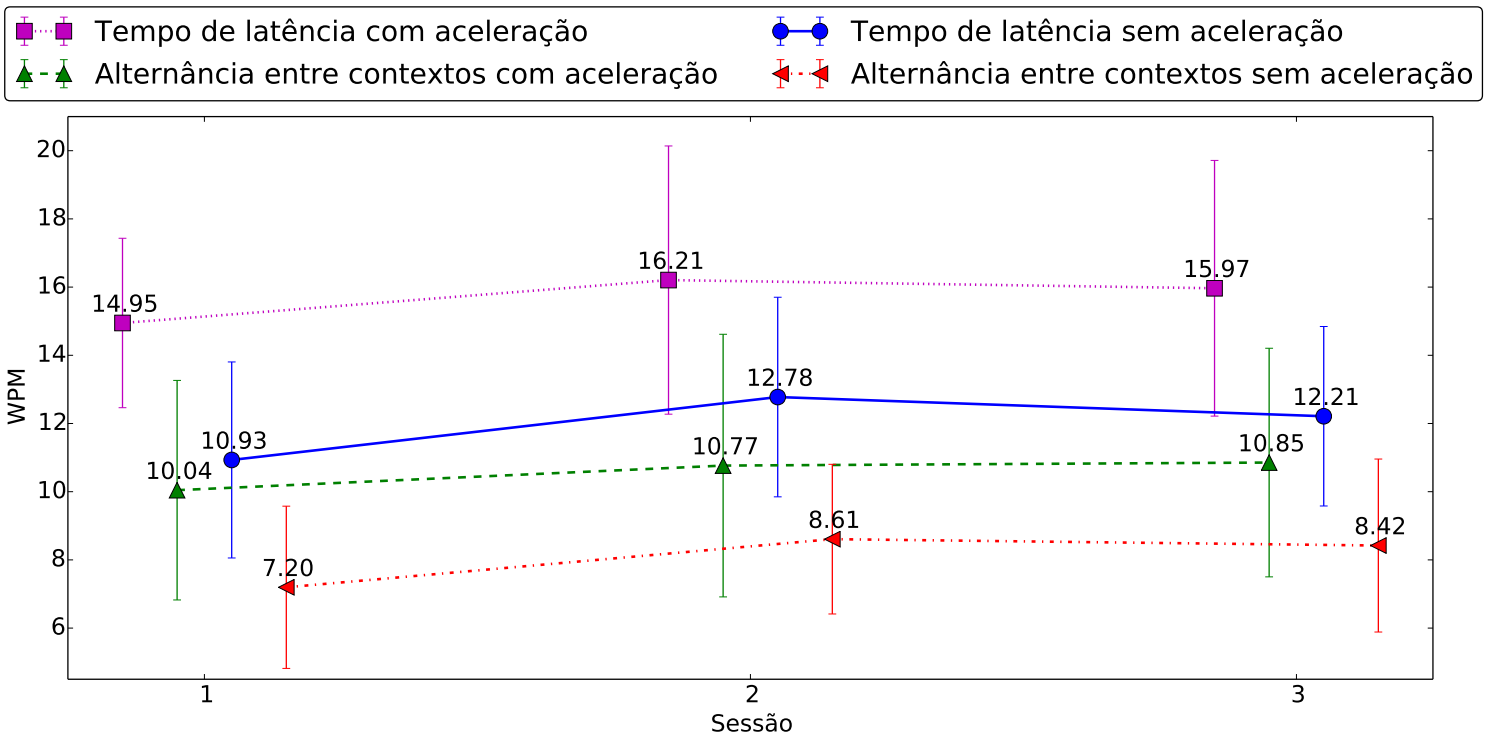

Figura 6.12: Média e um desvio padrão de 7 participantes para ppm, para os dois teclados com e sem aceleração durante 3 sessões.

tiveram um STPC maior que os sem aceleração. Além disso, a alternância entre contextos teve um STPC maior que o tempo de latência, com e sem aceleração. Um teste ANOVA de medições repetidas para Método (tempo de latência, alternância entre contextos) $\times$ Aceleração $(c o m, s e m)$ $\times$ Sessão $(2,3)$ mostrou um efeito principal significativo de Método (embora muito perto do limiar de significância), $\mathrm{F}(1,6)=6.71, \mathrm{p}=0.041, \eta_{p}^{2}=0.53$, de Aceleração, $\mathrm{F}(1,6)=105.56, \mathrm{p}<0.001$, $\eta_{p}^{2}=0.95$, e também de Sessão, $\mathrm{F}(1,6)=10.1, \mathrm{p}=0.019, \eta_{p}^{2}=0.63$. Não houve interação significativa entre nenhum dos três fatores.

\section{Resultados dos questionários 2 e 3}

Ao final da $12^{a}$ sessão os participantes preencheram os questionários 2 e 3 , mostrados no apêndice B. O objetivo do questionário 2 é avaliar subjetivamente os dois métodos (tempo de latência e alternância entre contextos) sem aceleração, indicando qual deles achavam que era o mais rápido, com qual cometiam menos erros e qual era o mais confortável. Os resultados do questionário 2 são mostrados na figura 6.15. Todos os 7 participantes acharam o tempo de latência sem aceleração mais rápido e confortável do que a alternância entre contextos sem aceleração. Um participantes achou que cometia menos erros com a alternância entre contextos.

O objetivo do questionário 3 é avaliar subjetivamente todos os 4 métodos, considerando as versões com e sem aceleração. Além de ordenar os métodos de acordo com critérios usados nos questionários 1 e 2 (mais rápido, menos erros e mais confortável), os participantes tinham que indicar qual método escolheriam, caso tivessem que usar um deles para se comunicarem. Os resultados do questionário 3 são mostrados na figura 6.16 .

Seis participantes votaram no tempo de latência com aceleração como o mais rápido, enquanto que um participante dividiu o voto entre os dois métodos com aceleração como o mais rápido. Como segunda opção, 3 participantes escolheram a alternância entre contextos com aceleração e 4 o tempo de latência sem aceleração. Em terceiro lugar 3 participantes escolheram a alternância entre contextos com aceleração e outros 3 escolheram o tempo de latência sem aceleração. Já a alternância 


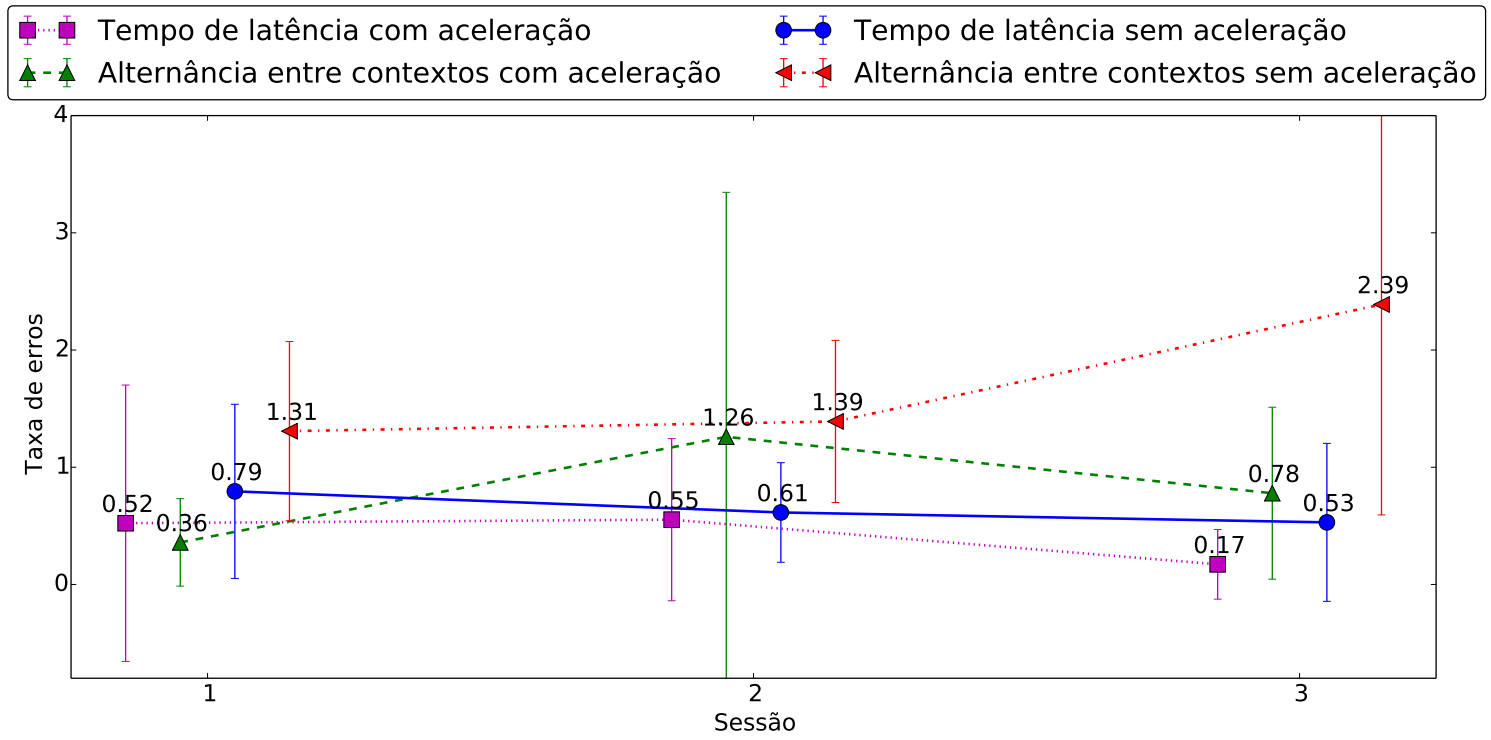

Figura 6.13: Média e um desvio padrão de 7 participantes para TE, para os dois teclados com e sem aceleração durante 3 sessões.

entre contextos sem aceleração foi considerada por todos os 7 participantes como o menos rápido dentre os 4 métodos.

Em relação ao conforto, todos os 7 participantes votaram no tempo de latência com aceleração como sendo o mais confortável. O tempo de latência sem aceleração recebeu 5 votos como sendo o segundo mais confortável, enquanto que a alternância entre contextos com aceleração recebeu 2 votos. Em terceiro lugar, 4 participantes escolheram a alternância entre contextos com aceleração, 2 escolheram o tempo de latência sem aceleração e 1 a alternância entre contextos sem aceleração. Como menos confortável dentre os 4 métodos, um participante votou na alternância entre contextos com aceleração e 6 na alternância entre contextos sem aceleração.

Considerando a percepção do número de erros cometidos, todos os 7 participantes acharam que erravam menos com o tempo de latência com aceleração. Em segundo lugar, 4 participantes escolheram o tempo de latência sem aceleração, 2 a alternância entre contextos com aceleração e 1 a alternância entre contextos sem aceleração. Como terceira escolha, 4 participantes votaram na alternância entre contextos com aceleração e 3 no tempo de latência sem aceleração. Seis participantes acharam que erravam mais com a alternância entre contextos sem aceleração, enquanto que um achou que errava mais com a alternância entre contextos com aceleração.

Considerando qual método seria o escolhido, todos os 7 participantes preferiram o tempo de latência com aceleração. Em segundo lugar, 4 participantes preferiram o alternância entre contextos com aceleração e 3 participantes o tempo de latência sem aceleração. Como terceira escolha, 2 participantes votaram na alternância entre contextos com aceleração, 4 no tempo de latência sem aceleração e 1 na alternância entre contextos sem aceleração. Como última opção, 6 participantes escolheram a alternância entre contextos sem aceleração e 1 participante escolheu a alternância entre contextos com aceleração.

Também no questionário 3, os participantes preencheram uma escala de Likert de 1 (muito baixo) a 5 (muito alto) para expressar em que nível a aceleração permitiu melhorar o desempenho, reduzir o número de erros cometidos, e fez os teclados mais agradáveis de usar. Os resultados da média e um desvio padrão para os 7 participantes são mostrados na figura 6.17. Como pode ser observado 


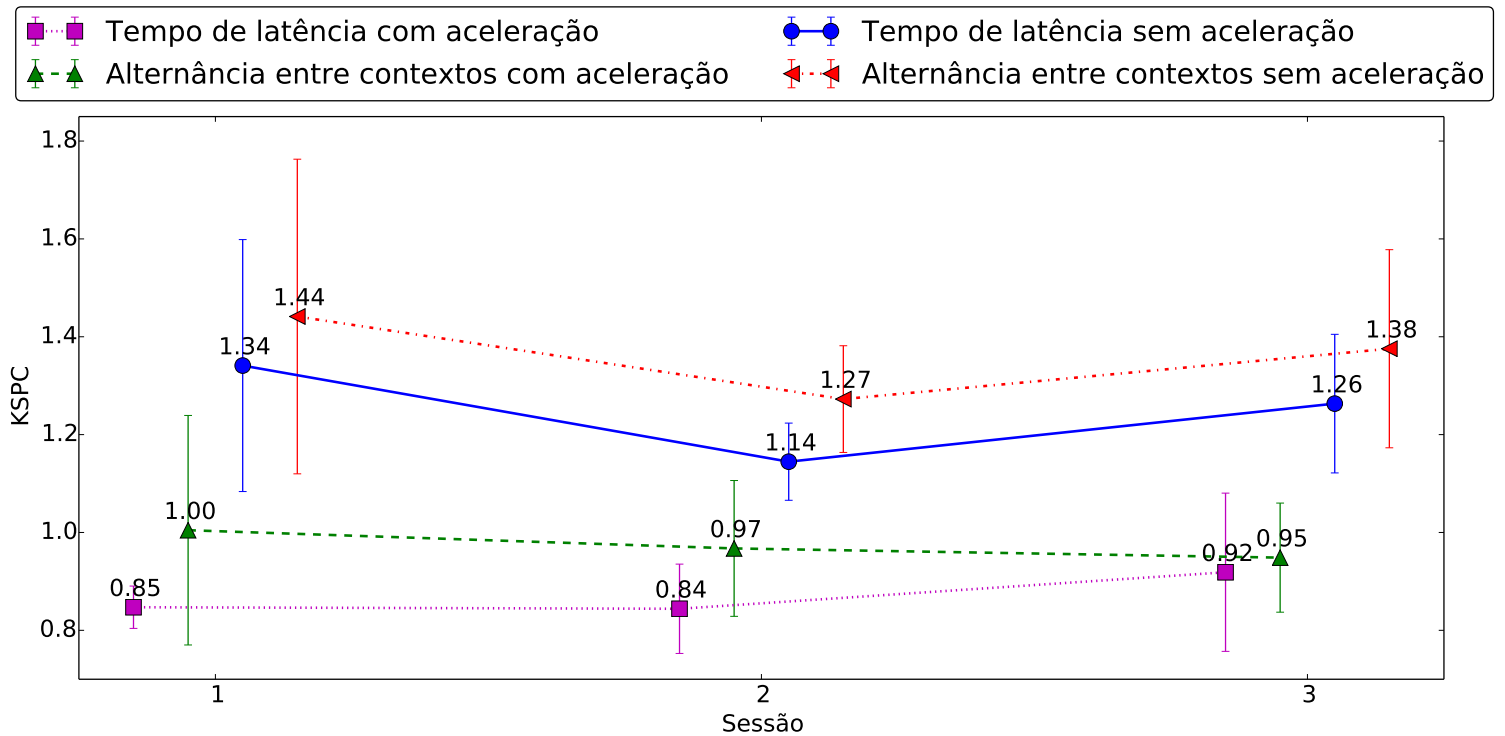

Figura 6.14: Média e um desvio padrão de 7 participantes para STPC, para os dois teclados com e sem aceleração durante 3 sessões.

na figura 6.17, na média os participantes acharam que a aceleração melhorou o desempenho em um nível alto a muito alto para ambos os métodos. Um resultado similar foi obtido em relação ao conforto. Na pergunta se a aceleração permite reduzir o número de erros, ambos métodos receberam a mesma avaliação, com um nível de médio a alto.

\section{Resultados do índice de carga de trabalho}

No fim da $12^{a}$ sessão os participantes preencheram o questionário da NASA para os métodos sem aceleração. A partir das respostas do questionário, calculamos o índice de carga de trabalho para ambos métodos sem aceleração. A média dos 7 participantes é mostrada na figura 6.18. Esses resultados foram comparados com um teste de Welch, que não assume a normalidade dos dados. O teste mostrou que a diferença no índice de carga de trabalho entre o tempo de latência e a alternância entre contextos sem aceleração não foi significativa, $\mathrm{t}(8.35)=1.68, \mathrm{p}=0.13$.

\subsubsection{Discussão dos resultados dos métodos sem aceleração}

Como observado na figura 6.12, a velocidade atingida com o tempo de latência sem aceleração foi entre 12 e 13 ppm. Esse resultado é superior ao obtido por Rough et al. (2014), no qual 12 participantes, usando um teclado virtual com tempo de latência ajustável, atingiram uma velocidade de 7 ppm após 9 sessões de 15 minutos cada. Além disso, a taxa de erros do nosso estudo foi inferior ao erro obtido no estudo de Rough et al. Um fator que pode ter influenciado nessa diferença, além das características próprias dos participantes de cada estudo, é o ajuste do tempo de seleção. No estudo de Rough et al. os participantes só puderam ajustar o tempo de seleção a partir da $6^{a}$ sessão, reduzindo-o até 700-750 ms nas últimas 4 sessões. Já no nosso estudo, o tempo de fixação foi de 436 ms na primeira sessão sem aceleração e de 400 ms na última sessão sem aceleração.

A velocidade que obtivemos com o tempo de latência sem aceleração é inferior à reportada por Majaranta et al. (2009), de aproximadamente 20 ppm com um teclado baseado em tempo de latência ajustável. No estudo de Majaranta et al. os participantes reduziram bastante o tempo de 


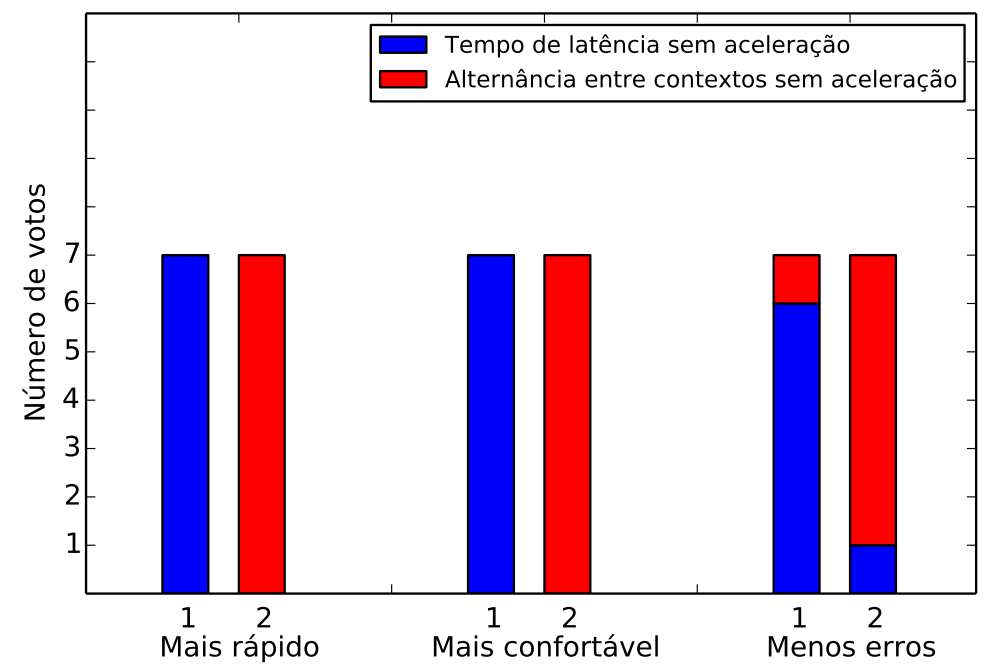

Figura 6.15: Resultados do questionário 2 sobre os métodos sem aceleração, em relação ao desempenho, taxa de erros e conforto.

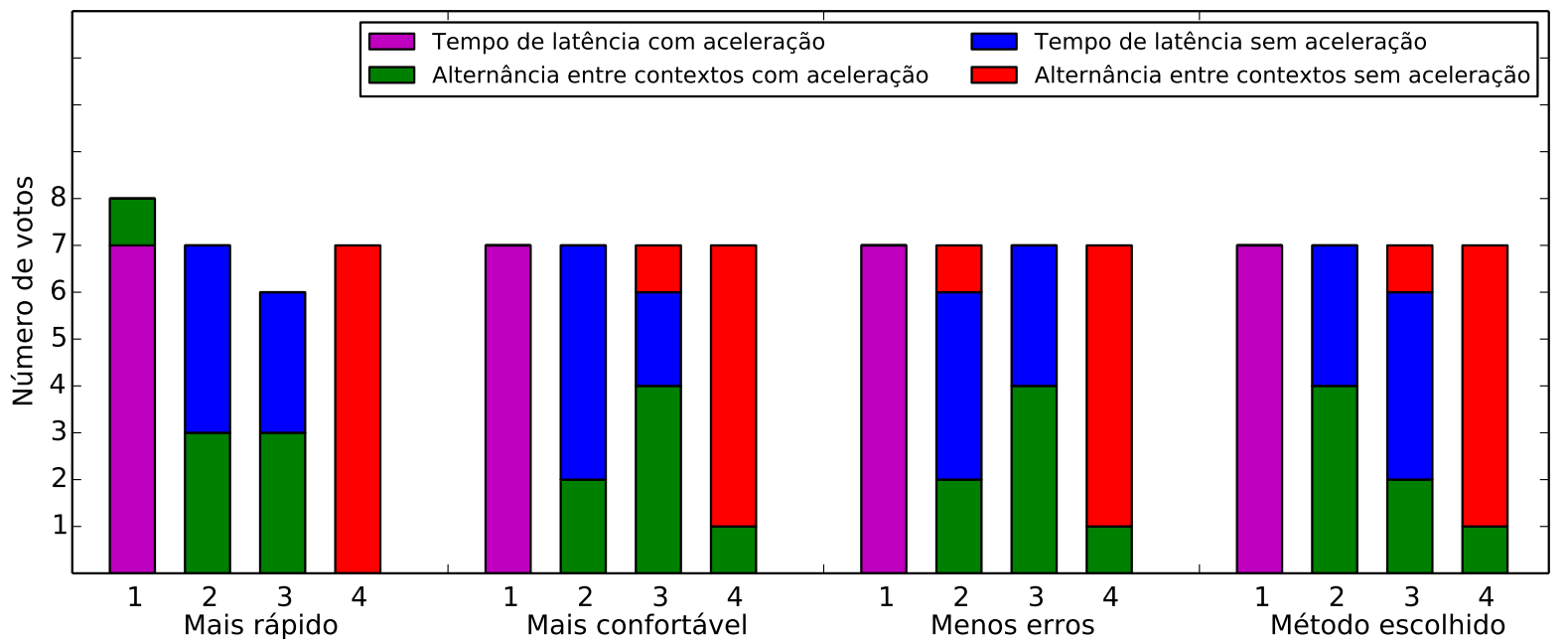

Figura 6.16: Resultados do questionário 3 sobre os métodos com e sem aceleração, em relação ao desempenho, taxa de erros, conforto e método escolhido.

latência durante as primeiras sessões, chegando a $284 \mathrm{~ms}$ na última sessão, fazendo uma diferença de mais de 100 ms se comparado com a média do tempo de seleção configurado pelos participantes do nosso experimento.

Já com a alternância entre contextos sem aceleração, o desempenho médio de 8-9 ppm obtido nesse estudo é inferior ao resultado obtido por Morimoto e Amir (2010), de aproximadamente 12 ppm após 8 sessões.

\subsubsection{Aceleração $\times$ sem aceleração}

Os resultados experimentais obtidos nesse estudo mostram que o AugFix permite melhorar tanto a velocidade quanto a experiência dos usuários na digitação pelo olhar, assim como reduzir a taxa de erros, quando combinado com predição de palavras. 


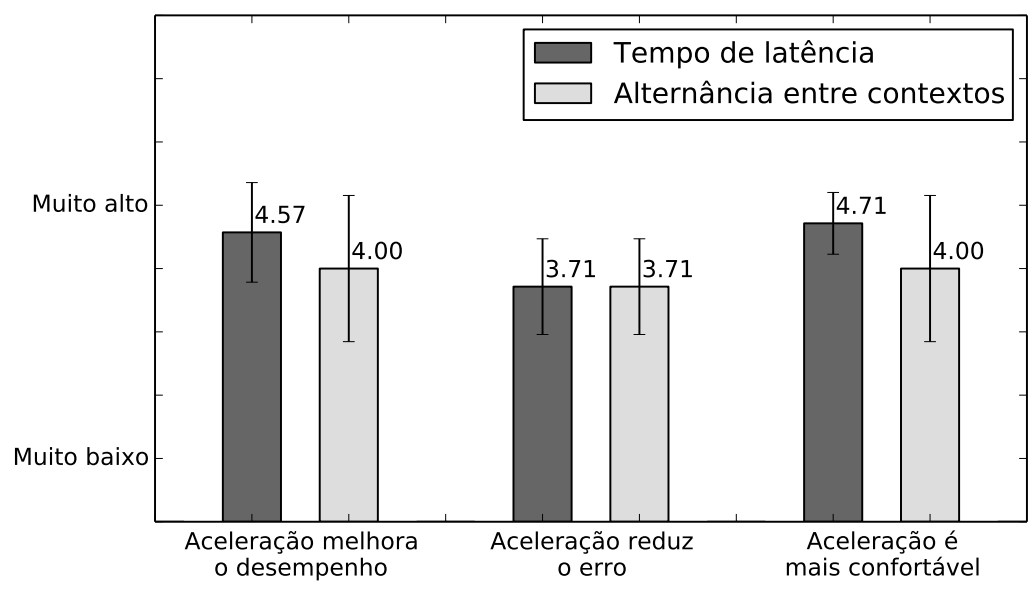

Figura 6.17: Média e um desvio padrão para 7 participantes sobre o questionário 3, avaliando o impacto da aceleração no desempenho, taxa de erros e conforto.

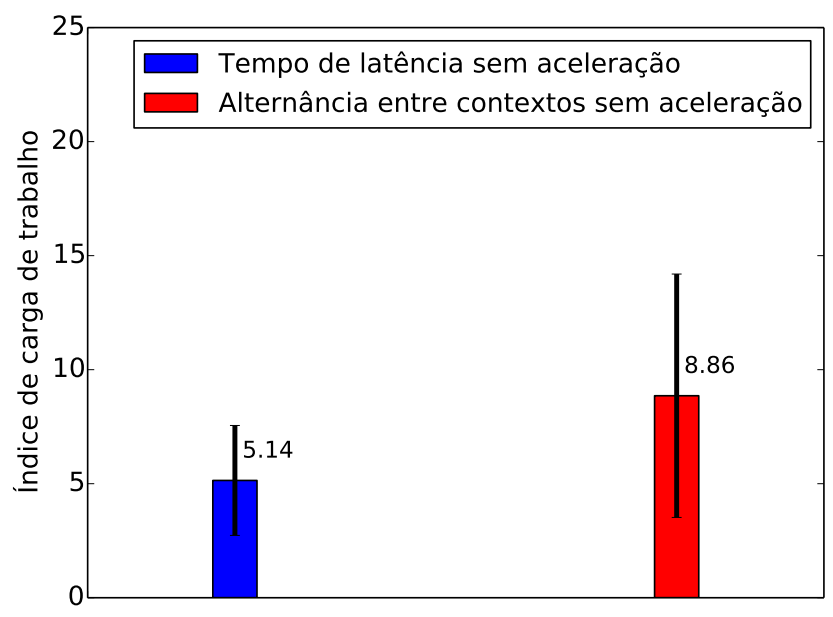

Figura 6.18: Média e um desvio padrão de 7 participantes para o índice de carga de trabalho, para os dois teclados sem aceleração.

\section{Desempenho e taxa de aceleração}

Como pode ser observado na figura 6.12, os métodos com aceleração tiveram um desempenho (medido em ppm) entre 25-30\% maior que os métodos sem aceleração. O ganho máximo que poderia ser atingido no ppm usando os métodos com aceleração é dado pela taxa de aceleração (figura 6.7), que foi entre 45-49\% nas três últimas sessões com aceleração.

Uma pergunta que poderia surgir é: por que os participantes não conseguiram chegar no ganho máximo possível no desempenho? Um dos fatores que pode ter influenciado nesse resultado é a correção de erros cometidos durante a digitação. Se um participante cometeu um erro e o corrigiu, a taxa de aceleração não é afetada, pois ela depende do texto final, mas o desempenho é prejudicado pelo tempo gasto na correção. Um outro fator é que a taxa de aceleração representa a condição ideal em que o participante seleciona a palavra assim que ela aparecer na lista. Na prática, porém, algumas palavras não eram selecionadas assim que apareciam na lista, pois isso depende de quão rápido o usuário percebe que o sufixo da palavra está sendo mostrado na área focada. 


\section{Taxa de erros}

A taxa de erros foi também significativamente menor nos métodos com aceleração. Uma explicação para esse resultado é que, devido a que com predição de palavras vários caracteres são digitados de uma vez só, caso a palavra selecionada estiver correta, então todos esses caracteres também estarão corretos. Já na digitação sem aceleração, todos os caracteres precisam ser digitados um por um, tendo assim uma chance maior de cometer erros.

\section{Número de seleções de tecla por caractere}

A diferença no $S T P C$ entre os métodos com e sem aceleração é esperada, pois sem aceleração é necessário selecionar pelo menos uma tecla para produzir cada caractere. Se o usuário corrigir erros, o $S T P C$ é maior que 1, como pode ser observado na figura 6.14. Já nos métodos com aceleração, devido a que vários caracteres podem ser digitados com apenas uma seleção, o $S T P C$ pode ser menor que 1 , como de fato aconteceu nesse estudo, mesmo existindo correções de erros que incrementam essa métrica.

\section{Avaliações subjetivas}

Em relação à avaliação subjetiva, nosso modelo de feedback recebeu avaliações positivas de todos os participantes, que manifestaram sua preferência pelo teclado baseado em tempo de latência com aceleração como método mais rápido, confortável, com menos erros e também como o método escolhido. O teste da NASA mostrou que o índice de carga de trabalho para os métodos com aceleração foi levemente inferior aos métodos sem aceleração, como pode ser conferido na figura 6.19. Para comparar o índice de carga de trabalho dos métodos com e sem aceleração utilizamos um teste de Welch. Os resultados mostraram que não houve diferença significativa entre o tempo de latência com e sem aceleração, $\mathrm{t}(10.84)=0.18, \mathrm{p}=0.86$, nem entre a alternância entre contextos com e sem aceleração, $\mathrm{t}(10.01)=0.66, \mathrm{p}=0.52$.

Assim, podemos afirmar que, a diferença dos resultados obtidos por Koester e Levine (1994) e Pouplin et al. (2014), o uso da aceleração combinada com AugFix permitiu melhorar a usabilidade (velocidade e taxa de erros) e experiência dos usuários de teclados virtuais controlados pelo olhar. Tal melhoria é devido a que os usuários não precisam ficar alternando o olhar entre o teclado e a lista de palavras, pois a informação sobre as palavras que estarão na lista já é mostrada na área da tecla focada.

Vários participantes comentaram que o prefixo (os três últimos caracteres selecionados) foi muito útil para saber as últimas seleções feitas, sem precisar olhar para a área de texto. Além disso, para corrigir erros o prefixo foi particularmente útil, pois os usuários podiam apagar todos os caracteres errados em sequência, sem olhar para a área de texto.

O uso de AugFix não está limitado apenas a interfaces controladas pelo olhar, mas pode ser estendido a outras formas de interação baseadas em teclados virtuais. Por exemplo, algumas pessoas com deficiência utilizam a cabeça para controlar a posição do cursor na tela e fazem a seleção com algum gesto, como piscar os olhos, abrir e fechar a boca, entre outros. Embora o olhar não esteja sendo usado para apontamento nessas modalidades de interação, o usuário precisa conferir se o cursor está na tecla certa. Nesse contexto, o uso de AugFix tem o potencial de melhorar o desempenho e experiência dos usuários. 


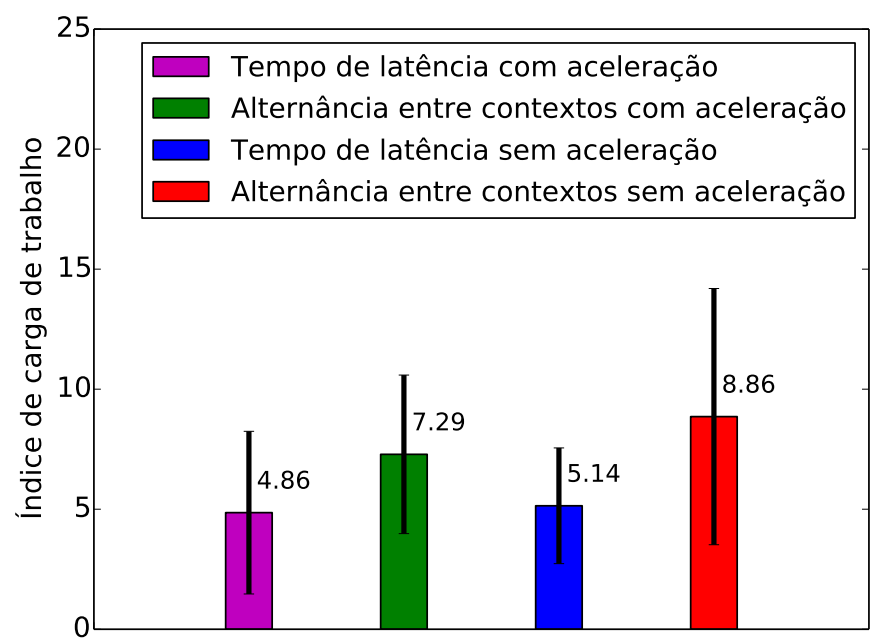

Figura 6.19: indice de carga de trabalho para os dois métodos (tempo de latência e alternância entre contextos) com e sem aceleração. .

\subsection{Considerações finais sobre AugFix}

O novo método AugFix, proposto nessa tese, aumenta a informação visual durante a interação com o prefixo e os sufixos, que são mostrados na tecla com o foco do usuário. O prefixo mostra as últimas letras selecionadas para agilizar a detecção de erros na digitação, sem que o usuário fique olhando repetidamente para a área de texto. Os sufixos mostram as próximas predições, eliminando a incerteza de se a palavra desejada encontra-se ou não na lista de palavras. Em conjunto, o prefixo/sufixos permitem melhorar a velocidade e a experiência do usuário durante a digitação pelo olhar, como mostrado no experimento apresentado nesse capítulo: sete voluntários conseguiram na média uma velocidade de digitação entre 25-30\% mais rápida com AugFix, comparado com a condição sem aceleração. Além disso, a taxa de erros foi menor com AugFix. Do ponto de vista subjetivo, todos os usuários preferiram os teclados com AugFix sobre os teclados sem aceleração.

Uma outra característica do método é que ele pode ser usado tanto no tempo de latência quanto na alternância entre contextos. Além disso, o AugFix tem potencial de aplicação em outras formas de interação para pessoas com deficiências, por exemplo em teclados virtuais nos quais a posição do cursor é controlada por movimentos de cabeça ou por meio de um joystick. 


\section{Capítulo 7}

\section{Conclusões}

Na presente tese de doutorado abordamos diversos problemas existentes na interação pelo olhar e apresentamos várias contribuições originais.

Nossa primeira contribuição foi resultado da investigação da relação entre a manipulação do estímulo visual sob fixação e o tempo de reação sacádico por meio de experimentos psicofísicos com usuários. Esses resultados nos permitiu propor o uso do efeito gap gradiente como novo modelo de feedback visual para facilitar os movimentos sacádicos durante a interação pelo olhar. Esse modelo foi comparado com um modelo de feedback tradicional de animação em um estudo de digitação pelo olhar. Embora os resultados tenham mostrado um ganho discreto no desempenho com o efeito gap gradiente, esse novo feedback foi preferido sobre o modelo tradicional pela maioria dos participantes no estudo. Como generalização da relação entre mudanças no contraste do estímulo sob fixação e o tempo de reação sacádico, propomos um modelo matemático do tempo de reação sacádico em função do ganho de brilho. Nosso modelo apresenta uma correlação $R^{2}$ de 0.9 com relação aos dados obtidos no experimento psicofísico, e tem aplicação potencial no design de interfaces controladas pelo olhar.

Nossa segunda contribuição foi a proposta de duas extensões do paradigma de alternância entre contextos. A primeira extensão propôs o uso de contextos com tamanhos dinâmicos para melhorar o aproveitamento da área útil do monitor. A segunda extensão consiste nos meta-keys, ou seja, pequenos gestos de olhar para ativação de comandos e menus secundários. Tais extensões foram avaliadas em experimentos com usuários, mostrando que em tarefas de navegação e seleção a taxa de erros usando contextos dinâmicos é inferior ao tempo de latência, com um desempenho similar. Esses resultados evidenciam o potencial de aplicação das extensões propostas em tarefas de navegação e seleção de objetos pelo olhar, nas quais a ativação por tempo de latência pode apresentar um error maior devido ao problema do toque de Midas.

Nossa terceira contribuição original foi o AugFix, um novo método para melhorar a usabilidade e a experiência dos usuários na digitação pelo olhar. O método aumenta a informação visual da tecla sob foco do usuário, eliminando a necessidade de olhar repetidamente para a área de texto para detectar erros de digitação. Além disso, combinando AugFix com predição de palavras, o usuário tem certeza das palavras que estão sendo apresentadas na lista sem precisar escaneá-la, eliminando ou reduzindo o tempo de busca pelas palavras na lista. Os resultados de um estudo de digitação pelo olhar, que comparou o AugFix com a condição sem aceleração, mostraram que com o AugFix a velocidade de digitação tem aumento entre 25-30\%, com uma taxa de erros menor e uma carga de trabalho similar. Do ponto de vista subjetivo, os usuários acharam o AugFix fácil de aprender e 
usar, e manifestaram sua preferência pelas interfaces baseadas nesse novo método. Uma limitação do estudo é que contou apenas com um participante com deficiência física. De forma geral, o AugFix mostrou que pode ter um grande impacto na comunicação de pessoas com deficiência por meio do olhar. Além disso, o novo método tem potencial de aplicação em outras formas de interação utilizando teclados virtuais, como as baseadas em movimentos de cabeça e joystick.

\subsection{Sugestões para Pesquisas Futuras}

A seguir descrevemos algumas das direções para dar continuidade à pesquisa feita nessa tese de doutorado.

O estudo sobre o tempo de reação sacádico poderia ser estendido a cenários nos quais o contraste (e não apenas o brilho) do ponto de fixação é manipulado, dado que a saliência depende do contraste, e não do brilho absoluto. Além disso, novos experimentos sobre o modelo de tempo de reação sacádico que manipulem a atenção do usuário poderiam ser feitos, com o objetivo de confirmar se é a atenção que está sendo modulada, ou algum outro processo de baixo nível (recebemos essa sugestão dos revisores do artigo publicado no periódico Attention, Perception, 8 Psychophysics). Além disso, outros fatores podem engajar a atenção, como o movimento. Futuros experimentos poderiam avaliar o efeito do movimento do estímulo observado no tempo de reação sacádico.

O efeito gap também existe nos movimentos de perseguição lenta. Portanto, todos os estudos realizados nessa tese com um estímulo fixado, poderiam ser replicados com estímulos em movimento, forçando o usuário a perseguir o objeto com o olhar. Os resultados, além do potencial de serem aplicados em técnicas mais recentes de interação pelo olhar que usam perseguições lentas, como o SMOOVS, poderiam ajudar a entender melhor a relação estrutural e funcional dos mecanismos que controlam a execução de sacadas e perseguições lentas no cérebro.

Os meta-keys poderiam ser avaliados na realização de outras tarefas pelo olhar, como gerenciar arquivos (salvar o texto escrito, abrir um arquivo existente), mas também para navegação na web pelo olhar. O uso dos contextos dinâmicos poderia ser avaliado em tarefas que requerem uma carga cognitiva maior, como navegar em coleções de imagens ou vídeos, classificar as imagens em álbuns entre outras, para as quais o tempo de latência pode apresentar um grande número de erros devido ao toque de Midas.

Em relação ao modelo de aceleração baseado no AugFix, uma linha de investigação seria avaliar o desempenho na digitação pelo olhar com uma taxa máxima de aceleração maior (entre 80-90\%) que a usada nessa tese (que foi de 50\%). Uma potencial aplicação do AugFix é aumentar a velocidade de digitação em um teclado virtual controlado pelo movimento da cabeça, como o Camera Mouse, de Betke et al. (2002), ou controlado por meio de joysticks ou outros dispositivos de apontamento. Além disso, o AugFix pode ser explorado em outros cenários além da digitação pelo olhar. Por exemplo, uma interface musical controlada pelo olhar poderia mostrar, na tecla com o foco do usuário, quais são as próximas notas da melodia, sem que o usuário precise olhar constantemente para a pauta musical. 


\section{Apêndice A}

\section{Publicações}

A seguir enumeramos por ordem cronológica as publicações em conferências e periódicos conseguidas durante o doutorado:

- Antonio Diaz Tula, Filipe M. S. de Campos e Carlos H. Morimoto. Dynamic context switching for gaze based interaction. Em Proceedings of the Symposium on Eye Tracking Research and Applications, ETRA'12, páginas 353-356, New York, NY, USA. ACM. ISBN 978-1-4503-1221-9. doi: 10.1145/2168556.2168635.

- Antonio Diaz Tula, Andrew T.N. Kurauchi e Carlos H. Morimoto. Facilitating gaze interaction using the gap and overlap effects. Em CHI '13 Extended Abstracts on Human Factors in Computing Systems, CHI EA '13, páginas 91-96, New York, NY, USA. ACM. ISBN 978-1-4503-1952-2. doi: 10.1145/2468356.2468374.

- Antonio Diaz Tula, Andrew T. N. Kurauchi, Carlos H. Morimoto e Ronald D. P. K. C. Ranvaud. Gap effect by gradual brightness reduction. Em Book of Abstracts of the 17th European Conference on Eye Movements, volume 6, página 371. K. Holmqvist, F. Mulvey \& R. Johansson (Eds.)

- Antonio Diaz Tula e Carlos H. Morimoto. Meta-keys: Extending the functionality of gaze-based interaction. Em Proceedings of the 13th Brazilian Symposium on Human Factors in Computing Systems (IHC '14), páginas 285-292, Porto Alegre, Brasil. Sociedade Brasileira de Computação. ISBN 978-85-7669-291-1.

- Andrew T. N. Kurauchi, Antonio Diaz Tula e Carlos H. Morimoto. Facilitating accessibility and digital inclusion using gaze-aware wearable computing. Em Proceedings of the 13th Brazilian Symposium on Human Factors in Computing Systems (IHC '14), páginas 417420, Porto Alegre, Brasil. Sociedade Brasileira de Computação. ISBN 978-85-7669-291-1.

- Antonio Diaz Tula, Andrew T. N. Kurauchi, Carlos H. Morimoto, Silvia Veitzman e Jéssica S. Ianof. Sistema Móvel de Baixo Custo Para Rastreamento do Olhar Voltado à Identificação de Disfunções Oculomotoras. Em XXIV Congresso Brasileiro de Engenharia Biomédica, CBEB'14. Uberlândia, MG, Brasil, p.2830-2833, out. 2014.

- Antonio Diaz Tula, Andrew T. N. Kurauchi e Carlos H. Morimoto. Método de Calibração de Rastreadores de Olhar Móveis Utilizando 2 Planos Para Correção de Para- 
laxe. Em XXIV Congresso Brasileiro de Engenharia Biomédica, CBEB'14. Uberlândia, Brasil, p.2683-2686, out. 2014.

- Antonio Diaz Tula, Carlos H. Morimoto e Ronald D. Ranvaud. A mathematical model of saccadic reaction time as a function of the fixation point brightness gain. Attention, Perception, \& Psychophysics, 77(6):2153-2165, 2015. ISSN 1943-3921. doi: 10.3758/s13414015-0902-9. URL http://dx.doi.org/10.3758/s13414-015-0902-9.

- Antonio Diaz Tula e Carlos H. Morimoto. Dynamic and Meta-Context Switching for Gaze-Based Interaction. Em SBC Journal on Interactive Systems, Vol. 6, No. 1 (2015), páginas 66-75, 2015.

- Carlos H. Morimoto, Antonio Diaz Tula, Jose A. T. Leyva e Carlos E. L. Elmadjian. EyeJam: A Gaze-Controlled Musical Interface. Em Proceedings of the 14th Brazilian Symposium on Human Factors in Computing Systems (IHC '15), páginas 1-9, Porto Alegre, Brasil. Sociedade Brasileira de Computação. ISBN 978-85-7669-306-2. 


\section{Apêndice B}

\section{Questionários aplicados no de digitação pelo olhar usando AugFix}

\section{Questionário 1}

Por favor, responda as seguintes perguntas:

1. Considerando os 2 métodos com aceleração, qual você achou mais rápido (ordene)?

_ Tempo de latência com aceleração

_ Alternância entre contextos com aceleração

2. Qual você achou mais confortável (ordene)?

_ Tempo de latência com aceleração

_ Alternância entre contextos com aceleração

3. Com qual você acha que cometeu menos erros (ordene)?

_ Tempo de latência com aceleração

_ Alternância entre contextos com aceleração 


\section{Questionário 2}

Por favor, responda as seguintes perguntas:

1. Considerando os 2 métodos sem aceleração, qual você achou mais rápido (ordene)?

_ Tempo de latência

Alternância entre contextos

2. Qual você achou mais confortável (ordene)?

_ Tempo de latência

Alternância entre contextos

3. Com qual você acha que cometeu menos erros (ordene)?

_ Tempo de latência

_ Alternância entre contextos 


\section{Questionário 3}

Por favor, responda as seguintes perguntas:

1. Considerando todos os 4 métodos (com e sem aceleração), qual você achou mais rápido? Por favor, ordene.

_ Tempo de latência com aceleração

_ Alternância entre contextos com aceleração
_ Tempo de latência

_ Alternância entre contextos

2. Qual você achou mais confortável (ordene)?

_ Tempo de latência com aceleração

_ Alternância entre contextos com aceleração
_ Tempo de latência

Alternância entre contextos

3. Com qual você acha que cometeu menos erros (ordene)?

_ Tempo de latência com aceleração

_ Alternância entre contextos com aceleração
Tempo de latência

Alternância entre contextos

4. Se você tivesse que usar um método para se comunicar, qual escolheria? Por favor, ordene:

_ Tempo de latência com aceleração

_ Alternância entre contextos com aceleração
_ Tempo de latência

_ Alternância entre contextos

5. Em que nível a aceleração permitiu melhorar seu desempenho? Marque com um "x" na casinha correspondente:

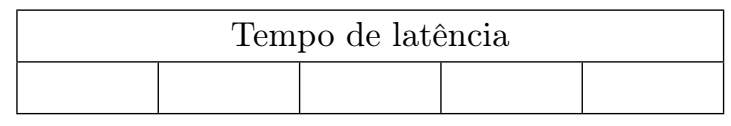

Muito

baixo
Muito

alto

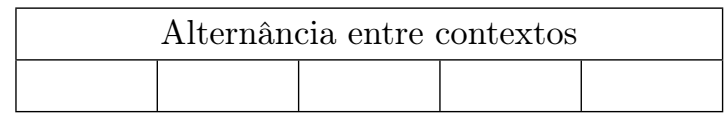

Muito

baixo
Muito alto

6. Em que nível a aceleração permitiu reduzir o número de erros cometidos? Marque com um "x" na casinha correspondente:

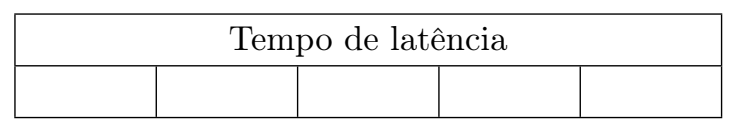

Muito

baixo
Muito

alto

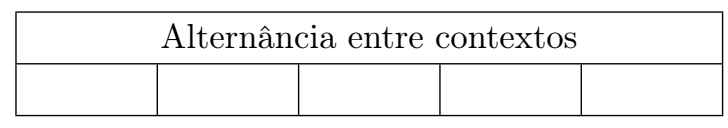

Muito

Muito

baixo

7. Em que nível as interfaces com aceleração foram mais agradáveis de usar? Marque com um "x" na casinha correspondente:

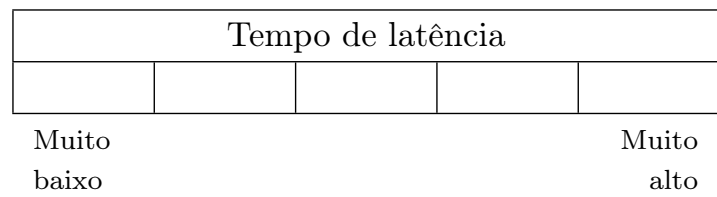

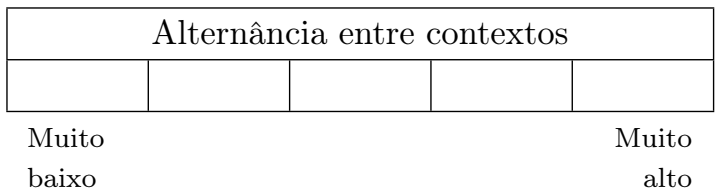


APÊNDICE B 
Apêndice C

Instruções para preencher o teste de índice de carga de trabalho da NASA 


\section{Instruções para preencher as escalas de avaliação}

\section{Fase 1}

No presente estudo, além de avaliar o desempenho das interfaces de entrada de texto com olhar, estamos interessados em saber sua como foi sua experiência, mais especificamente, a "carga de trabalho" experimentada por você. Esse termo, embora difícil de definir com precisão, é simples de entender de forma geral. Os fatores que influenciam a experiência sobre a carga de trabalho podem vir da própria tarefa em si, da percepção sobre o desempenho alcançado durante sua realização, do esforço requerido, ou do estresse e frustração que você sentiu. Esses elementos que contribuem para a carga de trabalho podem mudar conforme você se familiarizar mais com a tarefa, ou mudar de uma tarefa para a próxima. Os componentes físicos da carga de trabalho são relativamente fáceis de conceitualizar e avaliar. No entanto, os componentes mentais podem ser mais difíceis de medir.

Devido a que a carga de trabalho é experimentada de forma diferente por cada pessoa, não existem "regras" eficazes para estimá-la durante a realização de atividades diferentes. Uma forma de estudar a carga de trabalho é pedir para a pessoa descrever os sentimentos experimentados durante a realização da tarefa. Devido à existência de vários fatores que podem influenciar na carga de trabalho, gostaríamos que você avaliasse alguns desses fatores de forma individual, ao invés de fornecer uma avaliação global da carga de trabalho. As seis escalas de avaliação usadas no teste foram desenvolvidas para que você avalie suas experiências durante a execução de cada uma das tarefas. Por favor, leia cuidadosamente a descrição de cada uma das escalas e, caso tiver alguma dúvida, pergunte para o experimentador. Uma cópia impressa com as descrição ficará disponível sempre que precisar.

Em todas as sessões do experimento, depois de utilizar cada interface, você terá de preencher as escalas de avaliação em uma planilha de Excel. Para isso, escreva um " $x$ " na casinha correspondente com o nível da experiência que você sentiu durante a execução da tarefa. Por favor, preste especial atenção ao significado de cada extremo da escala, que é descrito na planilha. Em particular, note que a escala "Desempenho" vá de "Muito bom” até "Muito ruim”, a diferença das outras 5 escalas, que vão de "Muito baixo" até "Muito alto".

Por favor, seja muito cuidadoso na hora de avaliar cada escala, considerando cada interface de forma independente das outras, assim como as escalas também. Suas avaliações são muito importantes no estudo que estamos realizando, e agradecemos seu maior esforço no sucesso do experimento. 


\section{Instruções para avaliar os fatores da carga de trabalho}

Fase 2

As escalas de avaliação que você preenche ao longo da Fase 1 desse experimento são utilizadas para medir sua experiência durante o uso das diferentes interfaces de entrada de texto com o olhar. Embora muito úteis, escalas como essas podem ter interpretações individuais diferentes. Por exemplo, algumas pessoas acham que a exigência temporal ou mental são fatores essenciais na carga de trabalho, independentemente do esforço feito ou do nível de desempenho alcançado em uma tarefa. Outras pessoas acham que se o desempenho for bom então a carga de trabalho deve ter sido baixa, enquanto que um desempenho ruim indica que a carga de trabalho deve ter sido alta. Outros ainda acham que o esforço ou a frustração são os fatores mais importantes na carga de trabalho, e assim por diante. Além disso, os fatores que influenciam na carga de trabalho podem mudar dependendo da tarefa. Por exemplo, algumas tarefas podem ser difíceis porque devem ser completadas muito rápido, enquanto que outras podem parecer fáceis ou difíceis devido à intensidade do esforço físico e mental necessários. Outros pessoas ainda acham que uma tarefa é difícil devido a que não conseguem um bom desempenho, sem importar o esforço requerido.

A avaliação que você está prestes a fazer faz parte da Fase 2 de uma técnica desenvolvida pela NASA, para avaliar a importância relativa de seis fatores na determinação da carga de trabalho que você experimentou. O procedimento é simples: você terá um conjunto de pares de fatores (os mesmos utilizados nas escalas de avaliação na Fase 1, por exemplo, “Esforço VS Exigência Mental”) e deve escolher dentre os dois fatores aquele que você achar é mais importante na sua experiência sobre a carga de trabalho na tarefa realizada, escrevendo um " $\mathrm{x}$ " na casinha correspondente na planilha de Excel. Por favor, considere os pares de fatores em ordem aleatória, ou seja, escolha um par arbitrário e preencha-o, escolha outro par arbitrário e assim por diante, até preencher todos os 15 pares do teste.

Por favor, faça suas avaliações com muito cuidado e de forma consistente com a forma em que você preencheu as escalas de avaliação na Fase 1 do teste, para cada uma das tarefas realizadas. Não pense que existe um "padrão correto": nós estamos interessados apenas na sua opinião. Se ainda tiver dúvidas, por favor não hesite em perguntar para o experimentador, e novamente obrigado por sua participação! 


\section{Definição das escalas}

Exigência mental: Qual foi o nível de atividade mental e perceptual necessários (ex. pensar, decidir, calcular, lembrar, observar, procurar) para realizar a tarefa? A tarefa foi simples ou complexa, fácil ou difícil?

Exigência física: Qual foi o nível de atividade física necessária para realizar a tarefa (ex. puxar, empurrar, controlar, ativar etc.)? A tarefa foi fácil ou exigente, lenta ou rápida, leve ou pesada, tranquila ou agitada?

Exigência temporal: Quanta pressão de tempo sentiu em relação ao ritmo de execução da tarefa? O ritmo foi lento e ocioso ou rápido e frenético?

Desempenho: Qual foi o nível de sucesso que você teve em atingir os objetivos da tarefa? Quão satisfeito se sentiu em relação ao desempenho alcançado?

Esforço: Qual foi o nível de esforço (tanto físico como mental) necessário para atingir o desempenho alcançado na realização da tarefa?

Frustração: Durante a realização da tarefa, em que nível você se sentiu inseguro, desencorajado, irritado, estressado ou incomodado? 


\section{Referências Bibliográficas}

Arif e Stuerzlinger (2009) Ahmed Sabbir Arif e Wolfgang Stuerzlinger. Analysis of text entry performance metrics. Em 2009 IEEE Toronto International Conference Science and Technology for Humanity (TIC-STH), páginas 100-105. IEEE. ISBN 978-1-4244-3877-8. doi: 10.1109/ TIC-STH.2009.5444533. URL http://ieexplore.iee.org/articleDetails.jsp?arnumber $=5444533$. Citado na pág. 27, 58, 64

Awh et al. (2012) Edward Awh, Artem V Belopolsky e Jan Theeuwes. Top-down versus bottomup attentional control: a failed theoretical dichotomy. Trends in cognitive sciences, 16(8):437-43. ISSN 1879-307X. doi: 10.1016/j.tics.2012.06.010. Citado na pág. 30

Baloh et al. (1975) R. W. Baloh, A. W. Sills, W. E. Kumley e V. Honrubia. Quantitative measurement of saccade amplitude, duration, and velocity. Neurology, 25(11):1065-1070. Citado na pág. 7,70

Bee e André (2008) Nikolaus Bee e Elisabeth André. Writing with your eye: A dwell time free writing system adapted to the nature of human eye gaze. Em Proceedings of the 4th IEEE tutorial and research workshop on Perception and Interactive Technologies for Speech-Based Systems: Perception in Multimodal Dialogue Systems, PIT '08, páginas 111-122, Berlin, Heidelberg. Springer-Verlag. ISBN 978-3-540-69368-0. Citado na pág. 2, 41

Bell et al. (2006) A. H. Bell, M. A. Meredith, A. J. Van Opstal e D. P. Munoz. Stimulus intensity modifies saccadic reaction time and visual response latency in the superior colliculus. Experimental brain research. Experimentelle Hirnforschung. Expérimentation cérébrale, 174(1):53-59. ISSN 0014-4819. doi: 10.1007/s00221-006-0420-z. Citado na pág. 18, 29, 30

Betke et al. (2002) Margrit Betke, James Gips e Peter Fleming. The camera mouse: Visual tracking of body features to provide computer access for people with severe disabilities. IEEE Transactions on Neural Systems and Rehabilitation Engineering, 10:1-10. Citado na pág. 82

Bridgeman et al. (1975) B Bridgeman, D Hendry e L Stark. Failure to detect displacement of the visual world during saccadic eye movements. Vision Research, 15(6):719-722. URL http: //www.ncbi.nlm.nih.gov/pubmed/1138489. Citado na pág. 8, 50

Carpenter (2004) R.H.S. Carpenter. Contrast, probability, and saccadic latency: Evidence for independence of detection and decision. Current Biology, 14(17):1576 - 1580. ISSN 0960-9822. doi: http://dx.doi.org/10.1016/j.cub.2004.08.058. Citado na pág. 30

Collewijn et al. (1988) H Collewijn, C J Erkelens e R M Steinman. Binocular co-ordination of human vertical saccadic eye movements. The Journal of physiology, 404:183-97. ISSN 0022-3751. Citado na pág. 42

Craig et al. (1999) GregoryL. Craig, LewB. Stelmach e W.James Tam. Control of reflexive and voluntary saccades in the gap effect. Perception $\&$ Psychophysics, 61(5):935-942. ISSN 0031-5117. doi: 10.3758/BF03206907. Citado na pág. 17, 33 
Diaz-Tula e Morimoto (2015) Antonio Diaz-Tula e Carlos H Morimoto. Dynamic and MetaContext Switching for Gaze-Based Interaction. SBC Journal on Interactive Systems, 6(1):66-75. Citado na pág. 56

Diaz-Tula et al. (2015) Antonio Diaz-Tula, Carlos H. Morimoto e Ronald D. Ranvaud. A mathematical model of saccadic reaction time as a function of the fixation point brightness gain. Attention, Perception, 83 Psychophysics, 77(6):2153-2165. ISSN 1943-3921. doi: 10.3758/s13414-015-0902-9. URL http://dx.doi.org/10.3758/s13414-015-0902-9. Citado na pág. 29, 33

Dorris e Munoz (1995) M. C. Dorris e D. P. Munoz. A neural correlate for the gap effect on saccadic reaction times in monkey. Journal of Neurophysiology., 73(6):2558-2562. Citado na pág. 18

Drewes e Schmidt (2007) Heiko Drewes e Albrecht Schmidt. Interacting with the computer using gaze gestures. Em Proceedings of the 11th IFIP TC 13 international conference on Humancomputer interaction - Volume Part II, INTERACT'07, páginas 475-488, Berlin, Heidelberg. Springer-Verlag. ISBN 3-540-74799-0, 978-3-540-74799-4. URL http://dl.acm.org/citation.cfm? id $=1778331.1778385$. Citado na pág. 2

Duchowski (2000) Andrew Duchowski. Eye-Based Interaction in Graphical Systems: Theory 8 Practice, 2000. URL http://vret.ces.clemson.edu/sigcourse/. Citado na pág. 7, 8

Fechner (1860) G.T. Fechner. Elemente Der Psychophysik, volume 2. Breitkopf und Härtel, Leipzig. (reprint 1964. Amsterdam: Bonset). Citado na pág. 5, 30, 31

Fischer e Breitmeyer (1987) B. Fischer e B. Breitmeyer. Mechanisms of visual attention revealed by saccadic eye movements. Neuropsychologia, 25(1A):73-83. doi: 10.1016/0028-3932(87)90044-3. Citado na pág. 17, 18

Fitts (1954) Paul M. Fitts. The information capacity of the human motor system in controlling the amplitude of movement. Journal of Experimental Psychology, 47:381-391. doi: 10.1037/h0055392. Citado na pág. 17

Fuchs e Ansorge (2012) Isabella Fuchs e Ulrich Ansorge. Unconscious Cueing via the Superior Colliculi: Evidence from Searching for Onset and Color Targets. Brain sciences, 2(1):33-60. ISSN 2076-3425. doi: 10.3390/brainsci2010033. Citado na pág. 30

Fuller et al. (2009) Stuart Fuller, Yunsoo Park e Marisa Carrasco. Cue contrast modulates the effects of exogenous attention on appearance. Vision Research, 49(14):1825 - 1837. ISSN 00426989. doi: http://dx.doi.org/10.1016/j.visres.2009.04.019. Citado na pág. 30, 36

Hansen et al. (2008) Dan Witzner Hansen, Henrik H. T. Skovsgaard, John Paulin Hansen e Emilie Møllenbach. Noise tolerant selection by gaze-controlled pan and zoom in 3d. Em Proceedings of the 2008 symposium on Eye tracking research $\&$ applications, ETRA '08, páginas 205-212, New York, NY, USA. ACM. ISBN 978-1-59593-982-1. doi: http://doi.acm.org/10.1145/1344471.1344521. URL http://doi.acm.org/10.1145/1344471.1344521. Citado na pág. 2, 12, 13

Hansen e Ji (2010) D.W. Hansen e Qiang Ji. In the eye of the beholder: A survey of models for eyes and gaze. IEEE Transactions on Pattern Analysis and Machine Intelligence, 32(3):478 -500. ISSN 0162-8828. doi: 10.1109/TPAMI.2009.30. Citado na pág. 1

Hansen et al. (2004) John Paulin Hansen, Kristian Tørning, Anders Sewerin Johansen, Kenji Itoh e Hirotaka Aoki. Gaze typing compared with input by head and hand. Em Proceedings of the 2004 symposium on Eye Tracking Research 83 Applications, ETRA '04, páginas 131-138, New York, NY, USA. ACM. ISBN 1-58113-825-3. doi: 10.1145/968363.968389. URL http: //doi.acm.org/10.1145/968363.968389. Citado na pág. 2, 8, 10, 67 
Hart e Stavenland (1988) S. G. Hart e L. E. Stavenland. Development of NASA-TLX (Task Load Index): Results of empirical and theoretical research. Em P. A. Hancock e N. Meshkati, editors, Human Mental Workload, chapter 7, páginas 139-183. Elsevier. URL http://ntrs.nasa. gov/archive/nasa/casi.ntrs.nasa.gov/20000004342_1999205624.pdf. Citado na pág. 64

Holmqvist et al. (2011) Kenneth Holmqvist, Marcus Nystrom, Richard Andersson, Richard Dewhurst, Halszka Jarodzka e Joost van de Weijer. Eye Tracking. A comprehensive guide to methods and measures. Oxford University Press, Oxford. ISBN 978-0-19-969708-3. Citado na pág. 61

Huckauf e Urbina (2007) Anke Huckauf e Mario Urbina. Gazing with peye: new concepts in eye typing. Em Proceedings of the 4 th Symposium on Applied Perception in Graphics and Visualization (APGV'07), página 141. Citado na pág. 2

Isokoski (2000) P. Isokoski. Text input methods for eye trackers using off-screen targets. Em ETRA '00: Proceedings of the 2000 symposium on Eye tracking research ES applications, páginas 15-21, New York, NY. ACM. ISBN 1-58113-280-8. doi: http://doi.acm.org/10.1145/355017. 355020. Citado na pág. 2, 3

Jacob (1990) Robert J. K. Jacob. What you look at is what you get: eye movement-based interaction techniques. Em Proceedings of the SIGCHI conference on Human factors in computing systems: Empowering people, CHI '90, páginas 11-18, New York, NY, USA. ACM. ISBN 0-20150932-6. doi: http://doi.acm.org/10.1145/97243.97246. URL http://doi.acm.org/10.1145/97243. 97246. Citado na pág. 54

Jacob (1991) Robert J. K. Jacob. The use of eye movements in human-computer interaction techniques: what you look at is what you get. ACM Trans. Inf. Syst., 9(2):152-169. ISSN 10468188. doi: 10.1145/123078.128728. URL http://doi.acm.org/10.1145/123078.128728. Citado na pág. 2

Jin e Reeves (2009) Zhenlan Jin e Adam Reeves. Attentional release in the saccadic gap effect. Vision Research, 49(16):2045 - 2055. ISSN 0042-6989. doi: 10.1016/j.visres.2009.02.015. Citado na pág. $17,18,30,31,36$

Kean e Lambert (2003) Matthew Kean e Anthony Lambert. The influence of a salience distinction between bilateral cues on the latency of target-detection saccades. British journal of psychology (London, England : 1953), 94(Pt 3):373-388. ISSN 0007-1269. doi: 10.1348/000712603767876280. Citado na pág. 30

Kingstone e Klein (1993) Alan Kingstone e Raymond M. Klein. Visual offsets facilitate saccadic latency: Does predisengagement of visuospatial attention mediate this gap effect? Journal of Experimental Psychology: Human Perception and Performance, 19(6):1251-1265. ISSN 19391277(Electronic);0096-1523(Print). doi: 10.1037/0096-1523.19.6.1251. Citado na pág. 17, 18

Koester e Levine (1994) H.H. Koester e S.P. Levine. Modeling the speed of text entry with a word prediction interface. Rehabilitation Engineering, IEEE Transactions on, 2(3):177-187. ISSN 1063-6528. doi: 10.1109/86.331567. Citado na pág. 9, 78

Kowler (2011) Eileen Kowler. Eye movements: the past 25 years. Vision research, 51(13):1457-83. ISSN 1878-5646. doi: 10.1016/j.visres.2010.12.014. URL http://www.sciencedirect.com/science/ article/pii/S0042698910005924. Citado na pág. 7

Kristensson e Vertanen (2012) Per Ola Kristensson e Keith Vertanen. The potential of dwellfree eye-typing for fast assistive gaze communication. Em Proceedings of the Symposium on Eye Tracking Research and Applications, ETRA '12, páginas 241-244, New York, NY, USA. ACM. ISBN 978-1-4503-1221-9. doi: 10.1145/2168556.2168605. URL http://doi.acm.org/10. 1145/2168556.2168605. Citado na pág. 13 
Lankford (2000) Chris Lankford. Effective eye-gaze input into windows. Em Proceedings of the 2000 Symposium on Eye Tracking Research \& Applications, ETRA '00, páginas 23-27, New York, NY, USA. ACM. ISBN 1-58113-280-8. doi: 10.1145/355017.355021. URL http://doi.acm.org/10. 1145/355017.355021. Citado na pág. 2, 26

Liversedge et al. (2011) Simon Liversedge, Iain Gilchrist e Stefan Everling. The Oxford Handbook of Eye Movements. Oxford library of psychology. Oxford University Press. ISBN 9780195339789. Citado na pág. 7,36

Lutz et al. (2015) Otto Lutz, Antje Christine e Stefan Ruff. SMOOVS: Towards calibration-free text entry by gaze using smooth pursuit movements. Journal of Eye Movement Research, 8(1): 1-11. Citado na pág. $2,13,14$

Mackeben e Nakayama (1993) M. Mackeben e K. Nakayama. Express attentional shifts. Vision Research, 33(1):85-90. doi: 10.1016/0042-6989(93)90061-Z. Citado na pág. 18

MacKenzie e Soukoreff (2003) I. S. MacKenzie e R. W. Soukoreff. Phrase sets for evaluating text entry techniques. Em Extended Abstracts of the ACM Conference on Human Factors in Computing Systems - CHI 2003, páginas 754-755. ACM Press. Citado na pág. 26, 62

MacKenzie e Zhang (2008) I. Scott MacKenzie e Xuang Zhang. Eye typing using word and letter prediction and a fixation algorithm. Em Proceedings of the 2008 symposium on Eye tracking research 83 applications, ETRA '08, páginas 55-58, New York, NY, USA. ACM. ISBN 978-159593-982-1. doi: 10.1145/1344471.1344484. URL http://doi.acm.org/10.1145/1344471.1344484. Citado na pág. xiii, 9, 67, 68

Majaranta (2009) Päivi Majaranta. Text Entry by Eye Gaze. Tese de Doutorado, University of Tampere, Department of Computer Science, Tampere, Finland. Citado na pág. 2, 9, 26, 57

Majaranta e Räihä (2002) Päivi Majaranta e Kari-Jouko Räihä. Twenty years of eye typing: systems and design issues. Em Proceedings of the 2002 symposium on Eye tracking research 8 applications, ETRA '02, páginas 15-22, New York, NY, USA. ACM. ISBN 1-58113-467-3. doi: 10.1145/507072.507076. URL http://doi.acm.org/10.1145/507072.507076. Citado na pág. 2, 8

Majaranta e Räihä (2007) Päivi Majaranta e Kari-Jouko Räihä. Text entry by gaze:utilizing eye tracking. Em I.S. MacKenzie e K. Tanaka-Ishii, editors, Text entry systems: Mobility, accessibility, universality, chapter 9, páginas 175-187. Morgan Kaufmann. Citado na pág. 2, 26, 51

Majaranta et al. (2006) Päivi Majaranta, Scott MacKenzie, Anne Aula e Kari-Jouko Räihä. Effects of feedback and dwell time on eye typing speed and accuracy. Univers. Access Inf. Soc., 5 (2):199-208. ISSN 1615-5289. doi: 10.1007/s10209-006-0034-z. URL http://dx.doi.org/10.1007/ s10209-006-0034-z. Citado na pág. 9, 19, 26

Majaranta et al. (2009) Päivi Majaranta, Ulla-Kaija Ahola e Oleg Špakov. Fast gaze typing with an adjustable dwell time. Em Proceedings of the 27th international conference on Human factors in computing systems, CHI '09, páginas 357-360, New York, NY, USA. ACM. ISBN 978-1-60558-246-7. doi: http://doi.acm.org/10.1145/1518701.1518758. URL http://doi.acm.org/ 10.1145/1518701.1518758. Citado na pág. 8, 75

Møllenbach et al. (2013) Emilie Møllenbach, John Paulin Hansen e Martin Lillholm. Eye Movements in Gaze Interaction. Journal of Eye Movement Research, 6:1-15. Citado na pág. 7, 11, 43

Morimoto e Mimica (2005) C. H. Morimoto e M.R.M. Mimica. Eye gaze tracking techniques for interactive applications. Computer Vision and Image Understanding, 98:4-24. Citado na pág. 1 
Morimoto e Amir (2010) Carlos H. Morimoto e Arnon Amir. Context switching for fast key selection in text entry applications. Em Proceedings of the 2010 Symposium on Eye-Tracking Research \& Applications, ETRA '10, páginas 271-274, New York, NY, USA. ACM. ISBN 978-160558-994-7. doi: http://doi.acm.org/10.1145/1743666.1743730. Citado na pág. 3, 9, 10, 41, 42, 58, 76

Morimoto et al. (1999) C.H. Morimoto, D. Koons, A Amit, M. Flickner e S. Zhai. Keeping an eye for hci. Em Computer Graphics and Image Processing, 1999. Proceedings. XII Brazilian Symposium on, páginas 171-176. doi: 10.1109/SIBGRA.1999.805722. Citado na pág. 44

Munoz e Wurtz (1992) D. P. Munoz e R. H. Wurtz. Role of the Rostral Superior Colliculus in Active Visual Fixation and Execution of Express Saccades. Journal of Neurophysiology., 67(4): 1000-1002. Citado na pág. 18

Ohno (1998) T. Ohno. Features of eye gaze interface for selection tasks. Em Proceedings of the Third Asian Pacific Computer and Human Interaction, APCHI '98, páginas 176-181, Washington, DC, USA. IEEE Computer Society. ISBN 0-8186-8347-3. URL http://dl.acm.org/citation.cfm? id $=786112.786297$. Citado na pág. 3

Pedrosa et al. (2015) Diogo Pedrosa, Maria Da Graça Pimentel, Amy Wright e Khai N. Truong. Filteryedping: Design challenges and user performance of dwell-free eye typing. ACM Trans. Access. Comput., 6(1):3:1-3:37. ISSN 1936-7228. doi: 10.1145/2724728. URL http://doi.acm. org $/ 10.1145 / 2724728$. Citado na pág. xiii, 13, 14, 68

Peirce (2009) Jonathan W Peirce. Generating stimuli for neuroscience using psychopy. Frontiers in Neuroinformatics, 2(00010). ISSN ISSN=1662-5196. doi: 10.3389/neuro.11.010.2008. Citado na pág. 22

Porta (2015) Marco Porta. A study on text entry methods based on eye gestures. Journal of Assistive Technologies, 9(1):48-67. doi: 10.1108/JAT-12-2013-0037. URL http://dx.doi.org/10. 1108/JAT-12-2013-0037. Citado na pág. 2, 11

Porta e Turina (2008) Marco Porta e Matteo Turina. Eye-s: a full-screen input modality for pure eye-based communication. Em Proceedings of the 2008 symposium on Eye Tracking Research ES Applications, ETRA '08, páginas 27-34, New York, NY, USA. ACM. ISBN 978-1-59593-9821. doi: http://doi.acm.org/10.1145/1344471.1344477. URL http://doi.acm.org/10.1145/1344471. 1344477. Citado na pág. 11, 43

Posner e Petersen (1990) Michael I. Posner e Steven E. Petersen. The attention system of the human brain. Annual Review of Neuroscience, 13(1):25-42. doi: 10.1146/annurev.ne.13.030190. 000325. Citado na pág. 18

Pouplin et al. (2014) Samuel Pouplin, Johanna Robertson, Jean-Yves Antoine, Antoine Blanchet, Jean Loup Kahloun, Philippe Volle, Justine Bouteille, Frédéric Lofaso e Djamel Bensmail. Effect of dynamic keyboard and word-prediction systems on text input speed in persons with functional tetraplegia. Journal of rehabilitation research and development, 51(3):467-79. ISSN 1938-1352. doi: 10.1682/JRRD.2012.05.0094. Citado na pág. 9, 78

Pratt et al. (2006) J. Pratt, C. M. Lajonchere e R. A. Abrams. Attentional modulation of the gap effect. Vision Research, 46(16):2602-2607. doi: 10.1016/j.visres.2006.01.017. Citado na pág. 17, $18,23,33$

Pratt et al. (2000) Jay Pratt, Harold Bekkering e Mark Leung. Estimating the components of the gap effect. Experimental Brain Research, 130:258-263. ISSN 0014-4819. doi: 10.1007/ s002219900243. Citado na pág. 17, 18, 30, 31, 35 
Räihä e Ovaska (2012) Kari-Jouko Räihä e Saila Ovaska. An exploratory study of eye typing fundamentals: dwell time, text entry rate, errors, and workload. Em Proceedings of the 2012 ACM annual conference on Human Factors in Computing Systems, CHI '12, páginas 3001-3010, New York, NY, USA. ACM. ISBN 978-1-4503-1015-4. doi: 10.1145/2208636.2208711. URL http://doi.acm.org/10.1145/2208636.2208711. Citado na pág. 2, 8

Reulen (1984) Jos P. H. Reulen. Latency of visually evoked saccadic eye movements. ii. temporal properties of the facilitation mechanism. Biological Cybernetics, 50(4):263-271. doi: 10.1007/ BF00337076. Citado na pág. 17, 18, 29, 34, 35, 36

Reuter-Lorenz et al. (1995) P.A. Reuter-Lorenz, H.M. Oonk, L.L. Barnes e H.C. Hughes. Effects of warning signals and fixation point offsets on the latencies of pro-versus antisaccades: implications for an interpretation of the gap effect. Experimental Brain Research, 103(2):287-293. ISSN 0014-4819. doi: 10.1007/BF00231715. Citado na pág. 18, 31, 35

Reuter-Lorenz et al. (1991) Patricia A. Reuter-Lorenz, Howard C. Hughes e Robert Fendrich. The reduction of saccadic latency by prior offset of the fixation point: An analysis of the gap effect. Perception $\&$ Psychophysics, 49(2):167-175. ISSN 0031-5117. doi: 10.3758/BF03205036. Citado na pág. $17,18,23,29,30,31,33$

Rough et al. (2014) Daniel Rough, Keith Vertanen e Per Ola Kristensson. An evaluation of dasher with a high-performance language model as a gaze communication method. Em Proceedings of the 2014 International Working Conference on Advanced Visual Interfaces, AVI '14, páginas 169176, New York, NY, USA. ACM. ISBN 978-1-4503-2775-6. doi: 10.1145/2598153.2598157. URL http://doi.acm.org/10.1145/2598153.2598157. Citado na pág. 2, 8, 12, 59, 68, 75

Salvucci e Goldberg (2000) Dario D. Salvucci e Joseph H. Goldberg. Identifying fixations and saccades in eye-tracking protocols. Em Proceedings of the 2000 symposium on Eye tracking research $\&$ applications, ETRA '00, páginas 71-78, New York, NY, USA. ACM. ISBN 1-58113280-8. doi: 10.1145/355017.355028. URL http://doi.acm.org/10.1145/355017.355028. Citado na pág. 22,61

Saslow (1967) M. G. Saslow. Effects of components of displacement-step stimuli upon latency for saccadic eye movement. J. Opt. Soc. Am., 57(8):1024-1029. doi: 10.1364/JOSA.57.001024. Citado na pág. $7,17,18,23,29$

Scott MacKenzie e Ashtiani (2011) I. Scott MacKenzie e Behrooz Ashtiani. Blinkwrite: Efficient text entry using eye blinks. Univers. Access Inf. Soc., 10(1):69-80. ISSN 1615-5289. doi: 10.1007/s10209-010-0188-6. URL http://dx.doi.org/10.1007/s10209-010-0188-6. Citado na pág. xiii, 2,15

Soukoreff e MacKenzie (2001) R. William Soukoreff e I. Scott MacKenzie. Measuring errors in text entry tasks: an application of the levenshtein string distance statistic. Em CHI '01 extended abstracts on Human factors in computing systems, CHI EA '01, páginas 319-320, New York, NY, USA. ISBN 1-58113-340-5. doi: 10.1145/634067.634256. URL http://doi.acm.org/10.1145/ 634067.634256. Citado na pág. 27, 64

Taylor et al. (2006) M. J. Taylor, R. H. S. Carpenter e A. J. Anderson. A noisy transform predicts saccadic and manual reaction times to changes in contrast. The Journal of Physiology, 573(3): 741-751. ISSN 1469-7793. doi: 10.1113/jphysiol.2006.105387. Citado na pág. 30

Trnka et al. (2009) Keith Trnka, John McCaw, Debra Yarrington, Kathleen F. McCoy e Christopher Pennington. User interaction with word prediction: The effects of prediction quality. $A C M$ Trans. Access. Comput., 1(3):17:1-17:34. ISSN 1936-7228. doi: 10.1145/1497302.1497307. URL http://doi.acm.org/10.1145/1497302.1497307. Citado na pág. 59 
Tuisku et al. (2008) O. Tuisku, P. Majaranta, P. Isokoski e K.-J Räihä. Now dasher! dash away! longitudinal study of fast text entry by eye gaze. Em Proceedings of Eye Tracking Research \&6 Applications, ETRA 2008, páginas 19-26, Savannah,GA. ACM Press. Citado na pág. 12, 13, 59, 68

Tula et al. (2013a) Antonio D. Tula, Andrew T.N. Kurauchi e Carlos H. Morimoto. Facilitating gaze interaction using the gap and overlap effects. Em CHI'13 Extended Abstracts on Human Factors in Computing Systems, CHI EA '13, páginas 91-96, New York, NY, USA. ACM. ISBN 978-1-4503-1952-2. doi: 10.1145/2468356.2468374. Citado na pág. 27

Tula e Morimoto (2014) Antonio Diaz Tula e Carlos H. Morimoto. Meta-keys: Extending the functionality of gaze-based interaction. Em Proceedings of the 13th Brazilian Symposium on Human Factors in Computing Systems, IHC '14, páginas 285-292, Porto Alegre, Brazil. Sociedade Brasileira de Computação. ISBN 978-85-7669-291-1. URL http://dl.acm.org/citation.cfm?id= 2738055.2738101. Citado na pág. 56

Tula et al. (2012) Antonio Diaz Tula, Filipe M. S. de Campos e Carlos H. Morimoto. Dynamic context switching for gaze based interaction. Em Proceedings of the Symposium on Eye Tracking Research and Applications, ETRA '12, páginas 353-356, New York, NY, USA. ACM. ISBN 978-14503-1221-9. doi: 10.1145/2168556.2168635. URL http://doi.acm.org/10.1145/2168556.2168635. Citado na pág. 56

Tula et al. (2013b) Antonio Diaz Tula, Andrew T. N. Kurauchi, Carlos H. Morimoto e Ronald D. P. K. C. Ranvaud. Gap effect by gradual brightness reduction. Em Book of Abstracts of the 17th European Conference on Eye Movements, volume 6, página 371. K. Holmqvist, F. Mulvey \& R. Johansson (Eds.). Citado na pág. 24

Ueda et al. (2013) Hiroshi Ueda, Kohske Takahashi e Katsumi Watanabe. Contributions of retinal input and phenomenal representation of a fixation object to the saccadic gap effect. Vision Research, 82(0):52 - 57. ISSN 0042-6989. doi: 10.1016/j.visres.2013.02.008. Citado na pág. 17, 18

Urbina e Huckauf (2010) Mario H. Urbina e Anke Huckauf. Alternatives to single character entry and dwell time selection on eye typing. Em Proceedings of the 2010 Symposium on Eye-Tracking Research \& Applications, ETRA '10, páginas 315-322, New York, NY, USA. ACM. ISBN 978-160558-994-7. doi: 10.1145/1743666.1743738. URL http://doi.acm.org/10.1145/1743666.1743738. Citado na pág. 2, 9, 10, 11, 68

Vescovi (2004) Matteo Vescovi. Soothsayer: un sistema multi-sorgente per la predizione del testo. Dissertação de Mestrado, Politecnico di Milano, Dipartimento di elettronica e informazione. Citado na pág. 62

Vidal et al. (2013) Mélodie Vidal, Ken Pfeuffer, Andreas Bulling e Hans W. Gellersen. Pursuits: Eye-based interaction with moving targets. Em CHI '13 Extended Abstracts on Human Factors in Computing Systems, CHI EA '13, páginas 3147-3150, New York, NY, USA. ACM. ISBN 978-14503-1952-2. doi: 10.1145/2468356.2479632. URL http://doi.acm.org/10.1145/2468356.2479632. Citado na pág. 2, 13, 14

Špakov e Miniotas (2004) Oleg Špakov e Darius Miniotas. On-line adjustment of dwell time for target selection by gaze. Em Proceedings of the third Nordic conference on Human-computer interaction, NordiCHI '04, páginas 203-206, New York, NY, USA. ACM. ISBN 1-58113-857-1. doi: 10.1145/1028014.1028045. URL http://doi.acm.org/10.1145/1028014.1028045. Citado na pág. 8

Ward e MacKay (2002) David J. Ward e David J. C. MacKay. Fast hands-free writing by gaze direction. Nature, 418(6900):838. Citado na pág. 2, 9, 12 
Wobbrock et al. (2008) Jacob O. Wobbrock, James Rubinstein, Michael W. Sawyer e Andrew T. Duchowski. Longitudinal evaluation of discrete consecutive gaze gestures for text entry. Em Proceedings of the 2008 symposium on Eye Tracking Research $\& 3$ Applications, ETRA '08, páginas 11-18, New York, NY, USA. ACM. ISBN 978-1-59593-982-1. doi: http://doi.acm.org/10.1145/ 1344471.1344475. URL http://doi.acm.org/10.1145/1344471.1344475. Citado na pág. 2, 9, 11, 41, 43,67

Zhang et al. (2010) Xinyong Zhang, Xiangshi Ren e Hongbin Zha. Modeling dwell-based eye pointing target acquisition. Em Proceedings of the SIGCHI Conference on Human Factors in Computing Systems, CHI '10, páginas 2083-2092, New York, NY, USA. ACM. ISBN 978-160558-929-9. doi: 10.1145/1753326.1753645. URL http://doi.acm.org/10.1145/1753326.1753645. Citado na pág. 17 